\title{
Extensão do Ambiente de Simulação Automático (ASiA) para Simulação de Redes de Computadores
}

\author{
Célia Leiko Ogawa Kawabata
}

Orientadora: Profa. Dra. Regina Helena Carlucci Santana

Dissertação apresentada ao Instituto de Ciências Matemáticas e de Computação - ICMC-USP, como parte dos requisitos para obtenção do título de Mestre em Ciências - Área: Ciências de Computação e Matemática Computacional. 
Ao Masaki e ao Daniel, Por serem a razão da minha vida.

E aos meus pais, Por serem sempre o meu porto seguro. 


\section{Agradecimentos}

À amiga e orientadora Regina Helena C. Santana pela orientação sempre segura que tem me dado desde a graduação.

Ao Professor Marcos José Santana, pela amizade, companheirismo e paciência.

Ao Masaki e ao Daniel, por serem a parte mais importante da minha vida.

Aos meus pais, Susumu e Alice, pelo incentivo e pela ajuda em todos os momentos. E às minhas irmãs, Leila (Edson e Fernanda), Dirce (Sílvio) e Rosa, pela confiança, apoio e amizade que sempre me fizeram ver o melhor da vida.

Aos amigos: Sarita, Kalinka, Renata, Roberta, Paulo, Simone (Felipe), Omar, Cláudia (Lia), Mac, Márcio, Renato, Regiane, Andrezza, Jorge, Daniel, Tatiana, Fernanda, Ana Elisa, Adriana, Aletéia, Flávio, Rita, Roberto, e tantos outros que de uma forma ou de outra, contribuíram para a realização deste trabalho.

À Beth, Laura e Marília, da Secretaria da Pós-Graduação, por sempre me auxiliarem no que fosse preciso.

A todos da biblioteca, sempre prestativos e atenciosos.

A FAPESP e a Capes, pelo auxílio financeiro. 


\section{Resumo}

Esta dissertação de mestrado descreve a implementação de um módulo de simulação de redes de computadores para o ASiA (Ambiente de Simulação Automático). Este módulo permite ao usuário a simulação de redes já definidas (com a possibilidade de alteração dos parâmetros de entrada) ou definir novas redes através da utilização dos recursos da barra de ferramentas.

Para aumentar a gama de sistemas que o usuário pode modelar foram implementados e incluídos na barra de ferramentas novas funcionalidades que permitem a modelagem de sistemas mais complexos.

Este trabalho apresenta também uma revisão bibliográfica sobre simulação, redes de computadores e ambientes de simulação. 


\section{Abstract}

This MSc dissertation describes the implementation of a computer network simulation module for ASiA (an Automatic Simulation Environment). This module allows to the user the simulation of previously defined computer networks (with possible alteration of parameters) or the definition of new computer networks using the toolbar resources.

New resources were added into the toolbar in order to expand the range of systems that can be modeled, allowing the stydy of more complex systems.

This work also presents a literature review about simulation, computer networks and simulation environments. 


\section{Índice}

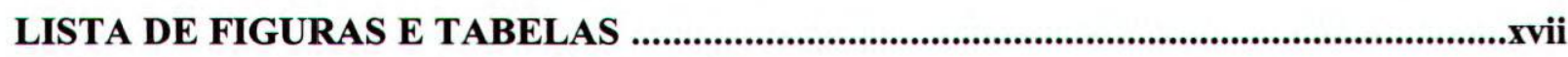

1 INTRODUÇÃ

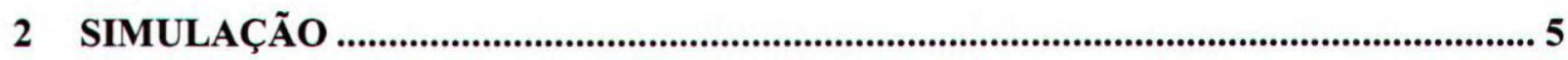

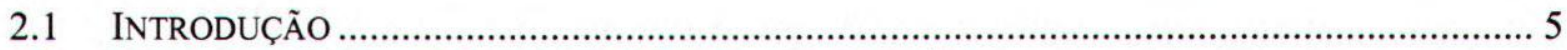

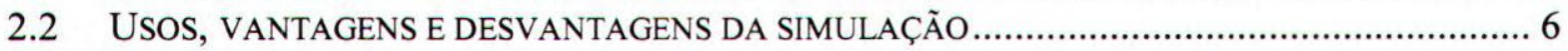

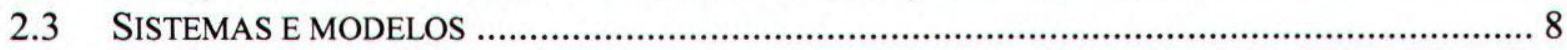

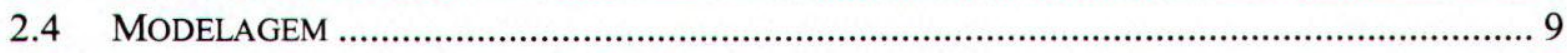

2.4.1 Modelagem para simulação discreta ...................................................................10

2.4.2 Modelagem para simulação contínua..................................................................13

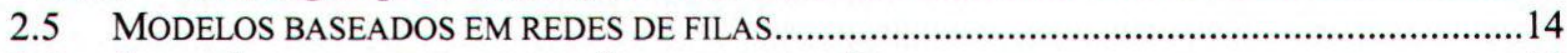

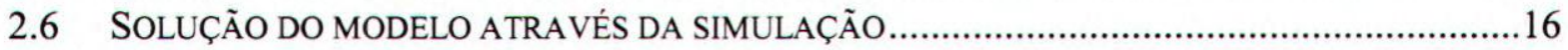

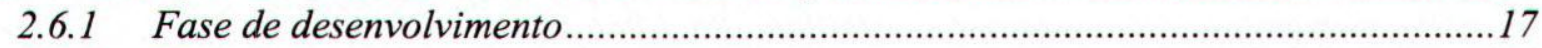

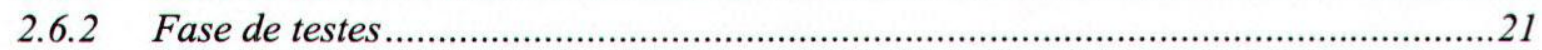

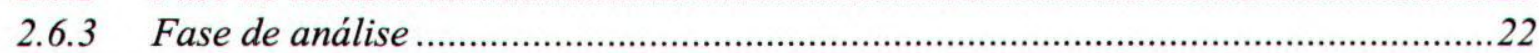

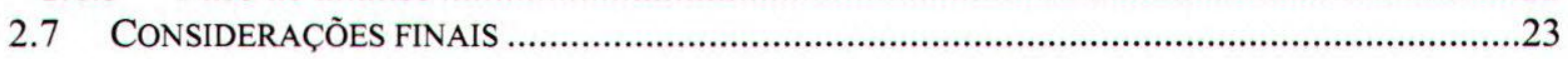

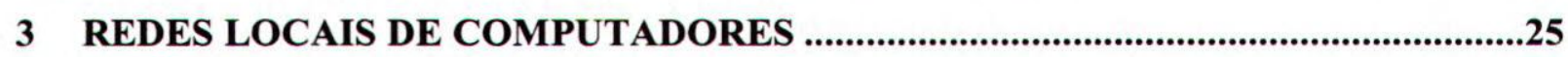

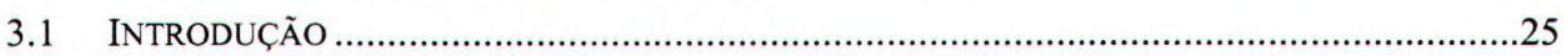

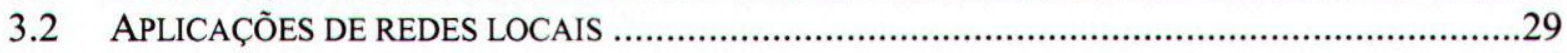

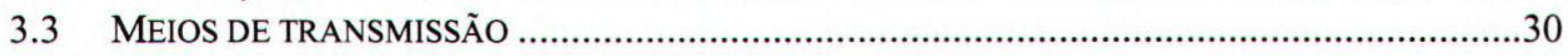

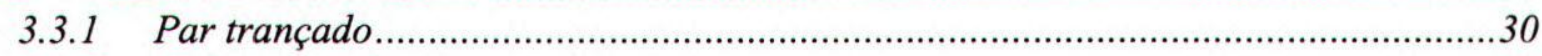

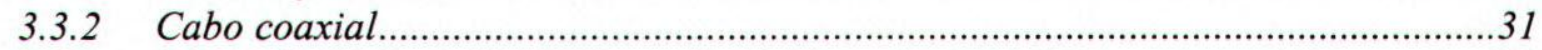

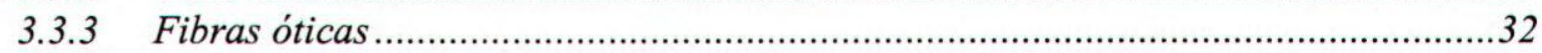

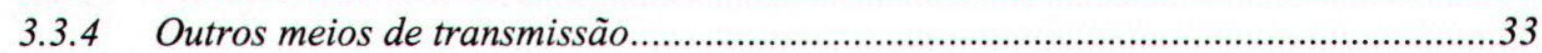

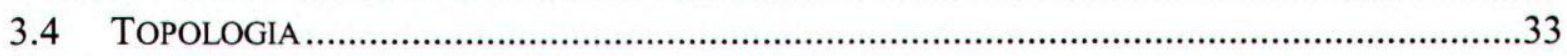

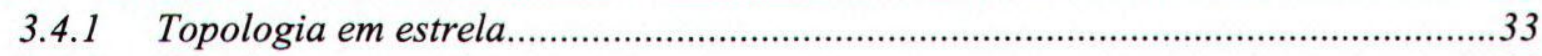

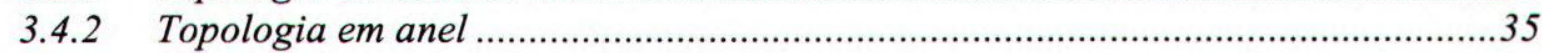

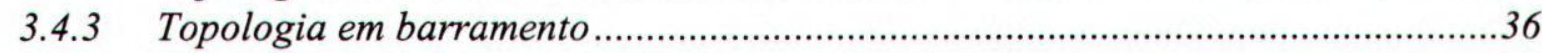

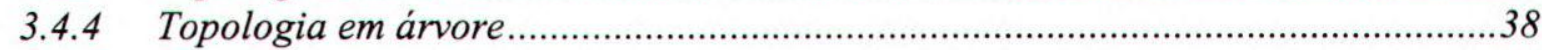

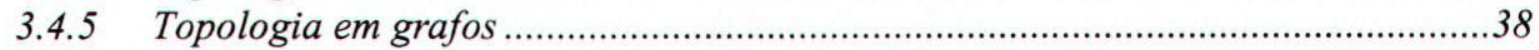

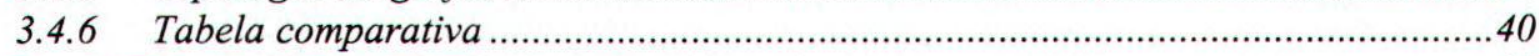

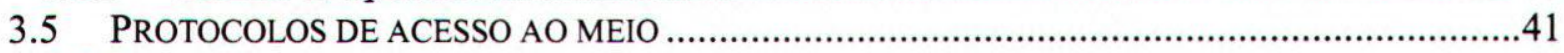

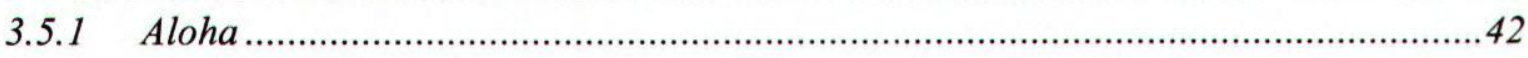

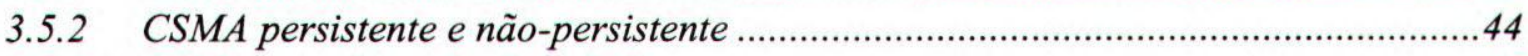

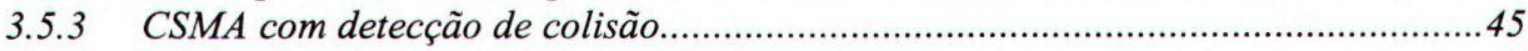

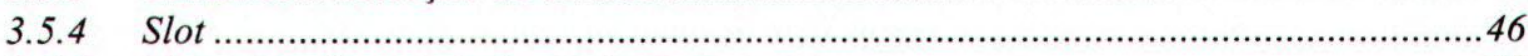

3.5.5 Passagem de permissão em barramento ...............................................................47

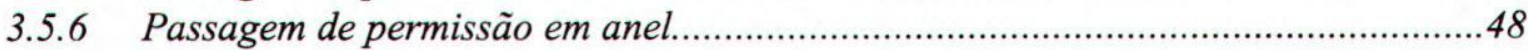

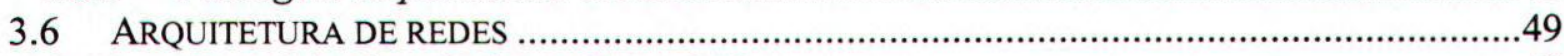

3.6.1 O modelo de referência ISO - OSI......................................................................... 49

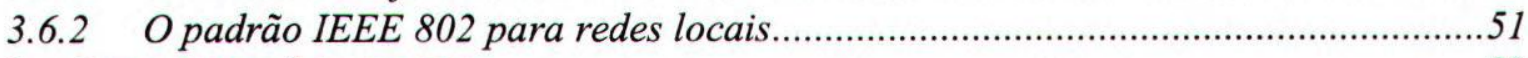

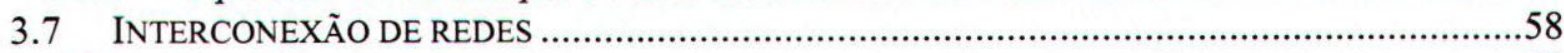

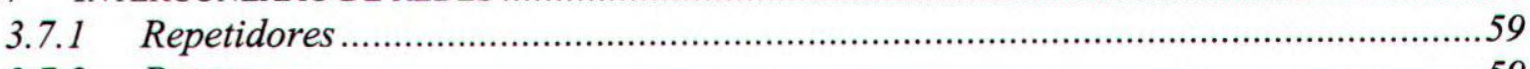

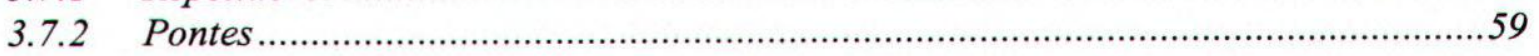




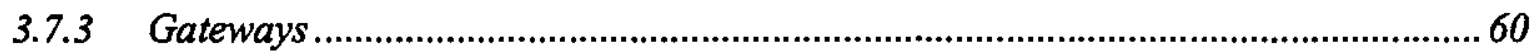

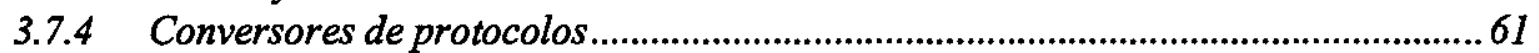

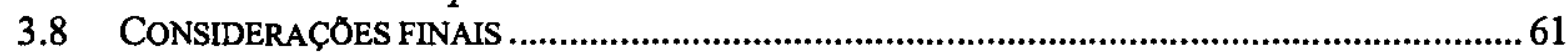

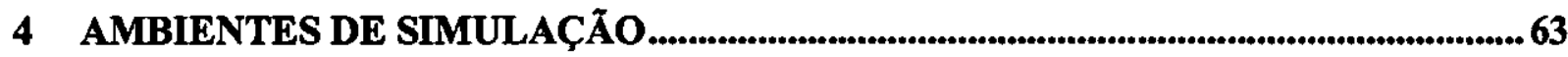

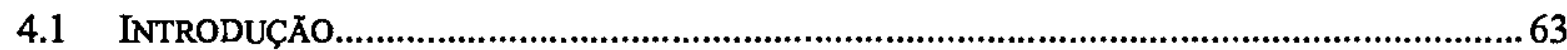

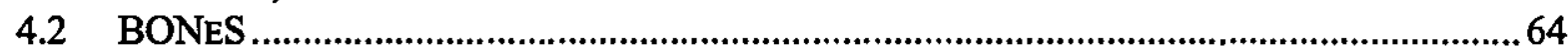

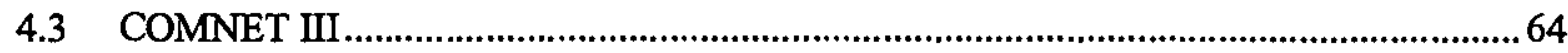

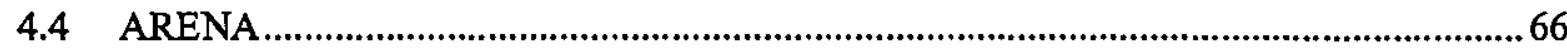

4.5 ASIA

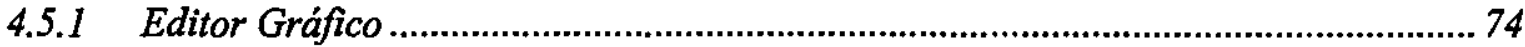

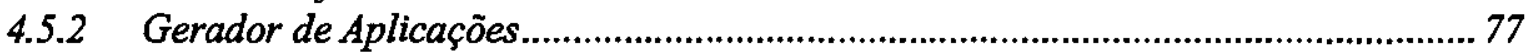

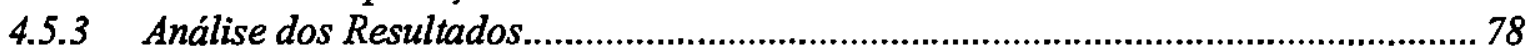

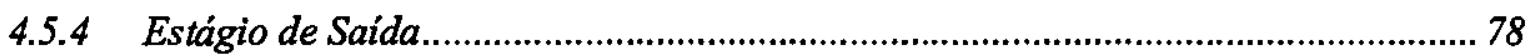

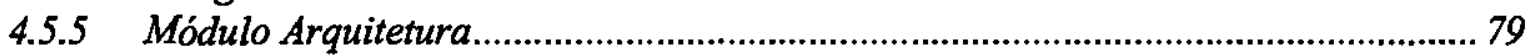

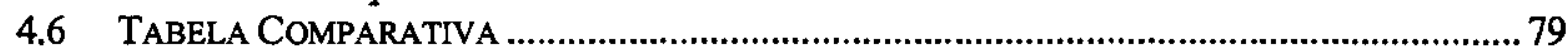

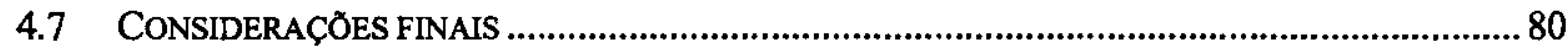

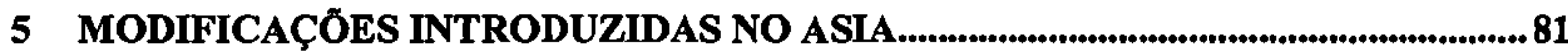

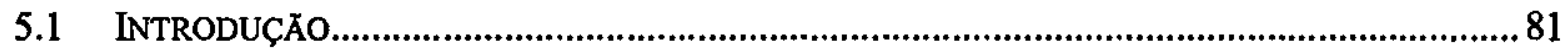

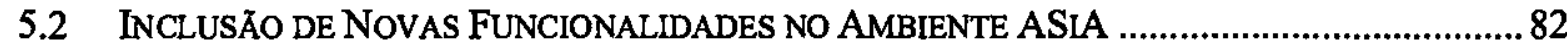

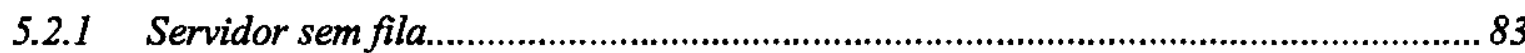

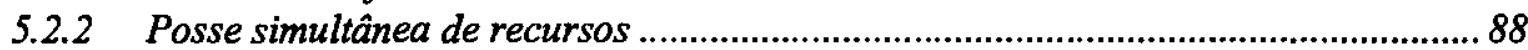

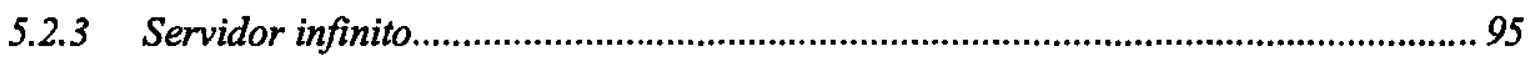

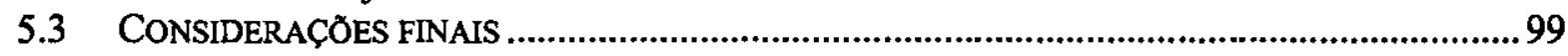

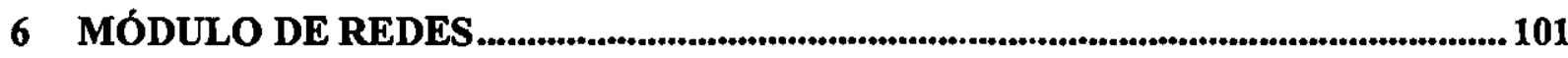

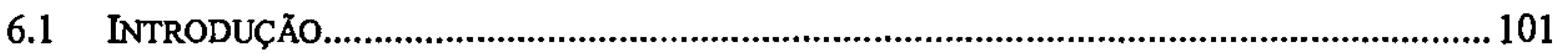

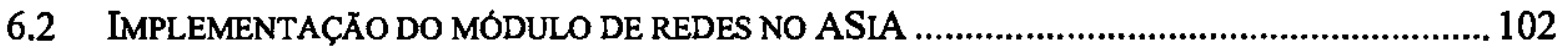

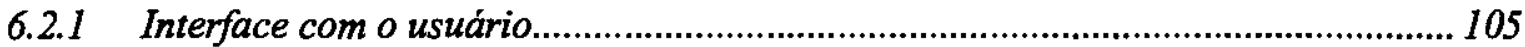

6.2.2 Verificação da consistência dos parâmetros ...............................................................107

6.2.3 Atualização das tabelas e gravação em arquivos ................................................... 108

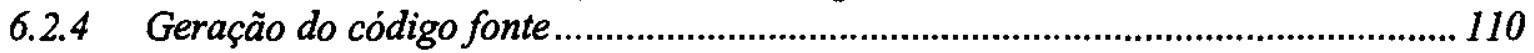

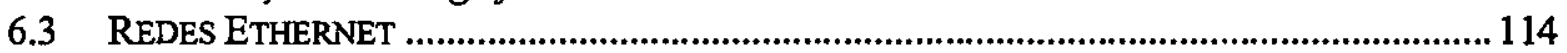

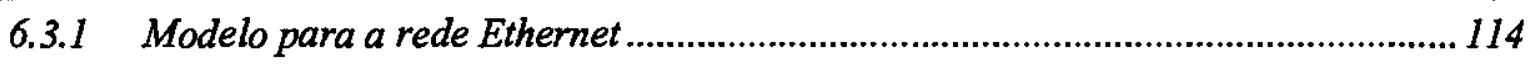

6.3.2 Programa de simulação para a rede Ethernet .......................................................... 115

6.3.3 Utilização da simulação de uma Ethernet no ASiA .............................................. 122

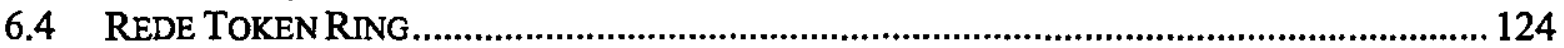

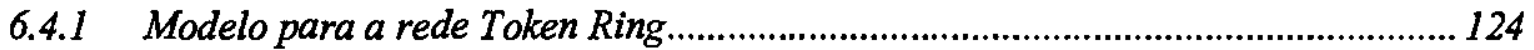

6.4.2 Programa de simulação para a rede Token Ring ................................................... 125

6.4.3 Utilização da simulação de uma Token Ring no ASiA ............................................. 132

6.5 OUTROS RECURSOS A SEREM INCLUIDOS NO MÓDULO DE REDES .................................... 133

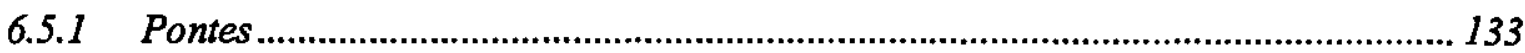

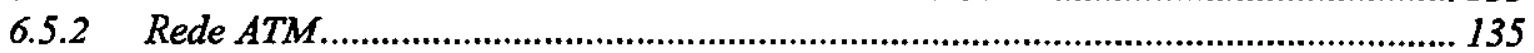

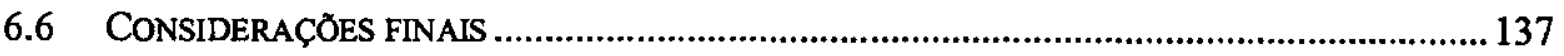

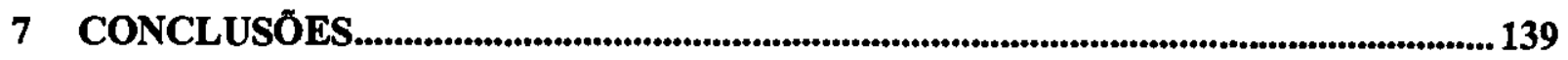

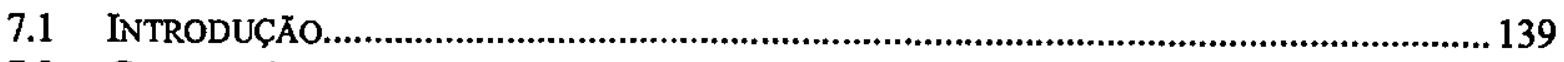

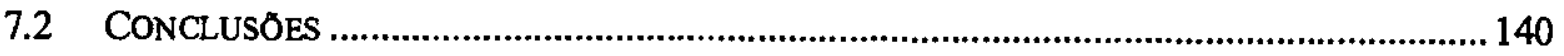




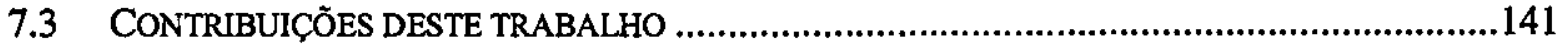

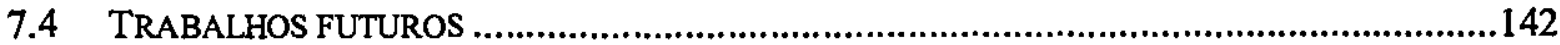

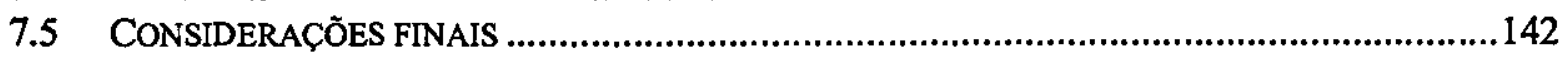

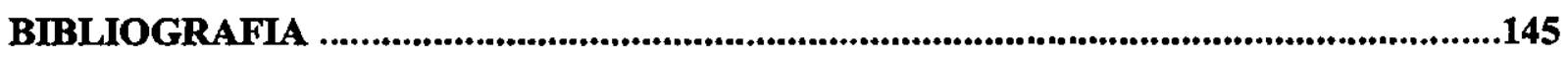




\section{Lista de Figuras e Tabelas}

FIGURA 2.1: RELAÇÕES ENTRE EVENTO, PROCESSO E ATIVIDADE...........................................11

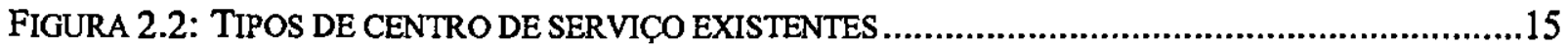

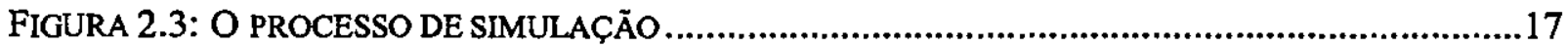

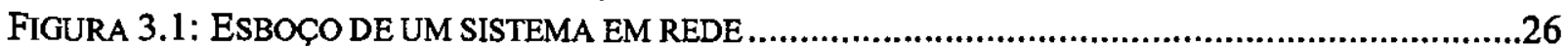

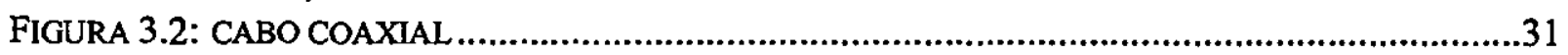

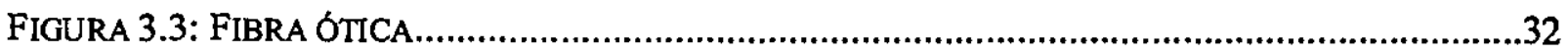

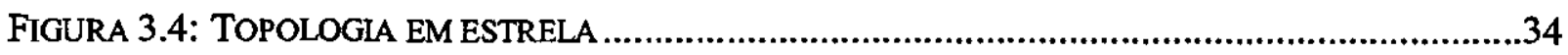

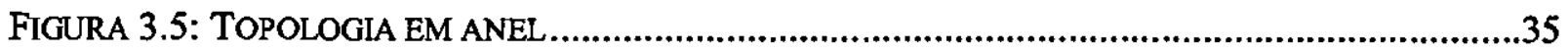

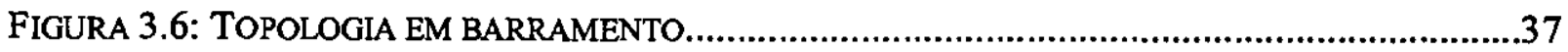

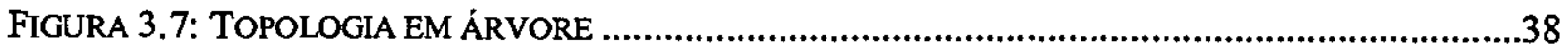

FIGURA 3.8: TOPOLOGIA EM GRAFO(ESTRUTURA PARCIALMENTE CONECTADA) .........................39

FIGURA 3.9: TOPOLOGIA EM GRAFO (ESTRUTURA COMPLETAMENTE CONECTADA) ........................39

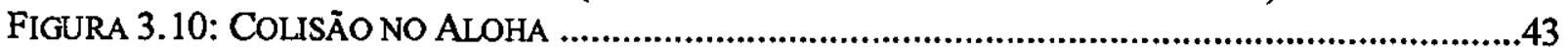

FIGURA 3.11: COMPARAÇÃO DA UTILIZAÇÃO DO CANAL EM FUNÇÃO DA CARGA PARA DIVERSOS

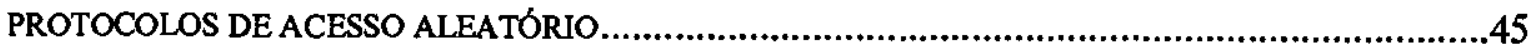

FIGURA 3.12: CSMA/CD PODE ESTAR EM UM DE TRÊS ESTADOS: DISPUTA, TRANSMISSÃOE

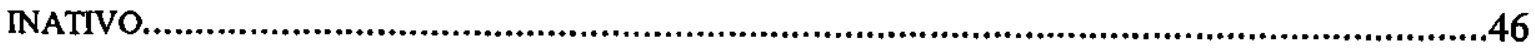

FIGURA 3.13: A ARQUITETURA DE REDE BASEADA NO MODELO OSI .......................................51

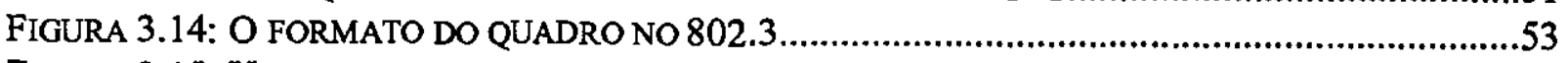

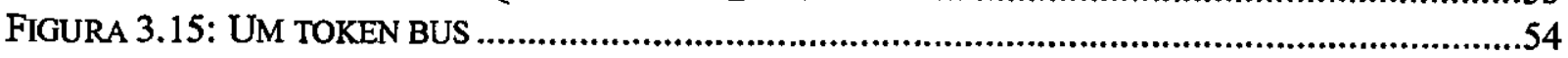

FIGURA 3.16: O FORMATO DO QUADRO NO 802.4 ...........................................................55

FIGURA 3.17: (A) UMA REDE EM ANEL. (B) MODO DE ESCUTA. (C) MODO DE TRANSMISSÃO ........56

FIGURA 3.18: (A) FORMATO DO TOKEN. (B) FORMATO DO QUADRO DE DADOS ............................57

FIGURA 4.1: O SISTEMA DE SIMULAÇÃO COMNET3 ...........................................................65

FIGURA 4.2: EXEMPLO DE UM MÓDULO SERVIDOR SIMPLES .................................................67

FIGURA 4.3: TELA DO SISTEMA ARENA COM UM EXEMPLO DE MODELO...................................68

FIGURA 4.4: BARRA DE FERRAMENTAS PADRÃO..........................................................68

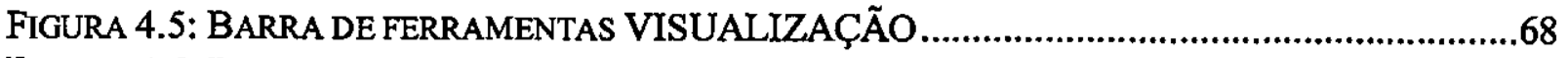

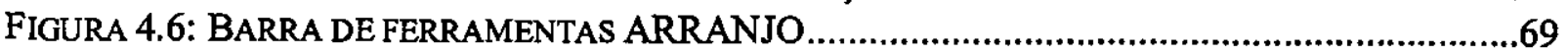

FIGURA 4.7: BARRA DE FERRAMENTAS DESENHO ........................................................69

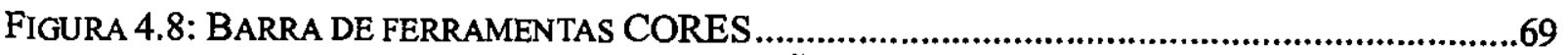

FIGURA 4.9: BARRA DE FERRAMENTAS ANIMAÇÃO ......................................................69

FIGURA 4.10: BARRA DE FERRAMENTAS BIBLIOTECAS ................................................70

FIGURA 4.11: BARRA DE FERRAMENTAS EXECUTAR ..........................................................70

FIGURA 4.12: BARRA DE FERRAMENTAS EXECUTAR INTERATIVAMENTE ..........................70

FIGURA 4.13: ESTRUTURA GERAL DO AMBIENTE DE SIMULAÇÃO AUTOMÁTICO..............................73

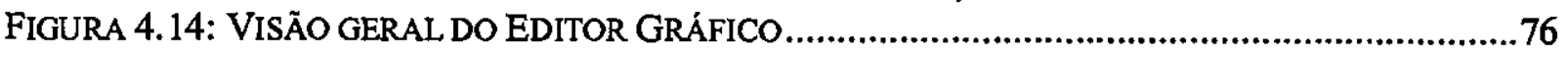

FIGURA 4.15: TELA PRINCIPAL DO EDITOR GRÁFICO .........................................................77

FIGURA 5.1: MODELO DE REDES DE FILAS: SERVIDOR DE ARQUIVOS DO SISTEMA DISTRIBUÍDO

- TRICE. NESSA CONFIGURAÇÃO OS PROCESSADORES FRONT-END SÃO AGRUPADOS EM UM

PROCESSO LÓGICO, E AS UNIDADES DE PROCESSAMENTO E DISCO SÃO REPRESENTADAS EM OUTRO PROCESSO

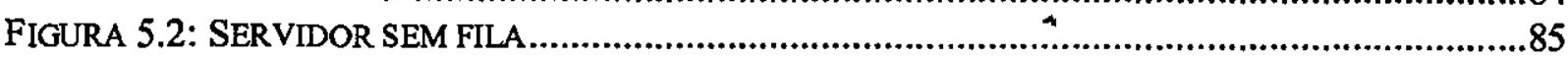

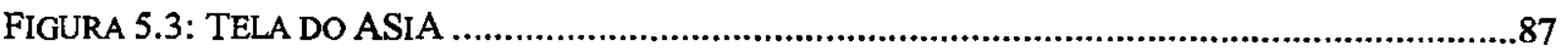

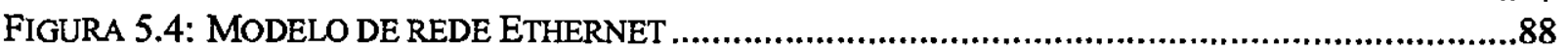

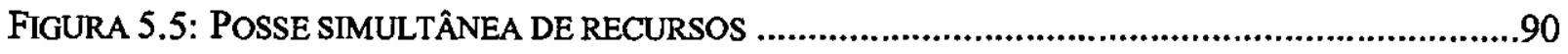

xvii 
FIGURA 5.6: TELA DO ASIA MOSTRANDO OS ÍCONES QUE REPRESENTAM POSSE SIMULTÂNEA DE

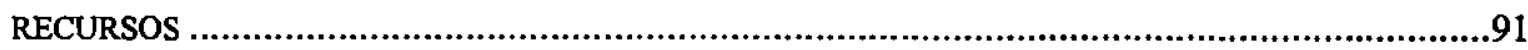

FIGURA 5.7: TELA DO ASIA COM UM EXEMPLO EM REDES DE FILAS........................................992

FIGURA 5.8: CAIXA DE DIÁLOGO DE PARAMETRIZAÇÃO DO RECURSO ......................................93

FIGURA 5.9: TELA DO ASIA COM UM EXEMPLO DE POSSE SIMULTÂNEA E A PARAMETRIZAÇÃO

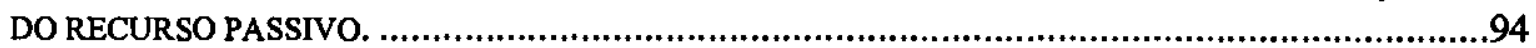

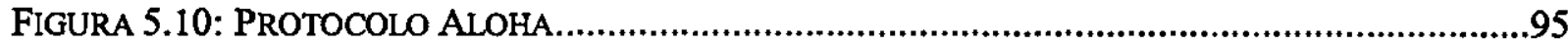

FIGURA 5.11: SERVIDOR INFINITO ............................................................................97

FIGURA 5.12: CAIXA DE DIÁLOGO PARAMETRIZAÇÄO DE RECURSO PARA O RECURSO SERVIDOR

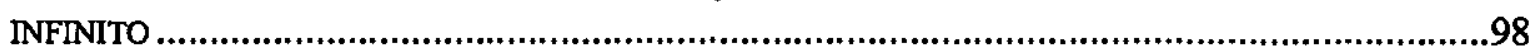

FIGURA 5.13: TELA DO ASIA COM AS NOVAS FUNCIONALIDADES .........................................99

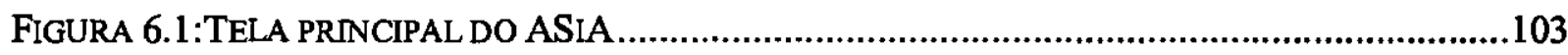

FIGURA 6.2: VISÃO GERAL DO MÓDULO DE SIMULAÇÃO DE REDES............................................104

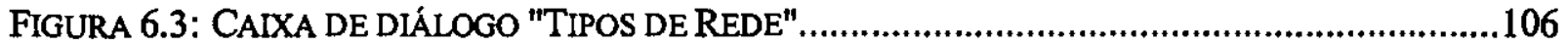

FIGURA 6.4: CAIXA DE DIÁLOGO DE PARAMETRIZAÇÃO DA REDE ETHERNET .............................106

FIGURA 6.5: CAIXA DE DIÁLOGO DE PARAMETRIZAÇÃO DA REDE TOKEN RING ..........................107

FIGURA 6.6: GABARITO PADRÃO DO ASIA.....................................................................111

FIGURA 6.7: GABARITO PARA SIMULAÇÃO DE REDES DE COMPUTADORES ...............................113

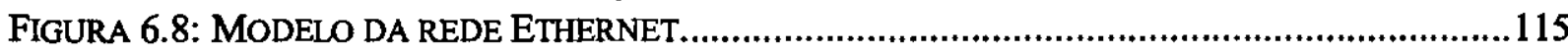

FIGURA 6.9: MODELO DE SIMULAÇÃO PARA REDE ETHERNET ..............................................116

FIGURA 6.10: PROGRAMA DE SIMULAÇÃO PARA REDE ETHERNET .........................................121

FIGURA 6.11: CAIXA DE DIÁLOGO DE PARAMETRIZAÇÃO DA REDE ETHERNET ...........................122

FIGURA 6.12: MODELO DE SIMULAÇÃO DA REDE ETHERNET .................................................123

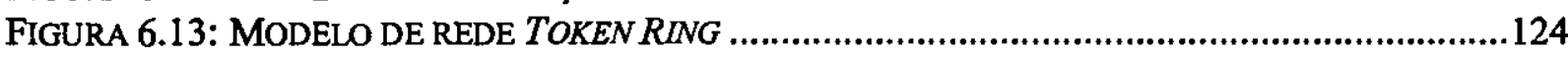

FIGURA 6.14: MODELO DE SIMULAÇÃO PARA REDE TOKEN RING.......................................126

FIGURA 6.15: PROGRAMA DE SIMULAÇÃO PARA REDE TOKEN RING ...................................131

FIGURA 6.16: CAIXA DE DIÁLOGO DE PARAMETRIZAÇÃO DA REDE TOKEN RING ........................133

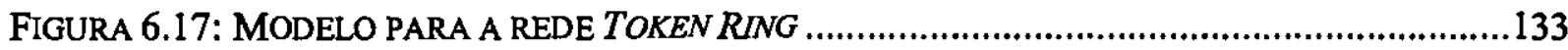

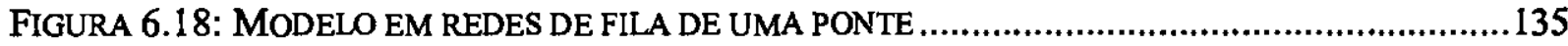

FIGURA 6.19: MODELO DE SIMULAÇÃO PARA A REDE ATM..............................................137

TABELA 1.1: COMPARAÇÃO ENTRE AS DIVERSAS TOPOLOGIAS NOS SEUS ASPECTOS GERAIS .........40

TABELA 2.1: TABELA COMPARATIVA ENTRE OS AMBIENTES DE SIMULAÇÃO. .............................80

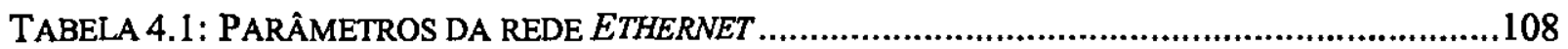

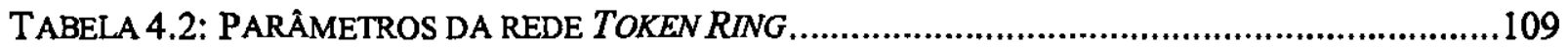

TABELA 4.3: TABELA DOS PARÂMETROS DAS REDES ........................................................110 


\section{Introdução}

Os sistemas computacionais e as redes de computadores têm apresentado uma rápida evolução, se tornando cada vez mais rápidos e mais complexos. As técnicas, acopladas com o acréscimo de demanda por maior eficiência e menor tempo para disseminação da informação, conduzem a tecnologias mais rápidas. Existe um crescimento explosivo na utilização, desenvolvimento e pesquisa em redes de comunicação e computadores de alto desempenho. Esse crescimento tem sido estimulado em grande parte pelos avanços nos sistemas computacionais e projetos de rede, protocolos, serviços, gerenciamento, arquitetura e aplicações [OBA97].

Devido ao grande avanço, tanto em termos tecnológicos quanto de utilização das redes de computadores, tornou-se essencial o desenvolvimento de um estudo sobre o desempenho dessas redes. Além da avaliação de desempenho é importante ainda a validação do sistema a ser utilizado. Dentre as formas de avaliação e validação de sistemas, a utilização de modelagem de sistemas computacionais e redes de computadores se destacam. Um estudo da modelagem e simulação é necessário quando o projetista de sistemas computacionais precisa tecer comparações entre diversas alternativas de projeto para encontrar a abordagem de melhor relação custo/benefício. Não existem motivos para projetar e implementar novos sistemas que não tenham desempenho e que não podem competir com sistemas já existentes no mercado.

A utilização da técnica de modelagem também é necessária quando um gerente de um centro de computação precisa comparar diversos sistemas para decidir qual é o melhor para um dado conjunto de aplicações. A avaliação de desempenho de um sistema existente é também importante desde que auxilie na determinação de quão bem o sistema está, assim como quais melhoramentos são necessários para aumentar seu desempenho. As abordagens mais comuns para avaliar o desempenho de sistemas computacionais e redes de computadores são a modelagem analítica e a simulação.

A solução analítica permite a obtenção de resultados mais precisos, porém, à medida que o modelo se torna mais complexo, aumenta-se o grau de dificuldade da resolução por 
métodos analíticos. Além disso, alterações no modelo implicam em modificações em todas as equações e o recálculo das mesmas. A simulação, por outro lado, possui facilidades para modificações no modelo uma vez que apenas o programa deve ser alterado.

A simulação é uma ferramenta bastante útil para avaliação de desempenho de sistemas, porém, a sua utilização não é muito fácil, pois implica em aprendizado de linguagens de simulação, de modelagem de sistemas e de análise dos dados. Desse modo, para facilitar o uso da simulação existem ambientes de simulação automáticos que afastam o usuário da tarefa árdua de transcrição de um modelo em um programa de simulação.

No Grupo de Sistemas Distribuídos e Programação Concorrente do ICMC - USP está em desenvolvimento um Ambiente de Simulação Automático (ASiA) que permite ao usuário a utilização de simulação sem necessitar de conhecimento das diferentes áreas envolvidas no desenvolvimento e na análise dos resultados gerados por uma simulação, tais como: linguagens de simulação, estatística, etc. O ASiA fornece facilidades gráficas para o usuário desenhar o seu modelo através de redes de filas, e a partir de parametrizações desse modelo, o ambiente gera e executa o programa de simulação.

Devido a crescente importância que as redes de computadores tem adquirido, é essencial uma ferramenta de simulação de redes de computadores para o ASiA. A importância do sistema para simulação de redes do ASiA está relacionada com a grande flexibilidade apresentada pelo ASiA e pela possibilidade de se integrar a simulação de redes com outras facilidades disponíveis nesse sistema, tais como: simulação de arquiteturas de computadores; utilização de ferramentas para análise da saída; utilização de ferramentas para visualização dos resultados, etc.

Nessa dissertação são discutidos o projeto e a implementação de um módulo de simulação de redes de computadores para o ASiA. O módulo de redes permite que o usuário simule redes de computadores sem necessitar de conhecimentos específicos em redes de filas (que é a abordagem utilizada pelo ASiA) nem simulação. Essa ferramenta torna a simulação de redes uma tarefa mais simples pois fornece subsídios, tais como modelos prontos que o usuário pode utilizar de maneira mais fácil, podendo até modificar os parâmetros desses modelos prontos para obter resultados dessa rede com os parâmetros fornecidos pelo usuário. Desta forma, o objetivo deste trabalho é estender o ASiA para que este ofereça os recursos 
necessários para a simulação de redes de computadores e implementar uma versão inicial do módulo de redes que poderá ser facilmente estendido, através da inserção de novos modelos.

Um requisito inicial para o desenvolvimento do módulo de redes é o conhecimento de simulação de sistemas e dos parâmetros e dos elementos envolvidos no processo de simulação, além da análise dos dados obtidos. Desse modo, o capítulo 2 apresenta uma revisão sobre simulação, abordando a sua utilização, as vantagens e desvantagens da sua utilização, conceitos como modelo e sistema, os tipos de abordagem de simulação (orientada a evento, processo e atividade) e as fases de um processo de simulação.

Para a definição das redes e análise dos parâmetros de interesse é necessário um estudo sobre redes de computadores. O Capítulo 3 apresenta, desse modo, tópicos básicos referentes a redes locais de computadores, aplicação de redes, topologia, protocolos, meios de transmissão, arquitetura e interconexão de redes.

O ASiA é detalhado no Capítulo 4, onde são descritos os módulos: Editor Gráfico, Gerador de Aplicação, Análise dos Resultados, Módulo de Saída e Módulo Arquitetura que compõem o ASiA. Além disso, este capítulo apresenta outros ambientes para simulação disponiveis na literatura consultada, tais como: BONeS [CAD98], COMNET III [KIA96] e ARENA [SYS98].

Os Capítulos 5 e 6 apresentam o trabalho desenvolvido.

Concluindo, o Capítulo 7 apresenta as conclusões e as contribuiçб̃es desse trabalho, além de propostas para trabalhos futuros. 


\section{.}




\section{Simulação}

Esse capitulo discute tópicos relevantes sobre simulação. São apresentados os conceitos de modelo e sistema, as vantagens e as desvantagens da simulação e as fases que compõem o processo de simulação.

\subsection{Introdução}

A simulação é um método utilizado para entender, representar e resolver problemas complexos. É uma das mais poderosas ferramentas de análise de projeto e de operação de processos e sistemas em indústrias. É definido no dicionário Webster como "fingir, obter a essência de, sem a realidade". E, de acordo com Schriber [SCH87], "Simulação envolve a modelagem de um processo ou um sistema de tal modo que o modelo imita o comportamento do sistema real para eventos que ocorrem através do passar do tempo". E também, de acordo com Shannon [SHA92], "Simulação é o processo de projetar um modelo de um sistema do mundo real e conduzir experimentos com esse modelo com a proposta de entender o comportamento do sistema e/ou avaliar várias estratégias para a operação do sistema" [PEG91] [ROB83] [STA97].

Os modelos de simulação são chamados modelos de entrada/saída porque eles produzem uma saída para um determinado conjunto de dados de entrada. E esses modelos são executados e não resolvidos. Eles são incapazes de gerar uma solução ótima por si mesmos; eles somente servem como uma ferramenta de análise do comportamento do sistema sobre condições especificadas pelo experimentador.

A simulação vem se tornando bastante popular. Essa grande aceitação se deve a sua versatilidade, flexibilidade, poder e baixo custo. A simulação é versátil pois quase todos os tipos de sistema podem ser modelados. Ela é freqüentemente utilizada para modelar sistemas computacionais, de produção, de serviços, financeiros, governamentais, ambientais e sociais. 
Um exemplo simples de simulação é quando se deseja determinar se o acréscimo no número de caixas em um banco pode ser justificado pela redução de tempo de espera dos clientes.

A simulação é flexível devido a possibilidade de se ter respostas rápidas para modificações no modelo. Em teoria de filas, a decisão sobre o número de caixas a serem utilizadas em um banco requer o cálculo de um conjunto de fórmulas matemáticas para cada alternativa. Esses cálculos são tediosos e devem estar baseados em suposições bastante rigorosas. Em contraste, um modelo de simulação de um banco pode ser modificado em segundos para responder questões como: "Qual será o tempo de espera de um cliente se contratarmos mais um caixa ?".

A simulação pode reduzir custos pois permite que testes prévios sejam feitos antes do desenvolvimento de sistemas. O conceito básico da simulação é de fácil compreensão e por esta razão é freqüentemente mais simples a sua justificativa a gerentes e clientes do que os modelos analíticos. $\mathrm{E}$ além disso, a simulação pode ter mais credibilidade porque o seu comportamento pode ser comparado ao sistema real.

A seguir são descritos os usos, as vantagens e as desvantagens da simulação.

\subsection{Usos, vantagens e desvantagens da simulação}

As técnicas de simulação têm sido utilizadas nas seguintes atividades [SHI75]:

- para experimentação e avaliação, de modo a prever as conseqüências causadas por mudanças de políticas, condições ou métodos, sem ter que implementá-las no sistema real, evitando grandes gastos e riscos de obter resultados inesperados.

- como maneira de estudar novos sistemas a fim de reprojetá-los ou refiná-los.

- como ferramenta que auxilia pessoas na sua familiarização com equipamentos ou sistemas ainda não operacionais.

- para estudar processos transitórios ou intermediários, pois a simulação possibilita o estudo de estados transitórios ou intermediários em qualquer ponto que se deseje. A solução por processos analíticos usuais freqüentemente especifica estados terminais ou estacionários. 
- para a verificação ou demonstração de uma nova idéia, sistema ou maneira de resolução de um problema.

- como meio de projeção no futuro, isto é, como ferramenta de previsão e planejamento quantitativo.

Em adição aos benefícios que a simulação traz, ela tem também as seguintes vantagens [STA97, BAN96]:

- Pode ser utilizada para explorar novos planos de ação, procedimentos operacionais, regras de decisão, estruturas organizacionais, fluxos de informação, etc. sem corromper operações em andamento.

- Novos projetos de hardware, esquemas físicos, programas, etc. podem ser testados antes de se submeter recursos para sua implementação.

- A simulação permite controlar o tempo. O tempo pode ser facilmente comprimido, expandido, etc. permitindo a visualização de períodos longos ou então estudar fenômenos com detalhes através da diminuição da velocidade do tempo.

- A simulação permite detectar quais são as variáveis mais importantes e como essas variáveis interagem.

- É possível identificar gargalos em fluxos de material, informação e produtos.

- Através da simulação é possível experimentar novas situações dentro do sistema, utilizando-se da habilidade de explorar questões do tipo "o que aconteceria se ?".

Todas essas vantagens tornam o uso da simulação muito atrativa, porém, apesar disso ela também tem seus problemas, tais como:

- A construção de um modelo é uma arte e requer treinamento especial. A qualidade da análise depende da qualidade do modelo e do conhecimento da pessoa que está modelando.

- Os resultados de uma simulação são, algumas vezes, dificeis de serem interpretados. Uma vez que o modelo está tentando capturar o comportamento de um sistema, é 
freqüentemente difícil determinar se uma observação durante uma execução está de acordo com o sistema.

- A análise de uma simulação pode ser um processo bastante caro e lento. Uma análise adequada pode não ser possível dentro do tempo e/ou dos recursos disponíveis e uma estimativa utilizando métodos analíticos pode ser preferivel.

- Ocasionalmente as pessoas utilizam a simulação animada no computador para impressionar quem toma as decisões, sem dar atenção ao significado dos dados de entrada e como esses dados se relacionam com a saída.

Todos esses fatores devem ser considerados no momento da escolha do método de resolução de algum problema. Muitas vezes a simulação é bastante benéfica de modo a auxiliar nas tomadas de decisão. Porém deve-se sempre lembrar que a simulação é apenas uma ferramenta de auxílio e não um resultado definitivo e que muitas vezes outros métodos devem ser utilizados antes da implementação de seus resultados.

Alguns conceitos, como sistemas e modelos, são importantes para o entendimento da simulação e são descritos a seguir.

\subsection{Sistemas a modelos}

Modelo é uma descrição do sistema. E para cada problema específico existe um modelo apropriado. Deste modo, pode-se ter várias descrições para o mesmo sistema, cada qual para a resolução de um problema particular. Os modelos requerem uma estrutura organizada qualquer, como por exemplo, uma linguagem de simulação. Assim, compilando-se um programa de simulação, a descrição do sistema é traduzida em uma forma aceitável por um sistema de computação. O computador então é utilizado para exercitar o modelo de modo a produzir saídas que podem ser analisadas [SOA90].

Pode-se dizer que sistema é uma coleção de itens, entre os quais se pode encontrar ou definir alguma relação, que são objetos de estudo ou interesse. $O$ interesse aqui é o estudo de sistemas descritos através de módelos, apoiados na estrutura dada por uma linguagem de simulação. 
Tendo definido modelo como uma descrição do sistema, pode-se ir mais além, e dizer que modelo é uma abstração do sistema. Ao se criar uma abstração, uma das tarefas mais difíceis que o modelador enfrenta é quais são os elementos que ele deve incluir no modelo. Para tomar esta decisão, deve estar bem claro qual o propósito do modelo e o que se espera obter dele.

Freqüentemente os modelos são classificados de acordo com os métodos utilizados na obtenção dos resultados. Desse modo, modelo analítico é definido como modelo cuja estrutura é formada por uma série de equações matemáticas através das quais o comportamento do sistema pode ser obtido pela atribuição de valores aos parâmetros do modelo e solução das equações.

Modelos para simulação podem ser definidos como aqueles representados por uma estrutura matemática/lógica que pode ser exercitada de forma a imitar o comportamento do sistema. Através da simulação várias observações são realizadas para dar subsídio às várias conclusões sobre o sistema.

As simulações permitem inferências sobre os sistemas sem a necessidade de construílos (ainda em fase de projeto), sem interferir em seu funcionamento (pois podem ser sistemas de alto custo operacional ou críticos para que se façam experimentos) e também sem destruílos (de modo a determinar os limites de funcionamento do sistema).

Dessa forma, a simulação possui quatro objetivos principais [SOA90]:

- Ferramenta explanatória para definição de um sistema ou problema.

- Ferramenta de análise para detecção de elementos críticos.

- Ferramenta de síntese e avaliação de soluções propostas.

- Ferramenta de planejamento para desenvolvimentos futuros.

\subsection{Modelagem}

Modelar um sistema é substituí-lo por algo que é mais simples e/ou mais fácil de estudar e é equivalente ao original em aspectos importantes [MIT92]. Se o sistema real 
interage com o mundo exterior de alguma maneira, essa interação deve estar refletida no modelo.

Os modelos de um sistema podem ser classificados como modelos de mudança discreta e modelos de mudança contínua. As mudanças, que são as alterações nas variáveis de estado do sistema são a base para a classificação dos modelos. O tempo, na maioria das simulações, é a principal variável independente. As outras variáveis inclúdas na simulação são funções do tempo, e portanto, dependentes. Os adjetivos discreto e contínuo na classificação dos modelos, referem-se ao comportamento dessas variáveis dependentes.

Modelo de mudança discreta ou simplesmente modelo discreto, é aquele em que as variáveis dependentes variam em pontos específicos do tempo simulado, que são chamados tempo de evento. A variável tempo pode ser contínua ou discreta em tais modelos, dependendo se as mudanças nas variáveis dependentes podem ocorrer em qualquer ponto do tempo real ou unicamente em pontos pré-determinados.

Modelo de mudança contínua ou simplesmente modelo contínuo é aquele em que as variáveis dependentes podem variar continuamente ao longo do tempo simulado. Um modelo contínuo pode ser tanto contínuo no tempo ou discreto no tempo, dependendo se os valores das variáveis dependentes estão sempre disponíveis em qualquer ponto do tempo simulado ou apenas em pontos específicos.

\subsubsection{Modelagem para simulação discreta}

Os objetos em um sistema discreto são chamados entidades, e cada entidade possui características próprias. Algumas vezes é interessante agrupar as entidades de mesmo atributo, mesmo que estejam envolvidas em atividades diferentes. A esse agrupamento dá-se o nome de arquivo ou conjunto.

Na simulação discreta, somente ocorrem mudanças no estado do sistema nos tempos de eventos. Devido a essa característica, pode-se ter uma descrição completa do estado do sistema através do avanço do tempo entre um evento e outro. Esse mecanismo é utilizado na maioria das linguagens para simulação discreta. 
A formulação de um modelo para simulação discreta pode ser realizada de três formas:

- Pela definição das mudanças nos estados que podem ocorrer a cada tempo de evento

- Pela descrição das atividades nas quais as entidades do sistema se envolvem

- Pela descrição do processo através do qual as entidades do sistema fluem.

As relações entre os conceitos de atividade, processo e evento pode ser melhor entendida pela Figura 2.1 [SOA90]

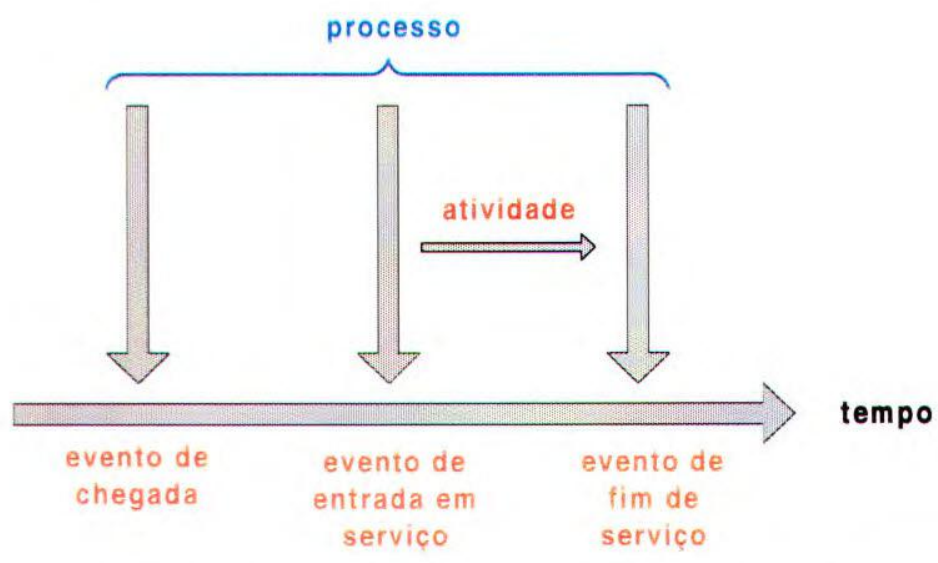

Figura 2.1: Relações entre evento, processo e atividade

Pode-se dizer que um evento ocorre em um ponto isolado do tempo, no qual decisões devem ser tomadas de forma a iniciar ou terminar uma atividade. Um processo é uma seqüência ordenada de eventos e pode englobar várias atividades. Esses conceitos levam naturalmente a três alternativas de enfoque de um modelo para simulação discreta:

- Modelo orientado a evento

- Modelo orientado ao exame da atividade

- Modelo orientado a processo 


\subsubsection{Simulação orientada a evento}

Nesse tipo de simulação, o sistema é modelado de acordo com a ocorrência de mudanças no sistema em pontos discretos do tempo (tempo de evento). $O$ modelador deve então determinar os eventos que causam mudanças no estado do sistema e desenvolver a lógica associada a esses eventos. A simulação do sistema consiste então na execução da lógica associada a cada evento, em uma seqüência ordenada no tempo.

Quando ocorre um evento, o estado do sistema pode mudar de quatro modos ou por uma combinação desses quatro modos:

- Pela alteração do valor de uma ou mais variáveis associadas com a simulação.

- Pela alteração do número de entidades presentes no sistema.

- Pela alteração do valor designado a um ou mais atributos da entidade.

- Pela alteração da relação que existe entre as entidades através da manipulação de filas.

\subsubsection{Simulação orientada a atividade}

$\mathrm{Na}$ simulação orientada a atividade, deve-se definir quais são as atividades de cada entidade e quais são as condições de início e fim de cada atividade. Os eventos que iniciam ou terminam uma atividade não são escalonados pelo modelador, mas são iniciados a partir das condições especificadas para a atividade. À medida que o tempo de simulação avança, as condições para o início ou o fim de uma atividade são examinadas.

O uso dessa abordagem é adequado para certos tipos de probiemas, pois produz um modelo bem conciso. Em situações onde a duração da atividade é indefinida e determinada pelo estado do sistema que satisfaz uma condição pré-estabelecida, a simulação orientada ao exame da atividade é especialmente adequada. Entretanto, devido a necessidade de se escalonar todas as atividades a cada avanço do tempo o método é relativamente ineficiente quando comparado com a simulação orientada a evento, e por isso a maioria das linguagens de simulação não utilizam esta abordagem. 


\subsubsection{Simulação orientada a processo}

Muitos modelos de simulação possuem seqüências de eventos que ocorrem em padrões definidos, como por exemplo, uma fila de entidades esperando por um servidor. A lógica associada a essa sequiência de eventos pode ser generalizada e definida por uma única afirmação. Uma linguagem para simulação pode então traduzir tal afirmação na seqüência de eventos associada. Uma linguagem orientada a processo emprega tais afirmações para modelar o fluxo das entidades no sistema. Estas afirmações definem uma seqüência de eventos que é automaticamente executada pela linguagem de simulação.

A simulação orientada a processo combina as facilidades da simulação orientada a evento e da simulação orientada a atividade. Esta simplicidade reside no fato da lógica dos eventos associados às afirmações estar contida na linguagem de simulação. Porém, como existe restrição ao conjunto de afirmações padrão fornecido pela linguagem, a flexibilidade não é tão grande quando comparada com a simulação orientada a evento.

\subsubsection{Modelagem para simulação contínua}

Na simulação contínua, o estado do sistema é representado por variáveis que mudam com o passar do tempo. Um modelo para simulação contínua é construído através de equações que definem as relações entre as suas variáveis de estado, cujo comportamento dinâmico simula o sistema real.

Modelos de sistemas contínuos são normalmente escritos em termo de derivadas das variáveis de estado, uma vez que é mais simples construir uma relação para as taxas de variações das variáveis de estado, do que para as variáveis diretamente. A maioria das linguagens para simulação contínua utiliza orientação a equação. Nessas linguagens as equações diferenciais são codificadas em forma de equações. A vantagem dessa orientação está na flexibilidade que pode ser obtida das características lógicas e algébricas da linguagem. 


\subsection{Modelos baseados em redes de filas}

Modelagem para simulação é assunto de interesse de projetistas e analistas de sistemas. Os projetistas de sistema desejam ser capazes de prever o comportamento de um novo sistema proposto e selecionar o melhor projeto a partir de uma série de alternativas. $\mathrm{E}$ os analistas de sistemas estão preocupados com o efeito de mudanças em um sistema existente e se esses sistemas podem suportar um aumento de carga de trabalho.

Os sistemas são compostos por recursos. Um exemplo de recurso pode ser a CPU de um computador. E os usuários são aqueles que fazem uso dos recursos. Durante o uso do recurso por algum usuário, outro usuário pode querer utilizá-lo também, o que causa uma fila ou uma linha de espera.

Para a construção de um modelo um analista normalmente utiliza as características gerais de um modelo já existente. Assumindo-se que se está trabalhando com modelos relativamente abstratos, pode-se classificar os modelos baseados nas estruturas utilizadas para a sua construção. $O$ enfoque dado aqui será em estruturas de redes de filas e na modelagem discreta orientada a evento. A seguir é dada uma introdução sobre o conceito de redes de filas.

Uma rede de filas consiste de entidades chamados centros de serviço e um conjunto de entidades chamado usuários que requisitam serviços dos centros.

Um centro de serviço consiste de um ou mais servidores, correspondente a recursos no sistema modelado, e uma área de espera (fila) para usuários que estão requisitando serviço. A CPU de um computador pode ser modelado como um centro de serviço. A Figura 2.2 mostra os tipos de centros de serviço existentes.

Um usuário corresponde a uma entidade que circula pelo sistema modelado. Um programa de computador é um exemplo de entidade que pode ser modelada como usuário e que requisita serviço da CPU.

Pelo fato de serem redes de filas, deve haver uma política de escalonamento para a escolha do usuário que será o próximo a ser atendido pelo centro de serviço. Existem diversas disciplinas, e as mais usuais são: 


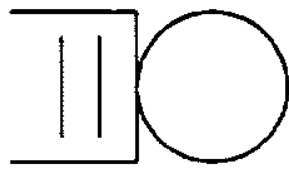

uma fila, um servidor

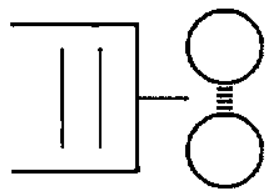

uma fila, vários servidores

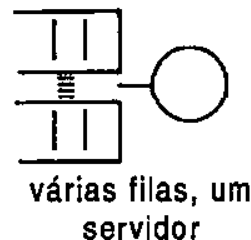

servidor

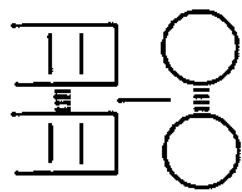

várias filas, vários servidores

Figura 2.2: Tipos de centro de serviço existentes

- FCFS (First Come First Served) - os usuários são atendidos na ordem em que chegaram ao centro de serviço.

- LCFS (Last Come First Served) - esta disciplina tem a estrutura de uma pilha, onde o último a chegar ao centro é que entrará em serviço assim que o servidor estiver disponível.

- RR (Round Robin) - um usuário escalonado é atendido por um intervalo de tempo, chamado quantum. Se o serviço requisitado não for completado, o usuário é colocado no final da fila e um outro usuário entra para receber seu quantum de serviço. Quando o usuário terminar o serviço que requisitou, ele deixa o centro de serviço.

- PS (Processor Sharing) - todos os usuários dividem a capacidade do centro de serviço, como se executassem em paralelo.

- IS (Infinite Server) - nunca existe fila. Todos os usuários são servidos assim que chegam ao centro.

- PRTY (Nonpreemptive priority) e PRTYPR (Preemptive-resume Priority) - escalonamento com prioridade é utilizado para dar preferência a alguns usuários. Com prioridade não preemptiva, o usuário em atendimento não é afetado quando um usuário de prioridade mais alta chega ao centro. Já na prioridade preemptiva, a chegada de usuário com prioridade mais alta tira de serviço o de prioridade mais baixa, que só entrará em serviço assim que todos os usuários com prioridades maiores forem atendidos. 


\subsection{Solução do modelo através da şimulação}

A simulação é um método de solução de modelos que tenta imitar o comportamento de um sistema, se constituindo de um experimento estatístico que observa o comportamento do sistema no decorrer do tempo. O modelo pode ser exercitado a partir de dados obtidos de medidas do sistema ou, com valores aleatórios gerados a partir de distribuições, com a finalidade de representar o tempo de chegada entre usuários, tempos de serviço e probabilidades de roteamento. Esses valores aleatórios são produzidos por um algoritmo, de acordo com a distribuição de probabilidade.

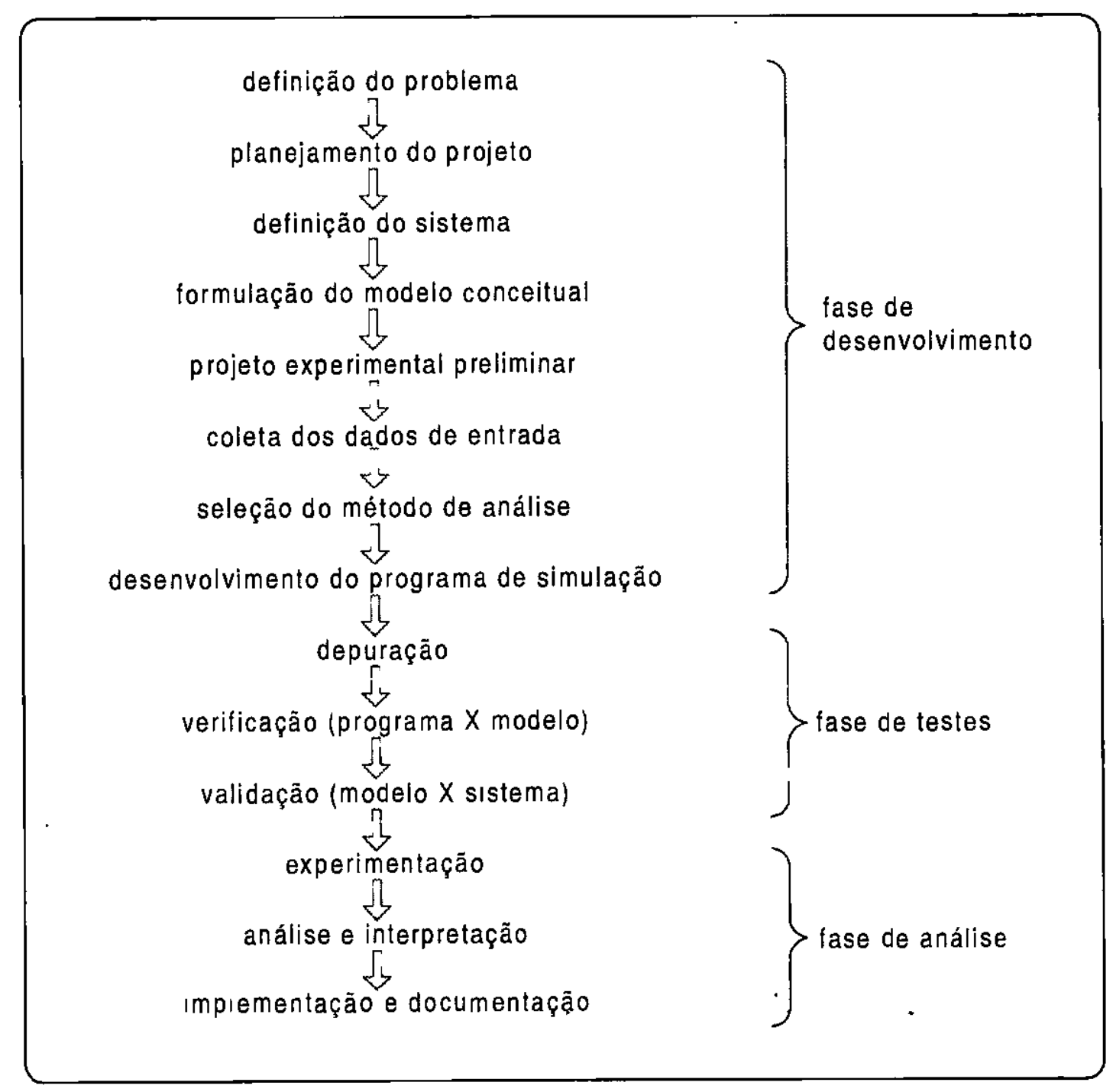

Figura 2.3: $O$ processo de simulação 
Durante a execução da simulação os usuários circulam entre os vários recursos. E diversas medidas de desempenho podem ser calculadas a partir dos dados observados.

A essência da proposta de modelagem por simulação é prover uma ajuda a pessoa que toma decisões para a solução de um problema. Entretanto, para aprender a ser um bom modelador deve-se aprender a unir metodologias de técnicas de solução de problemas com boa prática de engenharia de software. A Figura 2.3 mostra os passos que podem ser identificados no estudo de simulação [STA97] [SOA90] [PEG91] [MAC87] [SPO94a]:

\subsubsection{Fase de desenvolvimento}

\section{Definição do problema}

O primeiro passo na elaboração de uma simulação é definir claramente os objetivos do estudo visando um profundo conhecimento do problema a ser resolvido. A experiência mostra que iniciar o processo de simulação de modo apropriado é a diferença entre o sucesso e o fracasso. Como a definição do problema é um processo contínuo, à medida que se ganha maior compreensão do problema, a definição deve ser revista.

\section{Planejamento do projeto}

Um aspecto importante dessa fase é verificar se certos fatores críticos foram considerados: se existem recursos suficientes para fazer o trabalho, tais como hardware, software, tempo e pessoal; se existe suporte gerencial adequado; projetar planos e datas; e principalmente, se existe o conhecimento e experiência necessários para o projeto.

\section{Descrição do sistema}

O sistema deve ser definido com grande precisão. Deve-se determinar as limitações e restrições que serão colocadas na definição do sistema e deve ser feita uma investigação minuciosa de como o sistema trabalha. $O$ tempo gasto em organizar o escrever essa descrição é compensado devido a eliminação de possíveis erros. 


\section{Formulação do modelo conceitual}

O desenvolvimento de um modelo preliminar pode ser gráfico ou em pseudo-código, para definir os componentes, variáveis descritivas e interações lógicas entre os componentes do sistema [PEG91] [STA97].

\section{Projeto experimental preliminar}

O modelo conceitual auxilia na aquisição de informações sobre o sistema real. Nessa etapa deve-se selecionar as medidas de efetividade que serão utilizadas, os fatores que irão variar e a que nível esses fatores serão investigados. Isto é, o que é necessário coletar do modelo, de que forma e quanto. E deve-se também saber como os elementos do sistema interagem causando mudanças no estado do sistema no decorrer do tempo [PEG91].

\section{Coleta dos dados de entrada}

Uma vez terminada a fase de descrição do modelo, adquiriu-se o conhecimento necessário sobre o tipo e o nível de detalhes dos dados que devem ser colhidos. O próximo passo é então listar os parâmetros do modelo que devem ser especificados numericamente e determinar seus valores. Quando se modela um sistema existente, os parâmetros do modelo podem tanto ser medidos diretamente (através de instrumentação de "hardware" ou "software") ou indiretamente (através de análise de regressão) [MAC87]. Quando se modela um sistema ainda não existente (um projeto), os valores dos parâmetros devem ser estimados (a partir de sistemas já existentes ou através da intuição [SPO94a]).

\section{Seleção do método de análise}

Nessa fase deve-se fazer a escolha do método de análise, ou seja, deve-se fazer a escolha entre o método analítico e a simulação. MacDougall [MAC87] defende o uso de ferramentas analíticas sempre que for viável, e afirma que esse é o melhor método. Porém, muitas vezes o método analítico não é passível de ser utilizado devido a falta de flexibilidade. 
Modificações no modelo implicam em reformulação do modelo e obrigam o modelador a recalcular todo o sistema. Nesses casos a simulação deve ser considerada.

\section{Desenvolvimento do programa de simulação}

O próximo passo consiste em traduzir o modelo para uma forma aceitável pelo computador. Existem diversos enfoques que podem ser seguidos [SPO94a]:

- Desenvolvimento do programa de simulação em uma linguagem convencional, como C, Pascal, ou Modula 2. O programador deve então, criar todo o ambiente necessário para a simulação. A vantagem dessa abordagem é que o programador não necessita aprender nenhuma linguagem, pois ele pode escolher uma que ele domine bem, porém, exige o desenvolvimento de todas as estruturas necessárias para uma simulação.

- Utilização de uma extensão funcional de uma linguagem de programação convencional. As extensões são bibliotecas feitas a partir de uma linguagem hospedeira (como $\mathrm{C}$ ou pascal), e que unida a ela, compõe um ambiente completo de simulação. $O$ programador tem, desse modo, todas as ferramentas necessárias para a simulação e pode utilizar uma linguagem de seu domínio. A vantagem dessa abordagem é que o programador não necessita aprender uma nova linguagem para a simulação de um modelo. Existem diversas extensões funcionais:

- SimPack [CUB95] (orientada a evento), SMPL [MAC87] (orientada a evento), CSIM [EDW92] (orientada a processo): extensões da linguagem C.

- HPSIM [SHA88] (orientada a processo): extensão da linguagem Modula 2.

- Utilização de linguagens de simulação de uso geral. Essas linguagens específicas possuem todas as estruturas necessárias para simulação. Permite também que um número maior de sistemas seja modelado, uma vez que possuem a estrutura necessária para isso. Porém, por serem específicas, um programador comum terá que aprender uma nova linguagem, demandando tempo para esse aprendizado.

- Utilização de pacotes de simulação de uso específico. Os pacotes de simulação normalmente são específicos para certos modelos, desse modo, deve-se escolher o pacote que melhor se adapte ao sistema sendo simulado. Nessa abordagem, deve-se apenas 
parametrizar o modelo pronto, tornando fácil a tarefa de construção do programa. A formulação do modelo é construída na própria ferramenta, e os parâmetros do modelo são especificados através de uma linguagem relacionada com o sistema modelado. Alguns exemplos estão listados abaixo [SOA90]:

- BEST/1, CMF, FIVE, PERFORMS, VM Predictor, XL: adequados para modelagem de sistemas computacionais e seus sistemas operacionais.

- PET, NETWORK II.5: para modelagem de redes de computadores.

- MAP/1, MAST: para modelagem de sistemas de manufatura.

- BETHSIM: para modelagem de operações de siderurgia.

- NetSim (Network Simulator): simulador de redes dirigido a eventos e que simula redes que utilizam passagem de mensagens [JUM93].

- CANE: ferramenta de projeto, análise, planejamento e simulação de redes de computadores [IMA97].

- COMNET III: ferramenta de simulação de redes de computadores [CAC97].

\subsubsection{Fase de testes}

\section{Depuração}

O programa de simulação deve ser conferido de modo a estar livre de erros e que os resultados apresentados estejam razoáveis. As ferramentas utilizadas para depuração são as tradicionais, tais como diagnóstico de erros, rastreamento e relatórios. Os seguintes passos podem ser seguidos para se fazer a depuração de um programa:

- Quando o programa compilar pela primeira vez, tente executá-lo, para se ter noção de como o programa está se comportando.

- Execute a simulação de um sistema simples, com apenas um cliente, rastreando-o por toda a simulação, de modo a determinar se o programa está executando corretamente. 
- Se o programa está executando corretamente com um cliente, aumente para dois clientes, de modo a saber se as variáveis estão sendo modificadas corretamente durantẹ a execução do programa.

- Aumente a complexidade do sistema e execute, rastreando os resultados para encontrar eventuais erros no programa.

- Quando o modelo executar sem erros, deve-se verificar se todos os valores gerados pelo programa estão corretos.

\section{Verificação}

Quando o programa começa a produzir resultados razoáveis, o processo de depuração pode ser considerado terminado. O próximo passo é então verificar se o programa de simulação é uma representação válida do modelo. Para modelos pequenos, uma inspeção é o suficiente, porém, para modelos maiores, análises mais detalhadas são necessárias. Uma possibilidade é a verificação através de comparação com modelos analíticos.

\section{Validação}

A validação é a tarefa de demonstrar que o modelo de simulação é uma representação razoável do sistema, ou seja, se ele reproduz o comportamento do sistema com fidelidade o suficiente para satisfazer os objetivos da análise. Isso é feito através da comparação da estrutura do modelo com o sistema.

Para se validar modelos de sistemas existentes, as medidas do sistema são comparadas com os resultados da simulação do sistema existente. Se essas medidas estiverem satisfatórias, é assumido que a simulação do sistema sendo modelado irá produzir valores válidos para efeito das mudanças do sistema em relação ao que já existe e é válido.

A validação e a verificação são tarefas que nunca terminam. Os resultados e o modelo devem ser periodicamente revisados para garantir a sua validade. A validação e a verificação estão intimamente ligadas e andam unidas durante o estudo. Elas não são tarefas do fim da simulação, ao contrário, são processos que iniciam no começo do estudo e continuam através da construção do modelo e do seu uso. 


\subsubsection{Fase de análise}

\section{Experimentação}

Nessa fase deve-se fazer a execução do modelo de simulação para gerar os dados desejados e para efetuar a análise das saídas. Devem ser consideradas diversas questões para garantir a validade dos resultados: quanto tempo o modelo deve ser executado, como serão as condições de início de simulação, se os dados de saída estão correlacionados e quais testes estatísticos são válidos para os dados.

\section{Análise e interpretação}

A fase de análise está relacionada a exercitação do modelo e interpretação das saídas através do desenho das estatísticas dos dados gerados pela simulação. Os métodos para análise de saída auxiliam na obtenção de uma estimativa precisa de uma medida de desempenho de um modelo; o quão precisamente tal medida representa o desempenho do sistema, depende da validade das suposições utilizadas para construir o modelo.

\section{Implementação e documentação}

Nesse ponto, completaram-se todos os passos de projeto, desenvolvimento e execução do modelo. Finalmente, o estágio final é a implementação dos resultados, guardando as descobertas e documentando o modelo e seu uso. Uma boa documentação facilita modificações e garante que o modelo pode ser reutilizado. A documentação, quando bem elaborada, pode auxiliar a descoberta de erros, além de ser uma fonte de submodelos para a construção de novos modelos. Vale ressaltar que nenhum projeto de simulação pode ser considerado completo até que seus resultados sejam utilizados. 


\subsection{Considerações finais}

A simulação é um método utilizado para validar e avaliar sistemas, existentes ou não, através do desenvolvimento e solução de um modelo que reproduz as características do sistema em estudo. É uma das mais poderosas ferramentas de análise de projeto e de operação de processos e sistemas em indústrias. Ela vem se tornando bastante popular, devido a sua versatilidade, flexibilidade, poder e baixo custo.

A modelagem de um sistema é feita através de diversas fases, que incluem a fase de desenvolvimento, a fase de teste e a fase de análise dos resultados obtidos. Na fase de desenvolvimento o modelo a ser simulado é definido, são obtidos seus dados de entrada e o programa de simulação é gerado. $\mathrm{Na}$ fase de testes o programa é depurado para que fique livre de erros, são feitas também a validação e a verificação para saber se o programa é uma representação válida do modelo e se o modelo é uma representação válida do sistema real. $\mathrm{E}$, por fim, na fase de análise dos resultados obtidos, são utilizadas técnicas estatísticas para avaliar quanto tempo e quantas vezes o programa de simulação deve ser executado de forma a se obter valores confiáveis.

Um programa de simulação possui três objetivos principais: gerar caminhos de operação para o sistema sendo estudado, coletar estatísticas sobre as variáveis de interesse e obter boas estimativas das medidas de desempenho desejadas [MIT92].

A simulação é bastante utilizada em várias áreas do conhecimento humano e uma das suas aplicações é a modelagem de redes de computadores. O próximo capítulo discute os principais aspectos de redes de computadores e sua importância no estudo desenvolvido aqui. 


\section{Redes Locais de Computadores}

Esse capitulo discute os tópicos básicos de redes locais de computadores, incluindo topologia, protocolos, meios de transmissão, aplicações de redes, arquitetura e interconexão.

\subsection{Introdução}

O início da computação foi marcado pelos mainframes, que são computadores de grande porte e processamento centralizado, em que diversos usuários estão ligados. Inicialmente, estas máquinas eram mono-usuários, e cada tarefa era iniciada e concluída antes de uma nova tarefa ser considerada. Com o passar do tempo, as máquinas mono-usuários deram lugar às máquinas de tempo compartilhado, onde se obtém concorrência entre as tarefas de vários usuários. Com o avanço da microeletrônica, começaram a surgir computadores menores, os mini e microcomputadores, com menor poder de processamento, porém, mais fáceis de ser transportados e com uso bastante significativo para processamento leve.

Com a diminuição dos custos dessas máquinas, os mini e microcomputadores se proliferaram em diversas empresas e nas mais diversas áreas [AGH88]. Tornou-se imprescindível uma forma de interconexão dessas máquinas, tanto para o compartilhamento de periféricos de alto custo quanto para o compartilhamento de informações.

As redes de computadores surgiram então para interconectar sistemas computacionais, a fim de compartilhar recursos de hardware e software, visando uma melhora no desempenho e na confiabilidade [SOA90a].

Dessa forma, um sistema em rede é formado por um conjunto de módulos processadores (MP) interligados por um sistema de comunicação, conforme pode ser visto na Figura 3.1. 


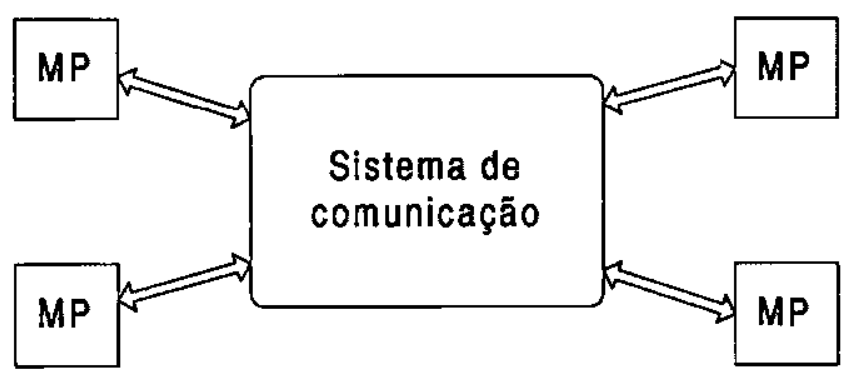

Figura 3.1: Esboço de um sistema em rede

O sistema de comunicação nada mais é do que um arranjo topológico que interliga os diversos módulos processadores através de enlaces físicos (meio de transmissão) e de um conjunto de regras cujo objetivo é organizar a comunicação (protocolos).

As redes que possuem seus diversos módulos processadores entre distâncias na ordem de alguns quilômetros, são chamadas de redes locais. Os sistemas que atingem distâncias maiores, ou seja, na ordem de muitos quilômetros utilizam as redes geograficamente distribuídas.

As redes geograficamente distribuídas surgiram da necessidade de compartilhamento de recursos especializados entre usuários geograficamente dispersos. Devido ao custo de comunicação dessas redes ser alto (circuitos para satélites e enlaces de microondas), essas redes são em geral públicas. ${ }^{1}$ Também por problemas de custo, a interligação entre os diversos módulos processadores é ponto a ponto e parcial, pois uma ligação de todos os pares de módulos seria inviável financeiramente. A velocidade de transmissão é baixa em relação à alcançada em redes locais.

As redes locais foram desenvolvidas para permitir o compartilhamento de recursos (discos de grande capacidade, impressoras, banco de dados, etc.).

Uma máquina de arquitetura distribuída é um sistema distribuído composto por módulos autônomos de processamento interconectados formando um único sistema, no qual o controle global é realizado pela cooperação de todos os elementos de processamento.

As redes locais surgiram nos institutos de pesquisas e nas universidades para objetivos específicos desses ambientes. Porém, durante os anos 70 , os sistemas centralizados estavam

\footnotetext{
${ }^{1}$ O sistema de comunicação, chamado sub-rede de comunicação, é de propriedade pública e é mantido e gerenciado por ela.
} 
dando lugar à distribuição do poder computacional. O desenvolvimento tecnológico, o contínuo decaimento do custo de hardware e o aumento da capacidade computacional levou ao aumento do uso de sistemas pequenos e dedicados e de microcomputadores de propósito geral. Esses sistemas são mais acessíveis ao usuário e são mais fáceis de utilizar que os grandes sistemas centralizados de compartilhamento de tempo [SOA90a].

A interconexão entre vários sistemas para o compartillamento de dispositivos periféricos é importante pois minimiza custos de se ter, por exemplo, uma impressora para cada usuário. A capacidade de troca de informação também é uma razão importante para a interconexão, pois usuários podem precisar de dados ou programas de outros usuários.

Uma das primeiras redes projetadas foi a rede ALOHA, que foi construída para permitir o acesso de um grande número de terminais a um sistema computacional central no Havaí. A principal característica dessa rede é o uso de um canal de radiodifusão por todos os usuários que competem pela sua utilização.

Seguindo esta experiência, outros grupos de pesquisa começaram a desenvolver as suas redes. Entre estas, pode-se citar o laboratório de pesquisa da Xerox Corporation em Palo Alto, Estados Unidos, que utilizou a mesma idéia da rede ALOHA de compartilhamento do meio de transmissão. A esse meio deu-se o nome de Ether, e o sistema foi chamado Ethernet. Outras pesquisas foram realizadas nessa época, utilizando as mesmas idéias [TAN94].

Cada rede local possui características próprias que a tornam adequada para aplicações particulares. Cada aplicação deve ser cuidadosamente analisada para que todos os fatores sejam levados em consideração [STA94]. Nenhuma solução pode ser considerada ótima, pois existem muitos fatores que devem ser levados em consideração na comparação das redes. Esses atributos são [SOA90a]:

- Custo: o custo de uma rede local engloba as estações de processamento, a interface com o meio de comunicação e o próprio meio de comunicação. O custo das conexões depende muito do desempenho esperado da rede [SOA90a]. Redes de baixo a médio desempenho normalmente utilizam poucas estações com pouco tráfego, e por isso são de baixo custo e limitadas a algumas aplicações. As redes de alto desempenho possuem interface de custo maior, devido ao protocolo e ao meio de comunicação utilizado. É claro que se o custo não 
for problema, a seleção da rede se torna mais fácil, pois se pode utilizar os melhores servidores e o melhor cabeamento disponíveis [STA94].

- Número de estações: O número de estações é um fator chave para a configuração de uma rede, pois cada rede dá suporte a um número máximo de estações. Se esse número máximo for excedido, deve ser utilizada alguma técnica de particionamento da rede [STA94].

- Tempo de resposta: tempo de resposta é a soma dos tempos de acesso e do tempo de transmissão. Tempo de acesso é o intervalo entre a geração da mensagem e a obtenção da permissão de envio, sem a ocorrência de colisão; tempo de transmissão é o tempo entre o início do envio de uma mensagem até ela chegar ao destino. Os fatores: velocidade, desempenho e tempo de resposta são de vital importância em redes locais, e são diretamente influenciados pela escolha adequada da arquitetura (estrutura da conexão, protocolo e meio de comunicação).

- Número de usuários concorrentes: o número de usuários que utilizarão a rede concorrentemente deve ser considerado pois algumas redes têm restrições quanto ao número de usuários que estão ativos em um determinado instante. Para solucionar esse problema deve ser selecionada uma rede mais rápida, servidores mais robustos ou um software de rede mais eficiente [STA94].

- Desempenho: é a capacidade efetiva de transmissão na rede. Diversos fatores influenciam a adequação de uma rede a uma aplicação particular, tais como a topologia, o meio de interconexão, o protocolo de comunicação e a velocidade de transmissão. A seleção de um mecanismo de interconexão adequado para a aplicação é vital para se atingir um bom desempenho.

- Confiabilidade: a confiabilidade pode ser medida pelo tempo médio entre falhas (relacionado com a confiabilidade de componentes e nível de redundância), degradação amena (mede a capacidade da rede continuar operando na presença de falhas), tolerância a falhas, tempo médio de reparo (pode ser minimizado através de redundância, mecanismos de autoteste e diagnóstico e manutenção eficiente) e tempo de reconfiguração após falhas (caminhos redundantes que podem ser acionados logo após a detecção de uma falha).

- Modularidade: grau de alteração de desempenho e funcionalidade que um sistema (ou rede) pode sofrer sem mudanças em seu projeto inicial. A modularidade traz três beneficios 
principais: facilidade em modificações (funções lógicas e elementos de hardware são facilmente substituídos), facilidade em crescimento (custo de expansão baixo) e facilidade de uso de componentes básicos (facilita a manutenção do sistema como um todo).

- Compatibilidade: capacidade de o sistema ser compatível com dispositivos de vários fabricantes, tanto em nível de software quanto em nível de hardware. Essa característica traz economia e flexibilidade.

Foram vistas as diversas características que permitem analisar as redes através das aplicações pretendidas e serviços oferecidos, da topologia da rede, do meio de transmissão e da arquitetura de protocolo. Esses tópicos serão abordados nos itens a seguir.

\subsection{Aplicações de redes locais}

Para as diversas aplicações de redes locais deve-se analisar o problema a ser resolvido e qual a disponibilidade de equipamento e capital para a implementação da rede. Existem fatores importantes que devem ser considerados para cada aplicação, tais como dispersão geográfica (se é uma sala, um edifício ou vários edifícios), ambiente de operação (com ruído ou com problemas de segurança), número máximo de nós, separação máxima e mínima entre nós, tempo de resposta, tipo de informação transmitida (dados, vídeo ou voz), tipo de interação entre os dispositivos (comunicação computador/terminal, ou entre pessoas ou computador/computador), taxa máxima de informação transmitida, confiabilidade necessária, tipo de tráfego além de outros fatores específicos a cada aplicação. Através da análise desses fatores é possível determinar o tipo de rede mais adequado a uma aplicação [SOA90a].

Uma aplicação de rede local bastante comum é a automação de escritório, que é a reunião de várias aplicações de computadores e redes de forma a realizar de mañeira eficiente as funções de um escritório. As funções de escritório são, por exemplo, processamento de palavras (digitação em um editor de texto), correio eletrônico, banco de dados, etc., sendo que todas as funções interagem entre si. 


\subsection{Melos de transmissão}

Meio de transmissão é a conexão física entre as estações da rede. Os diversos meios disponíveis diferem entre si em relação à faixa passante, potencial para conexão multiponto ou ponto a ponto, limitação geográfica devido à atenuação característica do meio, imunidade a ruído, custo, disponibilidade de componentes e confiabilidade.

Os fatores acima devem ser considerados na escolha adequada do meio de transmissão, em conjunto com o custo das interfaces com a rede. Qualquer meio físico capaz de transportar informações eletromagnéticas pode ser utilizado em redes locais. Os mais comuns são par trançado, cabo coaxial e fibra ótica. Podem ser utilizados também em certas circunstâncias o infra-vermelho e o microondas [SOA90a, TAN94].

\subsubsection{Par trançado}

No par trançado, dois fios são enrolados de forma helicoidal para reduzir o ruído e manter constante as propriedades elétricas do meio através de todo o seu comprimento. A transmissão pode ser analógica ou digital, e existe um limite na freqüência de transmissão. A faixa passante é alta e a taxa de transmissão é da ordem de megabits por segundo dependendo da distância, técnica de transmissão e qualidade do cabo [SOA90a, TAN94, STA94, NAU94].

Uma característica importante em qualquer meio de transmissão é a perda da energia, seja ela por radiação ou por calor, pois ela define a taxa máxima de transmissão e a distância máxima permitida. A perda de energia aumenta com o aumento da distância, até o ponto em que o sinal não é mais reconhecível. Em geral, o par trançado pode chegar a dezenas de metros com taxas de transmissão de megabits por segundo.

A desvantagem do par trançado é a sua susceptibilidade à interferência e à ruídos. Isso pode ser evitado através de blindagem, que melhora a qualidade do sinal, mas faz com que os custos cresçam. De modo geral, o par trançado é o meio de transmissão de ligação mais simples e de menor custo por comprimento. 
O par trançado é adequado para redes em estrela e em anel, sendo normalmente utilizado com transmissão em banda básica, com dois ou mais pares servindo como meio de transmissão do sinal.

\subsubsection{Cabo coaxial}

O cabo coaxial é um condutor interno circundado por um condutor externo. Entre esses condutores existe um dielétrico que os isola e existe ainda uma camada isolante que circunda a camada externa (Figura 3.2).

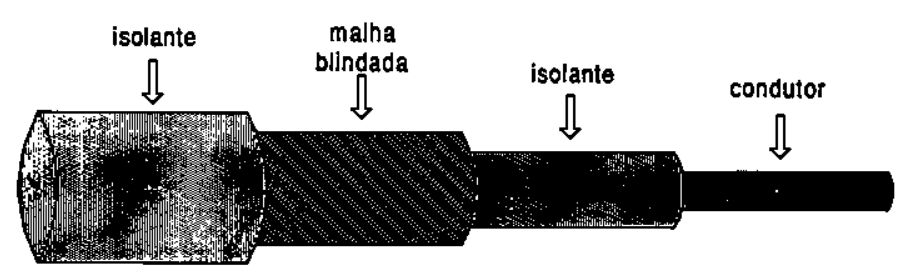

Figura 3.2: cabo coaxial

Existe uma grande variedade de cabos coaxiais: alguns são melhores para transmissão em alta freqüência, outros têm atenuações mais baixas, outros são imunes a ruídos e interferências. Para cada aplicação devem ser consideradas as características de diferentes cabos de modo a escolher o mais adequado.

Diferente do par trançado, o cabo coaxial mantém capacitância constante e baixa, independente do comprimento do cabo (teoricamente), evitando certos problemas técnicos. Devido a esta característica, esse tipo de conexão pode oferecer velocidades maiores sem a necessidade de regeneração de sinal e sem distorções ou ecos [SOA90a, TAN94, STA94]. É bom para sinais analógicos modulados e tem baixa velocidade para sinais em banda básica (digital).

O cabo coaxial pode ser utilizado em ligações ponto a ponto ou multiponto. Em barramento, o cabo deve ter terminadores em seus extremos para evitar reflexões. A imunidade 
a ruído do cabo coaxial é bem melhor que no par trançado, mas o custo é bem maior, principalmente em termos de interfaces para ligação ao cabo.

\subsubsection{Fibras óticas}

O cabo ótico é um filamento de sílica ou plástico, por onde é feita a transmissão da luz. Essa transmissão é feita pelo envio de um sinal de luz codificado dentro do domínio de freqüência do infravermelho $\left(10^{14}\right.$ a $\left.10^{15} \mathrm{~Hz}\right)$ através do cabo ótico. Em volta do filamento existe uma camada de uma substância de baixo índice de refração para que os raios sejam refletidos internamente sem muitas perdas na transmissão (Figura 3.3) [STA94, SOA90a].

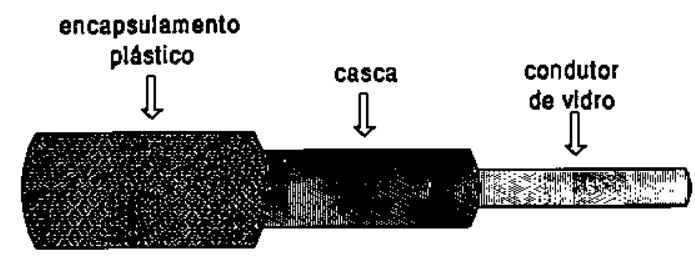

Figura 3.3: Fibra ótica

A tecnologia de transmissão de luz por um cabo de vidro é conhecida há muitos anos, mas começou a ser utilizada quando apareceram os cabos de fibra ótica de boa largura de banda e baixa atenuação. Para a transmissão da luz podem ser utilizados diodos emissores de luz (ou LEDs, que são uma solução barata e que se adaptam melhor à temperatura ambiente e têm um ciclo de vida maior que o laser) ou lasers semicondutores (preferidos devido a maior eficiência em termos de potência, e menor largura espectral, que reduz os efeitos de dispersão cromática).

A fibra ótica permite uma isolação elétrica muito grande, pois é imune a interferência eletromagnética e a ruídos (não existe irradiação de luz para fora do cabo ótico). A sua atenuação é independente da frequiência, o que permite velocidade de transmissão alta. A utilização de fibra ótica apresenta vantagens em relação a outros meios quando instalada em ambientes que geram fortes interferências eletromagnéticas, uma vez que o sinal propagado pela fibra não sofre alterações [TAR86]. 
Ela pode ser utilizada em ligações ponto a ponto ou multiponto, mas são mais comumente usadas em ponto a ponto, pois em multiponto é necessária a utilização de acopladores óticos, que possuem um custo bastante alto.

O custo das fibras óticas é bem elevado em relação ao par trançado e ao cabo coaxial, tanto em relação ao custo do metro do cabo quanto ao equipamento necessário para a sua utilização. Porém, ela traz muitas vantagens e acredita-se que com a melhora da tecnologia, a tendência é a diminuição dos custos e maior viabilidade na sua implementação em todos os tipos de redes.

\subsubsection{Outros meios de transmissão}

A radiodifusão possui um custo bastante alto e não é muito utilizada em redes locais. Seu uso é importante no caso de um ambiente de rede local móvel, e ela é adequada para ligações ponto a ponto e multiponto. A confiabilidade desse tipo de meio também é um fator muito importante, pois não existe a possibilidade de rompimento de cabos como nos outros meios estudados [SOA90a].

\subsection{Topologia}

Topologia é a configuração física de uma rede de computadores que define o "desenho" da rede, mostrando toda a estrutura de um dado sistema de comunicação [NAU94]. Existem diversos arranjos topológicos, e dentre os mais usuais podem ser citados: estrela, anel, barramento, árvore, totalmente conectada, parcialmente conectada [SOA90a].

\subsubsection{Topologia em estrela}

Nessa topologia, cada nó está interligado a um nó central (chamado aqui de mestre), pelo qual todas as mensagens passam (Figura 3.4). O nó central é quem faz o gerenciamento 
da rede, interligando os demais nós (escravos). Algumas redes em estrela possuem o nó central com a função de gerência da rede e também com facilidade de processamento de dados.

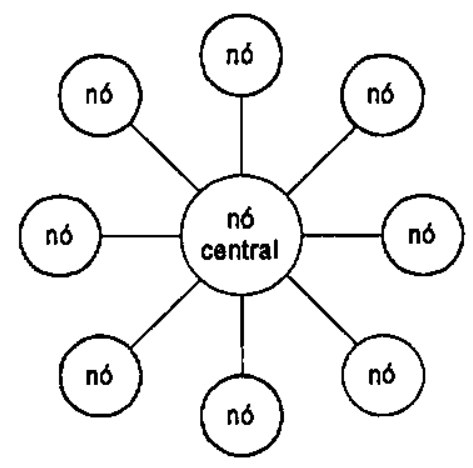

Figura 3.4: Topologia em estrela

O arranjo em estrela é bastante favorável para aplicações onde as estações secundárias devem se comunicar com o nó central. Um exemplo é as redes de computadores onde o nó central é um sistema de computação que processa as informações que as estações secundárias enviam.

As redes em estrela não precisam de roteamento, pois concentram todas as mensagens no nó central. $O$ nó central pode ter outras funções além de chaveamento e processamento normal, podendo realizar a compatibilidade da velocidade de transmissão entre o transmissor e o receptor, podendo fazer a conversão de protocolos caso sejam utilizados protocolos diferentes nas estações, fornecendo proteção contra acessos não autorizados, etc.

Na rede em estrela, a falha do meio de comunicação ou a falha de uma estação escrava deixa fora do ar apenas uma estação escrava. Porém, a queda do nó central significa uma parada total no sistema. A redundância poderia ser uma solução, porém, o preço a se pagar seria um alto custo e a perda da simplicidade da rede [SOA90a, NAU94].

Uma desvantagem desse tipo de rede é a complexidade do nó central, que realiza todo o gerenciamento da rede. Outro problema é a modularidade. A rede pode ser expandida apenas até o limite imposto pelo nó central: capacidade de chaveamento, número de circuitos concorrentes que podem ser gerenciados e número total de nós que podem ser servidos. 
O desempenho da rede em estrela é limitado pela capacidade de processamento do nó central, pois o tempo requerido para o envio de uma mensagem depende do processamento do nó central para encaminhar a mensagem, e também da carga de tráfego na conexão.

\subsubsection{Topologia em anel}

Nesse arranjo, as estações estão conectadas através de um caminho fechado (anel). Os nós não estão ligados diretamente à rede, o que existe são repetidores ligados por um meio físico, e ao qual o nó se interliga (Figura 3.5).

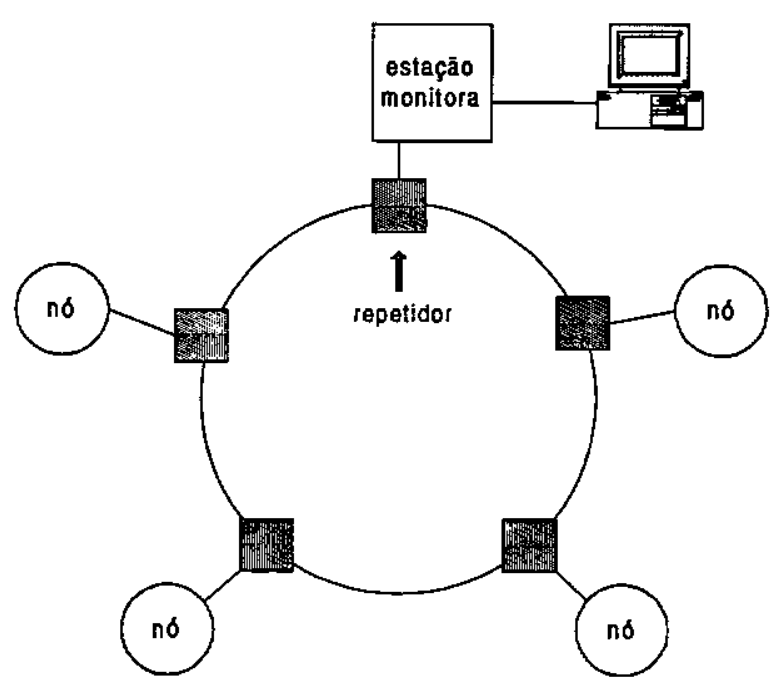

Figura 3.5: Topologia em anel

As redes em anel podem transmitị e receber dados em qualquer direção, porém, normalmente elas são unidirecionais para tornar os repetidores e os protocolos mais simples (não necessita de roteamento). Os repetidores normalmente são projetados para receber e transmitir dados simultaneamente, diminuindo o retardo da transmissão [NAU94, SOA90a].

Quando se envia uma mensagem, ela entra no anel e circula até ser retirada pelo nó destino ou pelo nó fonte, dependendo do protocolo utilizado. A retirada pelo nó fonte permite mensagens de difusão ("broadcast") e também que qualquer nó da rede receba pacotes, mesmo que ele não seja o destinatário. 
Para evitar problemas de perda de controle de acesso ao meio, as redes em anel utilizam uma estação monitora. Esse monitor além de garantir que o controle de acesso ao meio esteja funcionando, tem a função de iniciar o anel, enviar pacotes de teste, além de outras funções de manutenção.

$\mathrm{Na}$ topologia em anel, cada nó deve ser capaz de remover de modo seletivo as mensagens da rede ou então passá-las para o próximo nó. Para isso é preciso um repetidor ativo em cada nó. Quebras no enlace ou no repetidor podem parar toda a rede. Para resolver esse problema, um relé é inserido em cada repetidor, que no caso de falha, remove da rede o repetidor com problema. Essa solução não pode ser utilizada se a distância entre o nó anterior e o posterior for maior que o limite para interconexão de dois nós.

Uma solução é a utilização de caminhos alternativos, como a utilização de vários anéis para a rede. Na solução de vários anéis, o conjunto de anéis seria conectado através de uma ponte ("bridge"). A ponte encaminha os dados de uma sub-rede para a outra com base nas informações de endereçamento do pacote. A falha em um anel paralisa apenas aquele anel $e$ múltiplos anéis podem ser utilizados para aumentar o desempenho.

Como as redes em anel são unidirecionais, as redes com essa topologia são ideais para a utilização de fibra ótica.

\subsubsection{Topologia em barramento}

Nessa topologia, todas as estações (nós) se conectam ao mesmo meio de transmissão (Figura 3.6). Diferente da topologia em estrela ou em anel, que eram ponto a ponto (cada enlace conecta dois dispositivos), a topologia em barramento é multiponto (mais de dois dispositivos estão conectados ao meio de transmissão) [SOA90a].

Dada a simplicidade dessa topologia, seu custo é baixo. Porém, a configuração de um único cabo é um ponto de falha. No caso de quebra do cabo, a rede é completamente interrompida [NAU94]. 


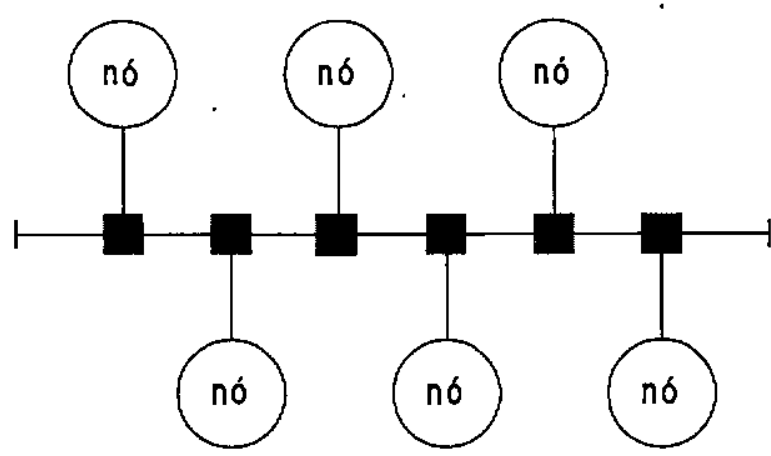

Figura 3.6: Topologia em barramento

Nessas redes, cada nó conectado ao barramento ouve todas as informações transmitidas. Essa característica facilita o broadcast e possibilita que todas as estações possam pegar pacotes da rede mesmo que não seja o destinatário.

Os mecanismos de controle de acesso ao barramento podem ser centralizado ou descentralizado. Em um controle centralizado, o direito de acesso é determinado por uma estação especial da rede. Já no controle descentralizado, a responsabilidade de acesso é distribuída entre todos os nós. As formas de controle de acesso ao meio serão discutidas na seção 0.

A ligação ao meio de transmissão deve alterar o mínimo possível suas características elétricas. $\mathrm{O}$ meio deve terminar em seus dois extremos em uma carga igual à sua impedância característica, para que não haja interferência no sinal transmitido. A distância máxima entre dois nós e o número máximo de nós dependem do meio de transmissão utilizado, da taxa de transmissão e da quantidade de ligações ao meio. Para aumentar a distância máxima entre dois nós devem ser utilizados repetidores, que por serem ativos, podem diminuir a confiabilidade da rede.

O desempenho depende de diversos fatores, como o meio de transmissão, o número de nós conectados, o controle de acesso, o tipo de tráfego, entre outros. Como utilizam interfaces passivas que não precisam de armazenamento local e não têm o retardo do repetidor, o tempo de resposta não depende desses fatores, apenas do protocolo de acesso utilizado. 


\subsubsection{Topologia em árvore}

A topologia em árvore consiste de uma série de barramentos interconectados, onde geralmente existe uma barra central onde outros ramos menores se conectam (Figura 3.7). A ligação entre as barras é feita através de derivadores e as conexões das estações são feitas do mesmo modo que o barramento comum. Esse tipo de topologia permite a expansão dinâmica da rede, porém, provê apenas um caminho entre dois pontos da rede [NAU94]. A taxa de transmissão em redes em árvore é menor que no barramento, pois como o sinal deve se propagar por dois caminhos, as velocidades de propagação podem ser diferentes e os sinais serão enviados de maneira diferente também [SOA90a].

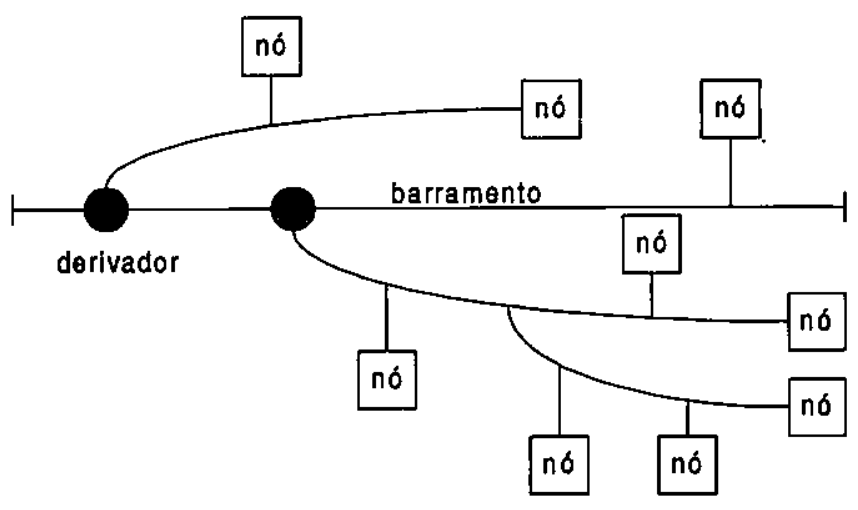

Figurz 3.7: Topologia em árvore

\subsubsection{Topologia em grafos}

A topologia em grafos consiste de vários nós conectados na forma de um grafo. Dela derivam diversas topologias, como a completamente conectada (Figura 3.8), em que cada nó está conectado a todos os outros nós, e também a parcialmente conectada (Figura 3.9), em que os nós estão conectados de forma em que há pelo menos um caminho ligando um nó a outro, através da passagem por outros nós. $\mathrm{Da}$ topologia em grafo também derivam as redes em estrela e anel. As redes ponto a ponto crescem em complexidade com o crescimento do número de estações conectadas. Como o custo das ligações é alto, não se utiliza muito as redes completamente conectadas, e sim as parcialmente conectadas [SOA90a]. 


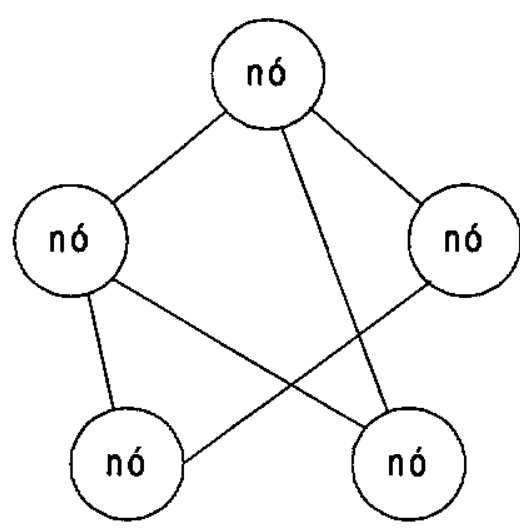

Figura 3.8: Topologia em grafo (estrutura parcialmente conectada)

A topologia em grafos visa a otimização do custo do meio de transmissão, uma vez que é bastante genérica, por isso, é largamente utilizada em redes de longa distância (redes geograficamente distribuídas) cujo custo de comunicação é bastante alto. Para redes locais essa topologia não é interessante pois exige mecanismos de roteamento, que podem ser mais caros do que o custo das estações.

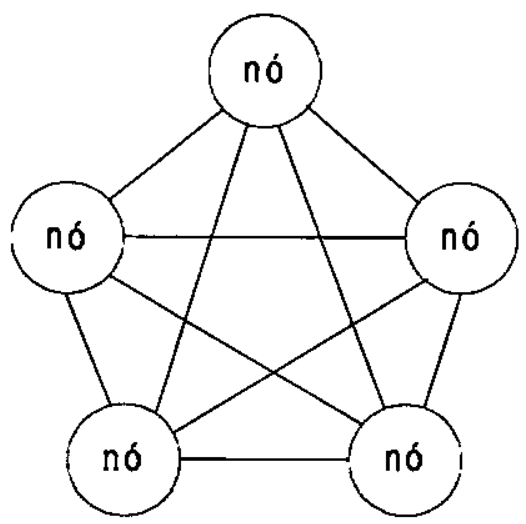

Figura 3.9: Topologia em grafo (estrutura completamente conectada) 


\subsubsection{Tabela comparativa}

A Tabela 3.1 apresenta uma comparação entre as diversas topologias nos seus aspectos gerais [SOA90a].

Tabela 3.1: Comparação entre as diversas topologias nos seus aspectos gerais

\begin{tabular}{|c|c|c|c|c|}
\hline \multirow[b]{2}{*}{ Caracteristicas } & \multicolumn{4}{|c|}{ Topologias } \\
\hline & Estrela & Anel & Barramento & Grafos \\
\hline $\begin{array}{l}\text { simplicidade } \\
\text { funcional }\end{array}$ & a melhor de todas & razoável & $\begin{array}{l}\text { razoável, um } \\
\text { pouco melhor que } \\
\text { anel }\end{array}$ & $\begin{array}{l}\text { extremamente } \\
\text { complicada }\end{array}$ \\
\hline roteamento & inexistente & $\begin{array}{l}\text { inexistente no anel } \\
\text { unidirecional, mas } \\
\text { simples nos outros }\end{array}$ & inexistente & bastante complexo \\
\hline custo de conexão & $\begin{array}{l}\text { alto (incluindo o } \\
\text { custo do nó } \\
\text { central) }\end{array}$ & baixo & baixo & muito alto \\
\hline $\begin{array}{l}\text { crescimento } \\
\text { incremental }\end{array}$ & $\begin{array}{c}\text { limitado a } \\
\text { capacidade do nó } \\
\text { central }\end{array}$ & $\begin{array}{l}\text { teoricamente } \\
\text { infinito }\end{array}$ & alto & alto \\
\hline $\begin{array}{l}\text { aplicação } \\
\text { adequada }\end{array}$ & $\begin{array}{c}\text { com } \\
\text { processamento } \\
\text { central de todas as } \\
\text { mensagens }\end{array}$ & sem limitação & sem limitação & sem limitação \\
\hline desempenho & $\begin{array}{l}\text { baixo, todas as } \\
\text { mensagens devem } \\
\text { passar pelo nó } \\
\text { central }\end{array}$ & $\begin{array}{l}\text { alto, possibilidade } \\
\text { de mais de uma } \\
\text { mensagem ser } \\
\text { transmitida ao } \\
\text { mesmo tempo }\end{array}$ & médio & $\begin{array}{c}\text { alto, pode se } \\
\text { adaptar ao volume } \\
\text { de tráfego } \\
\text { existente }\end{array}$ \\
\hline confiabilidade & pouca & $\begin{array}{l}\text { boa, desde que } \\
\text { sejam tomados } \\
\text { cuidados } \\
\text { adicionais }\end{array}$ & $\begin{array}{l}\text { a melhor de todas, } \\
\text { interface passiva } \\
\text { ao meio }\end{array}$ & $\begin{array}{l}\text { boa devido a } \\
\text { existência de } \\
\text { caminhos } \\
\text { alternativos }\end{array}$ \\
\hline $\begin{array}{l}\text { retardo de } \\
\text { transmissâo }\end{array}$ & médio & baixo & $\begin{array}{l}\text { o mais baixo de } \\
\text { todos }\end{array}$ & alto \\
\hline $\begin{array}{l}\text { limitação quanto } \\
\text { ao meio de } \\
\text { transmissão }\end{array}$ & $\begin{array}{c}\text { nenhuma, ligação } \\
\text { ponto a ponto }\end{array}$ & $\begin{array}{c}\text { nenhuma, ligação } \\
\text { ponto a ponto }\end{array}$ & $\begin{array}{c}\text { por ser } \\
\text { multiponto, a } \\
\text { ligação ao meio } \\
\text { pode ter custo alto } \\
\text { (fibra ótica) }\end{array}$ & $\begin{array}{c}\text { nenhuma, ligação } \\
\text { ponto a ponto }\end{array}$ \\
\hline
\end{tabular}




\subsection{Protocolos de acesso ao meio}

De acordo com Soares [SOA90a], "Protocolo é o conjunto de regras que rege a comunicação de entidades abstratas, entidades essas que podem estar em diferentes nós da rede." Os protocolos de rede estão baseados em uma arquitetura hierárquica, de modo a terem uma estrutura modular que facilite modificações sem afetar a estrutura geral.

Um modelo de sistema foi definido pela ISO (International Standards Organizations) que é utilizado como referência para comparações entre os diversos protocolos existentes. Os protocolos foram estruturados em níveis para isolar funções de comunicação, de modo a tornar possível a construção de cada nível através de serviços da camada hierarquicamente inferior.

A maioria dos protocolos foi desenvolvida para uma topologia particular de rede, porém, qualquer estratégia de controle pode ser utilizada em qualquer topologia, apesar de poderem ser mais adequadas a uma topologia particular. Para se avaliar os protocolos de controle de acesso ao meio, diversas características podem ser comparadas, como: capacidade, eqüidade, prioridade, estabilidade em sobrecarga e tempo de resposta [SOA90a]. Essas características são discutidas a seguir:

- Capacidade é o desempenho do método de acesso, que pode ser visto pela porcentagem da faixa passante disponfvel.

- Eqüidade de acesso permite às estações o uso dos recursos compartilhados, ou seja, pode existir prioridade, mas em algum momento a estação terá prioridade máxima.

- Prioridade é sempre importante, principalmente em aplicações de tempo real.

- Estabilidade é importante em redes onde a carga é grande. Os protocolos de acesso que alocam intervalos diferentes para cada nó são bastante estáveis e o retardo não tem grandes variações, mas os protocolos baseados em disputa (não existe ordem de acesso e dois nós ou mais podem transmitir ao mesmo tempo), são bastante dependentes da carga e precisam de tratamento de conflitos sofisticados para se tornarem mais estáveis.

- Tempo de resposta é a soma dos tempos de acesso e de transmissão. 
Os protocolos de acesso ao meio podem ser divididos em dois grupos: métodos baseados em disputa e de acesso ordenado sem disputa.

Em uma rede baseada em disputa, não existe ordem de acesso e dois ou mais nós podem transmitir simultaneamente, provocando colisão e perda de mensagens. Esse protocolo é bastante utilizado em topologia em barramento e o controle de disputa é feito pela estação que deve detectar a colisão e retransmitir a mensagem. $O$ protocolo é eficiente quando o número de colisões e retransmissões é pequeno e o tráfego da rede não é grande. Exemplos que podem ser citados é o Aloha e o CSMA.

As redes de acesso ordenado sem disputa evitam o problema de colisão, e existem diversos métodos que o utilizam. Cada método é adequado a um tịo de arquitetura. São exemplos o método de acesso por "polling", por "slot", por inserção de retardo, por passagem de permissão, entre outros.

Alguns exemplos de protocolos de acesso ao meio são apresentados nos próximos itens.

\subsubsection{Aloha}

A rede Aloha foi desenvolvida para interligar um centro de computação (em Honolulu Universidade do Havaí) a terminais espalhados pelas ilhas e entrou em operação em 1970. Essa rede utiliza radiodifusão via satélite através de dois canais de freqüência de rádio, uma para envio de mensagem do computador para o terminal e o outro para envio do terminal para o computador. $\mathrm{Na}$ transmissão do computador para o terminal não existe problema de envio porque há somente uma transmissão, porém, mais de um terminal pode querer transmitir mensagens para o computador, podendo ocorrer colisões. A rede Aloha não foi projetada para operar em redes locais, mas muitos dos protocolos atualmente utilizam as idéias vindas dessa rede.

\footnotetext{
${ }^{2}$ Polling: método de acesso em que a estação só transmite quando a controladora da rede der permissão. Se a estação não tem nada para transmitir, retorna apenas um reconhecimento para a controladora.

${ }^{3}$ Slot: a rede é dividida em pequenos intervalos, denominados slots, dentro dos quais a mensagem pode ser transmitida.
} 
Quando um terminal tem algo a transmitir, transmite e se ocorrer colisão, retransmite. Para se detectar a colisão, um relógio é disparado quando da transmissão da mensagem, e se a mensagem de reconhecimento não chegar em um tempo $\mathrm{X}$ (número aleatório), o terminal detecta que a mensagem foi perdida e retransmite.

O computador que recebe a mensagem reconhece uma colisão através do campo de redundância da mensagem, pois quando ocorre colisão a mensagem recebida fica ininteligível e não é mandado reconhecimento para o terminal. Desse modo, o terminal detecta a colisão e retransmite a mensagem. No sistema Aloha, para se melhorar o throughput, utilizam-se quadros (que são as mensagens) de tamanho uniforme [SOA90a, TAN94].

Nesse método de acesso, se um terminal enviar uma mensagem no fim da transmissão de uma mensagem de outro terminal (Figura 3.10), as duas mensagens serão perdidas e os dois terminais precisarão retransmitir a mensagem.

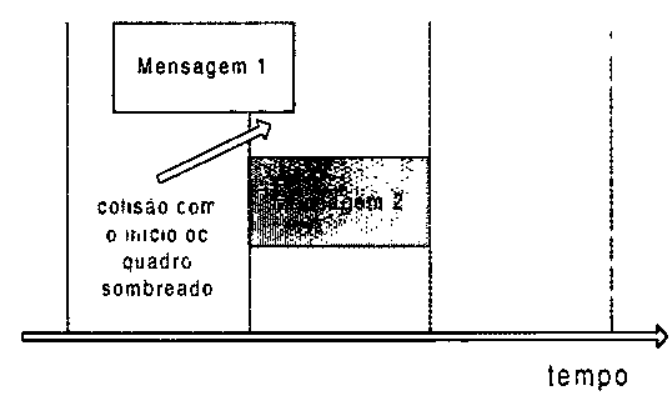

Figura 3.10: Colisão no Aloha

Para evitar muitas colisões, foi proposto um meio de limitar o tempo em que cada terminal pode transmitir. $O$ tempo foi dividido em intervalos discretos, cada intervalo correspondendo a um quadro. $O$ terminal só pode transmitir no início de cada intervalo, desse modo, evita-se o problema de uma mensagem estragar a outra no final de sua transmissão. Esse método, chamado "slotted Aloha" dobra o throughput em relação ao método anterior [TAN94, SOA90a].

\footnotetext{
${ }^{4}$ Throughput mede o número de bytes de dados transmitidos por segundo.
} 
A utilização da capacidade do canal é muita baixa na rede Aloha, 18\% para a Aloha pura e $37 \%$ para a slotted Aloha. Para cargas muito altas, a possibilidade de colisão pode se tornar tão alta que a rede fiça inoperante.

A vantagem desse protocolo é a sua simplicidade e baixo custo. Para cargas baixas ele pode ser utilizado sem problemas.

\subsubsection{CSMA persistente e não-persistente}

Os protocolos onde as estações agem de acordo com o que escutam do meio de transmissão são chamados de protocolos com deteç̧ão de portadora. Um exemplo desse tipo de protocolo é o CSMA 1-persistente, onde quando uma estação tem algo a transmitir, ela escuta o meio para verificar se alguém está transmitindo. Se o meio estiver livre, transmite; se não, fica esperando o meio ficar livre para transmitir. Se ocorrer uma colisão (quando duas estações decidem transmitir ao mesmo tempo), a estação espera um tempo aleatório para transmitir novamente.

Esse protocolo é chamado 1-persistente porque a estação transmite com probabilidade 1 sempre que o meio estiver livre. Um dos problemas encontrados aqui é o retardo de propagação, pois logo que uma estação começa a transmitir, existe a possibilidade de outra estação também querer transmitir. A segunda estação escuta o meio, mas a mensagem da primeira ainda não chegou, e começa a transmitir, resultando em colisão. $O$ desempenho do protocolo é diretamente afetado pelo retardo de propagação, que quanto maior, pior ficará o desempenho. Porém, mesmo que não houvesse retardo, ocorreriam colisões, pois se duas estações querem transmitir e uma terceira já está transmitindo, as duas esperam a terceira terminar a transmissão e logo em seguida transmitem, resultando em colisão [TAN94].

O desempenho do CSMA, mesmo com esses problemas, é bem melhor que o Aloha, pois as duas estações não interferem com a terceira.

Outro protocolo é o CSMA não-persistente, onde a estação escuta o meio e verifica se pode transmitir. Se o canal estiver livre, a mensagem é transmitida, se não, a estação espera um tempo aleatório para tentar transmitir novamente. A abordagem não-persistente difere da 
pérsistente por não se apoderar do canal logo após' a transmissão da outra estaçã̃o. Conseqüentemente, esse método tem uma melhor utilização do meio de comunicação e ựa possibilidade menor de colisão.

Outro protocolo é o CSMA p-persistente, que utiliza intervalos regulares de tempo para transmitir. Quando a estação tem algo a transmitir, ela escuta o meio de comunicação. Se estiver ocupado, espera até o próximo intervalo livre. Se estiver livre, transmite com probabilidade $\mathrm{p}$, e com probabilidade $\mathrm{q}=1-\mathrm{p}$, espera o próximo intervalo. Se o próximo intervalo estiver livre, a probabilidade $\mathrm{p}$ para transmitir é novamente considerada. Esse protocolo continua sendo aplicado até que a mensagem tenha sido transmitida ou alguma outra estação esteja transmitindo. Se outra estação transmitir, ela espera um tempo aleatório para recomeçar o algoritmo.

A Figura 3.11 [TAN94] mostra o througput $\mathrm{X}$ tráfego para os protocolos apresentados.

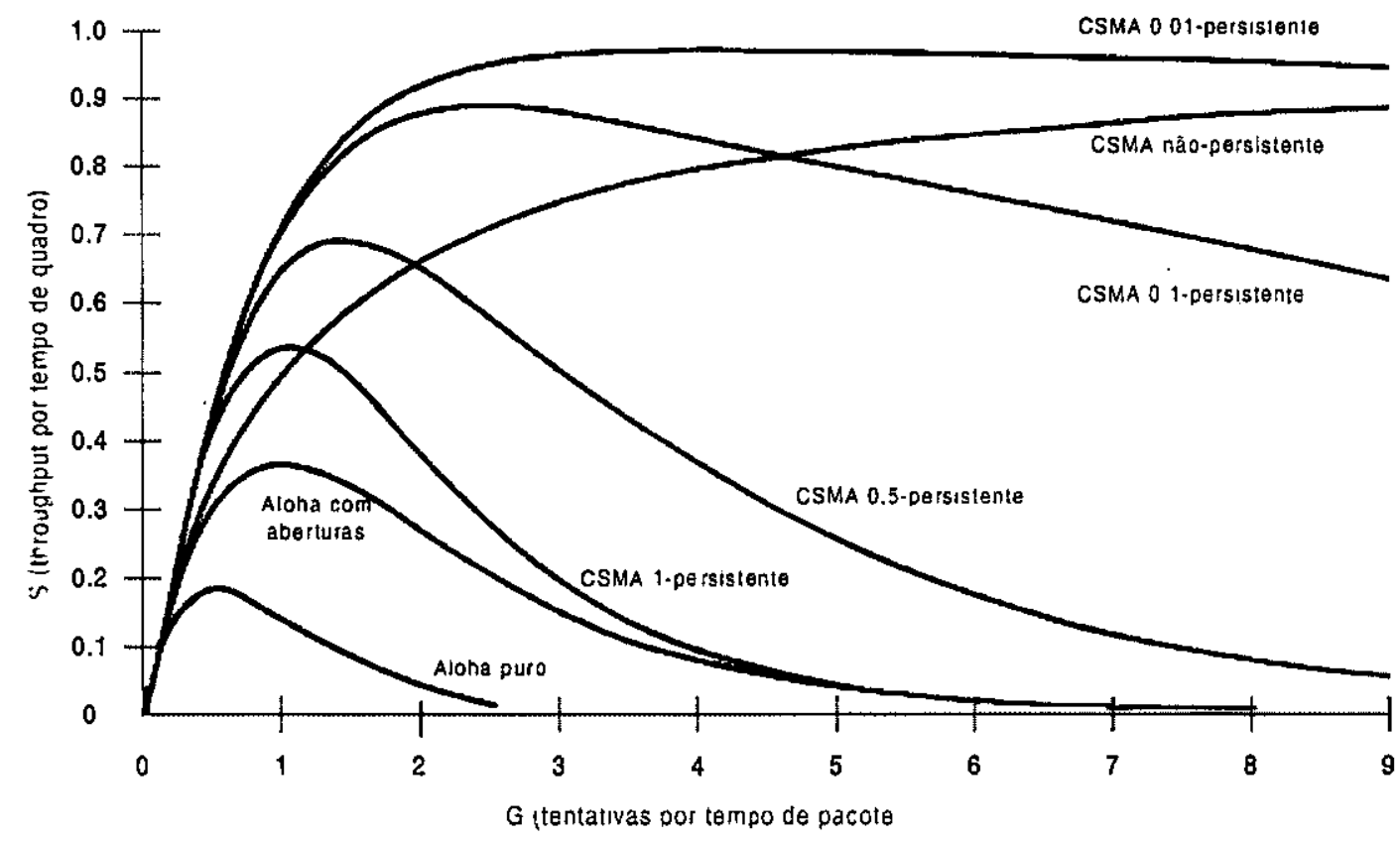

Figura 3.11: Comparação da utilização do canal em função da carga para diversos protocolos de acesso aleatório

\subsubsection{CSMA com detecção de colisão}


Nesse protocolo, quando a estação transmite e detecta uma colisão, ela pára de transmitir. Esse método é vantajoso em relação aos anteriores porque não há mais tempo perdido em transmitir uma mensagem ininteligível. Quando a estação percebe a colisão, ela simplesmente aborda a transmissão, economizando tempo e não desperdiçando a capacidade do meio de comunicação. Esse método é chamado CSMA/CD (Carrier Sense Multiple Access with Collision Detection).

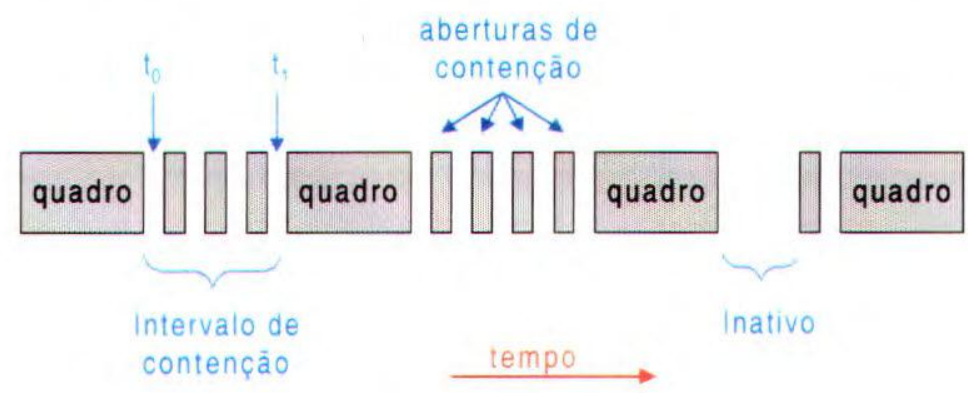

Figura 3.12: CSMA/CD pode estar em um de três estados: disputa, transmissão e inativo

A Figura 3.12 mostra o modelo conceitual do CSMA/CD. No ponto $t_{0}$, uma estação acabou a transmissão de um quadro. Outra estação está livre para transmitir sua mensagem, mas se duas estações quiserem transmitir, ocorrerá colisão. As duas devem então abortar a transmissão, esperar um tempo aleatório e tentar novamente, assumindo que nenhuma outra estação começou a transmitir no intervalo. O CSMA/CD consiste de intervalos de disputa e transmissão, além de intervalos inativos em que todas as estações não têm o que transmitir [TAN94, SOA90a].

As redes que utilizam esse protocolo são: Ethernet, Fibernet, entre outras.

\subsubsection{Slot}

O protocolo de controle de acesso ao meio por slot foi desenvolvido originalmente para topologia em anel e consiste em dividir o meio de comunicação em pedaços pequenos chamados slots, dentro dos quais a mensagem é armazenada. Cada slot contém um bit que indica se ele está livre ou se está cheio e esses slots circulam pela rede. Quando uma estação 
quer transmitir, ela deve esperar um slot vazio, modificar o bit para 1 (cheio) è colocar a sua mensagem. A estação destino verifica que a mensagem é para ela, lê a mensagem e quando a mensagem passar novamente na estação que a enviou, a mensagem é retirada e o bit que indica se o slot está livre é modificado para 0 (vazio).

O número de slots do anel é sempre o mesmo e para manter a eqüidade de acesso a estação não pode utilizar o mesmo slot que estava utilizando para não monopolizar a rede. Isso pode fazer com que muitos slots circulem vazios pela rede, quando apenas poucas estações estão transmitindo, diminuindo a eficiência da rede.

Uma consideração que deve ser feita nesse protocolo é o tamanho ideal do slot. Para dividir a mensagem um tempo considerável é despendido e essa perda seria evitada com slots grandes, de modo a caber a mensagem inteira. Porém, isso faria com que aumentasse o retardo na espera de um slot vazio, e algumas mensagens ocupariam apenas um pedaço do slot, que o subutilizaria. Desse modo, são utilizados slots pequenos, apesar da sobrecarga gerada pelo cabeçalho [SOA90a].

Independente do volume de tráfego, esse método é bastante estável e o tempo de transmissão é constante. Sua eficiência é maior quanto maior for o volume de mensagens.

\subsubsection{Passagem de permissão em barramento}

Nesse tipo de protocolo, utilizado em redes em barramento, existe uma permissão (identificação) que autoriza a estação a enviar sua mensagem. Quando uma estação está transmitindo, ela está com essa permissão. No término da transmissão, a estação passa a permissão para a próxima estação, que se tiver algo a transmitir, transmite. A permissão é passada de estação a estação formando um anel virtual [SOA90a].

Para o bom funcionamento desse protocolo algumas funções devem ser consideradas, sejam centralizadas ou distribuidas, são elas:

- adição e retirada de estações do anel virtual - deve ser possível retirar e inserir estações no anel, evitando a passagem desnecessária da permissão por uma estação que não faz mais parte da rede. 
- gerenciamento de falhas - diversos problemas podem ocorrer, como duplicação de endereços, onde duas estações recebem a permissão e transmitem ao mesmo tempo ou perda da permissão, por ruído ou problema em alguma estação.

- inicialização do anel virtual - deve haver algum algoritmo a seguir para a criação do anel virtual e da permissão.

A principal desvantagem da passagem de permissão em barramento é a sua complexidade, além da sobrecarga que existe para pouco tráfego (poucas estações estão transmitimdo, mas a estação que quer transmitir tem que esperar a permissão passar por todas as outras).

Por outro lado, é um protocolo bastante estável para cargas altas e sua eficiência é alta, independente do tamanho da mensagem e da taxa de transmissão. Outra vantagem é que ela não precisa de tratamento para colisão, pois elas não ocorrem.

Esse protocolo pode ser utilizado para aplicações de tempo real pois possui um tempo de resposta máximo limitado. As redes Modway e Arcnet são exemplos de rede que utilizam esse protocolo.

\subsubsection{Passagem de permissão em anel}

Esse protocolo se baseia em um pacote que contém uma permissão que circula pelo anel. Quando uma estação quer transmitir, ela espera o pacote passar com permissão livre e modifica-o para ocupado. Logo a seguir, coloca seus dados na rede. Após a tranșmissão, a estação fonte ou a estação destino tornam o pacote com permissão livre, possibilitando que outras estações utilizem o meio de comunicação.

Quando é a estação fonte que retira a mensagem da rede, é possível implementar um mecanismo em que a estação destino modifica alguns bits da mensagem de modo que a estação fonte, quando receber a mensagem de volta, possa diagnosticar se a mensagem chegou ao seu destino [SOA90a].

A passagem de permissão em anel precisa de uma estação monitora que verifique falhas, tais como uma mensagem que está circulando indefinidamente no anel, perda da 
permissão, entre outras. Esse protocolo possui as mesmas vantagens e desvantagens da passagem de permissão em barramento.

Algumas redes que utilizam passagem de permissão em anel são IBM Token Ring, Primenet, Ringnet, entre outros.

\subsection{Arquitetura de redes}

As redes de computadores modernas são projetadas de forma estruturada, em camadas ou níveis, reduzindo a complexidade de projeto de cada nível. Cada camada é construída sobre sua predecessora, e o número, o nome, o conteúdo e a função de cada camada pode diferir de uma rede para outra.

A divisão em níveis ou camadas foi a forma encontrada para dividir as complexas tarefas de intercomunicação em blocos específicos mais simples. Cada nível ou camada desempenha funções determinadas de tal forma que se utilize os serviços do nível inferior e proporcione outros serviços, mais elaborados, para o nível imediatamente superior [SYS93].

Uma arquitetura de rede é o conjunto de camadas e protocolos. Deve-se ter uma especificação completa o suficiente para que o implementador possa escrever o programa ou construir o hardware de modo apropriado.

\subsubsection{O modelo de referência ISO - OSI}

O modelo da Figura 3.13 mostra a proposta desenvolvida pela International Standards Organization (ISO) para a padronização internacional de protocolos [TAN94]. O modelo é chamado de modelo de referência ISO - OSI para interconexão de sistemas abertos ${ }^{5}$.

O modelo OSI tem sete camadas, que são: camada fisica, camada de enlace de dados, camada de rede, camada de transporte, camada de sessão, camada de apresentação e a camada

\footnotetext{
${ }^{5}$ Sistemas abertos à comunicação com outros sistemas.
} 
de aplicações. A seguir é dada uma breve explicação de cada uma dessas camadas [SOA90a, TAN94].

Camada física: trabalha com a transmissão dos bits pelo meio de comunicação. São funções dessa camada: garantir que os bits cheguem corretamente para a outra máquina, qual a voltagem de representação dos bits, quantos microssegundos dura um bit, se a transmissão é em ambos os sentidos ou não, qual o tipo de cabo, quais as distâncias máximas parą cada segmento em função do tipo de cabo [SYS93].

Camada de enlace de dados: tem como tarefa pegar os dados brutos e detectar e corrigir possíveis erros de transmissão. Isso é feito através do particionamento dos dados em quadros, que possuem alguma forma de redundância para a verificação de sua integridade.

Camada de rede: faz o controle da operação da sub-rede. Deve-se determinar como os pacotes são roteados da origem para o destino, se através de tabelas estáticas ou dinamicamente ou se a forma de roteamento é determinada no início de cada transmissão. A camada de rede também deve controlar os dados de modo a evitar congestionamentos.

Camada de transporte: responsável pela transmissão das mensagens sem erros (recuperação de erros) entre as camadas inferiores e a camada de sessão. Atua também na divisão inicial da mensagem em pacotes, no seqüenciamento dos mesmos e no controle do fluxo de comunicação. Essa divisão ocorre em um nível mais alto que a realizada no nível de enlace, que simplesmente quebra a mensagem em pacotes de tamanho definido por essa camada [SYS93].

Camada de sessão: permite a conexão entre dois processos, e provê serviços aperfeiçoados que podem ser utilizados em algumas aplicações. Essa camada gerencia o controle de diálogos, faz a sincronização, entre outras tarefas [SOA90a, TAN94].

Camada de apresentação: trata da sintaxe e da semântica dos dados transmitidos. É tarefa dessa camada compatibilizar os formatos das aplicações em diferentes equipamentos. Por exemplo, a compatibilização entre os dados em ASCII e em EBCDIC.

Camada de aplicações: essa camada tem por objetivo fornecer serviços aos usuários, além de transferência de arquivos (trata as incompatibilidades dos sistemas), correio eletrônico, consulta a diretórios, entre outros. 


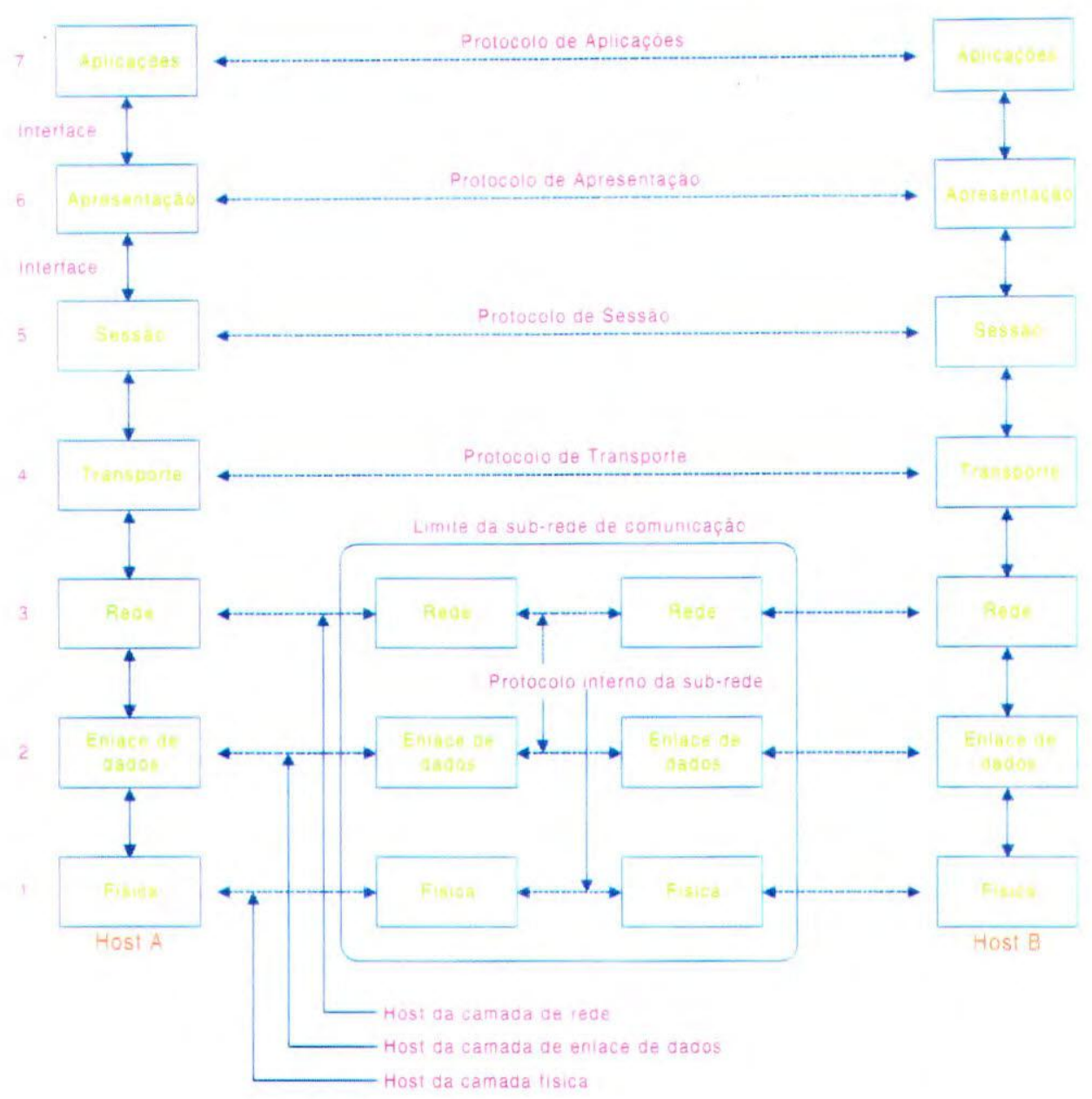

Figura 3.13: A arquitetura de rede baseada no modelo OSI

\subsubsection{O padrão IEEE 802 para redes locais}

A comunicação entre redes só é possível quando são utilizados o mesmo modelo e os mesmos protocolos. Devido a isso, foi necessária a criação de um padrão de referência que possibilitasse que duas redes fossem compatíveis entre si.

Dessa necessidade, reuniu-se um grupo de pessoas sob o comando do IEEE com o intuito de criar um padrão oficial para redes locais. Foram chamadas pessoas de diversas empresas que defendiam propostas de padronização diferentes. Desse impasse criam-se diversos padrões ao invés de apenas um, que era a proposta inicial. 
O IEEE produziu diversos padrões para redes locais. Ésses padrões, conhecidos como IEEEE 802, incluem CSMA/CD (padrão 802.3), passagem de permissão em barramento (token bus - padrão 802.4) e passagem de permissão em anel (token ring - padrão 802.5). O padrão 802.1 é uma introdução ao conjunto de padrões e define as primitivas de interface. $O$ padrão 802.2 descreve a parte superior da camada de enlace físico.

\subsubsection{O padrão IEEE 802.3 e Ethernet}

O padrão 802.3 considera uma rede local com protocolo CSMA/CD 1-persistente, que consiste de, quando uma estação quer transmitir, ela escuta o meio. Se estiver livre, transmite, senão, espera até o meio ficar desocupado para então transmitir. Se ocorrer colisão, as estações abortam a transmissão e esperam um tempo aleatório para começar a tentar transmitir novamente [TAN94, NAU94, SOA90a].

Esse padrão foi proposto pela Xerox na construção de um sistema para conectar estações de trabalho. $O$ sistema foi chamado ethernet porque na época se acreditava que as radiações se propagavam através do éter luminescente, o que posteriormente descobriu-se estar errado, já que as radiações se propagam no vácuo.

Esse sistema da Xerox foi bem sucedido, o que fez com que a Xerox, a Dec e a Intel redigissem um padrão para uma Ethernet de $10 \mathrm{Mbps}$.

As implementações do 802.3 utilizam a codificação Manchester ${ }^{6}$, de modo a sincronizar o transmissor e o receptor. O comprimento máximo do cabo no 802.3 é 500 metros. Para distâncias maiores, devem ser utilizados diversos cabos com repetidores, que amplificam e retransmitem o sinal. A estrutura do quadro da 802.3 é apresentada na Figura 3.14. O primeiro parâmetro é um preâmbulo que serve para a sincronização do transmissor e do receptor. O próximo parâmetro indica o início do quadro. $O$ terceiro e o quarto campo indicam os endereços fonte e destino. $\mathrm{O}$ bit mais significativo do endereço de destino é 0 para um endereço qualquer e 1 para endereços de grupos (multicast). Quando o endereço é formado todo por l's a mensagem é transmitida para todos os nós da rede (broadcast). 
O campo comprimento informa o tamanho da mensagem que está no campo de dados, em bytes. Deve ser no mínimo 0 e no máximo 1500. O tamanho de mensagem 0 causa problemas pois quando é detectada uma colisão, a mensagem é truncada, podendo ocorrer pedaços de mensagem no cabo. Para se saber, então, quando a mensagem é válida, toda mensagem tem um tamanho mínimo de 46 bytes (completando 64 bytes com os outros campos do quadro). Se a mensagem for menor, ela é preenchida com um campo de enchimento.

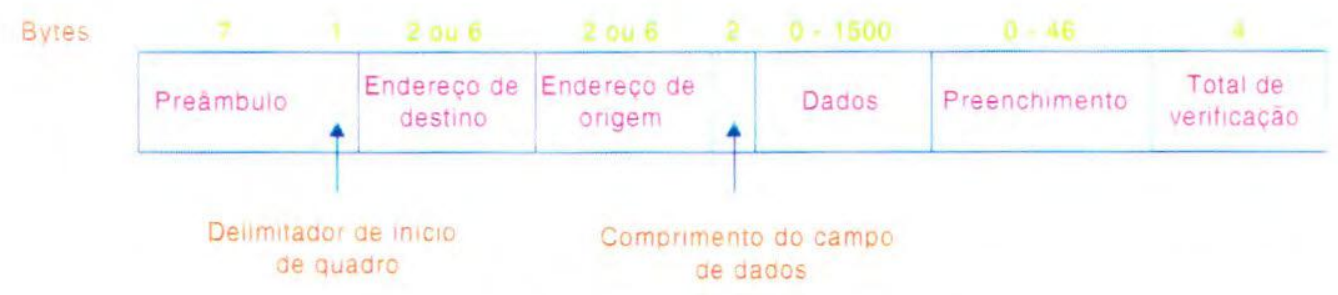

Figura 3.14: $O$ formato do quadro no 802.3

O último campo, soma de verificação, é um código de redundância cíclica, que indica se os dados estão errados ou não.

\subsubsection{O padrão IEEE 802.4: Token Bus}

O Token Bus foi criado devido às restrições encontradas no 802.3 e a algumas características não desejáveis do anel. O 802.3 não garante um tempo máximo para recebimento de uma mensagem, além de não ter quadros com prioridade (característica importante em alguns sistemas). E o anel tem uma implementação física na qual se um repetidor cai, o restante da rede é derrubado [TAN94].

\footnotetext{
${ }^{6} \mathrm{Na}$ codificação Manchester cada bit é dividido em dois intervalos iguais. O bit 1 é uma voltagem alta no primeiro intervalo e baixa no segundo. $\mathrm{O}$ bit 0 é o inverso.
} 


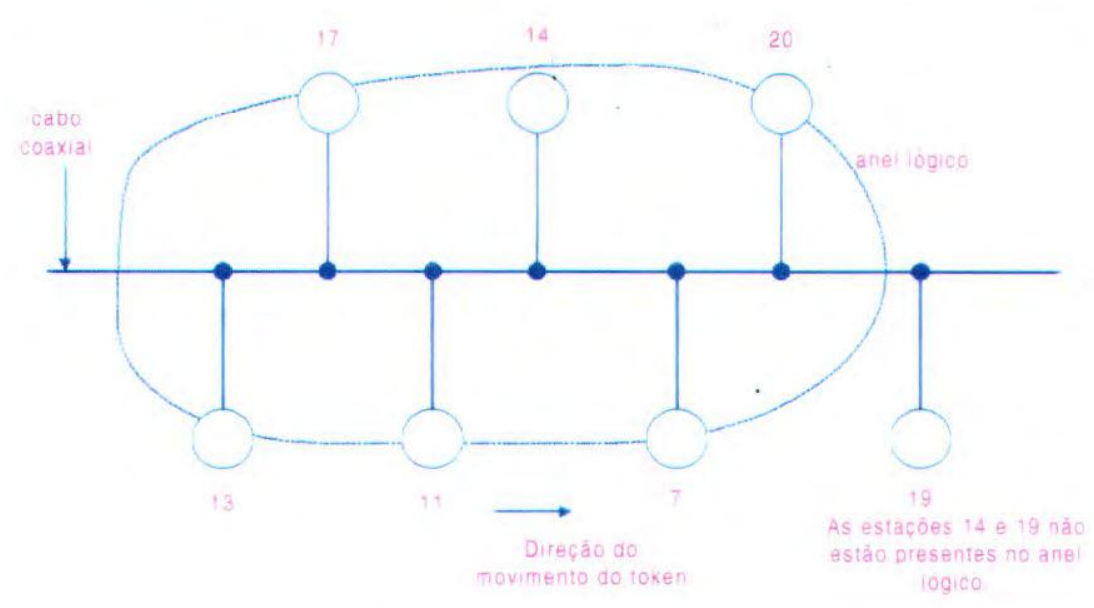

Figura 3.15: Um token bus

O Token Bus foi proposto como um cabo linear ou em forma de árvore na qual as estações estão ligadas. Virtualmente, existe um anel conectando as estações, onde cada estação tem o conhecimento dos endereços das estações adjacentes (Figura 3.15). A estação com o maior número recebe o direito de enviar dados e, caso tenha dados, envia. A seguir, a estação passa a permissão para a próxima estação, transmitindo um pacote especial de controle chamado token [SOA90a]. O token circula pela rede e aquele que detém o token pode enviar mensagens, fazendo com que não exista colisões.

A ordem física das estações conectadas a rede não implica na ordem em que o token circula pelo anel. As estações podem ser conectadas e desconectadas da rede, em uma ordem qualquer. Algumas podem não fazer parte da rede inicialmente, como por exemplo, as estações 14 e 19 (Figura 3.15). O cabo é um meio de difusão, assim, quando uma mensagem é enviada, somente o destinatário irá recebê-la, as demais irão descartar a mensagem. Assim, quando uma estação envia o token para outra estação, está enviando independente da posição física da estação na rede.

O token bus utiliza o cabo coaxial de $75 \mathrm{Ohms}$ para banda larga, o mesmo utilizado em televisão a cabo. Quando uma estação pega o token, ela pode transmitir quadros por um certo período de tempo e depois deve passar o token para a próxima estação.

O quadro do Token Bus é apresentado na Figura 3.16. O preâmbulo sincroniza o transmissor e o receptor, como no padrão 802.3. Existem os campos de delimitação (início e fim) do quadro, que fazem desnecessário um campo para o comprimento da mensagem. $\mathrm{O}$ 
campo controle de quadro indica se o quadro é de dados ou de controle. No quadro de dados, ele possui um campo de prioridade e um indicador de recepção correta ou incorreta que deve ser preenchido pelo destino. No quadro de controle, o campo controle de quadro é utilizado para especificar o tipo de quadro, por exemplo, quadro de manutenção, ou quadro para remoção de estação da rede.

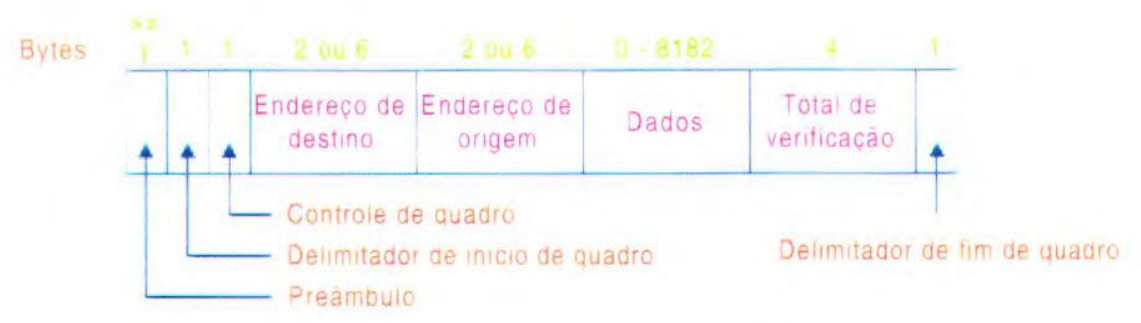

Figura 3.16: O formato do quadro no 802.4

Os campos de endereço de destino e endereço de origem são iguais ao 802.3. O campo de dados permite até 8182 bytes de comprimento. O campo soma de verificação é utilizado para detectar erros de transmissão.

\subsubsection{O padrão IEEE 802.5: Token Ring}

As redes em anel são bastante antigas e têm sido usadas em redes locais e em redes de longa distância. Elas podem ser implementadas através de par trançado, cabo coaxial ou fibra ótica. Existem diversos tipos de anéis e o padrão 802.5 é o Token Ring.

Um anel nada mais é do que um conjunto de estações conectadas ponto a ponto. Cada bit que chega à estação é copiado para o buffer e logo em seguida é colocado no anel novamente. Durante essa cópia, o bit pode ser modificado, e é introduzido um atraso de 1 bit em cada interface do anel. As interfaces e o anel podem ser vistos na Figura 3.17.

No Token Ring, um conjunto de bits especial (que é o token) fica circulando no anel. Quando a estação deseja transmitir, ela deve pegar o token para iniciar a sua transmissão. Como na rede existe apenas um token, não existe o problema de colisão. 
As interfaces do anel têm dois modos de operação, escuta e transmissão. Quando está em escuta, os bits são copiados para a saída, com um retardo de 1 bit (Figura 3.17b). No modo transmissão, a interface interrompe a conexão entre a entrada e a saída e começa a transmitir seus dados.
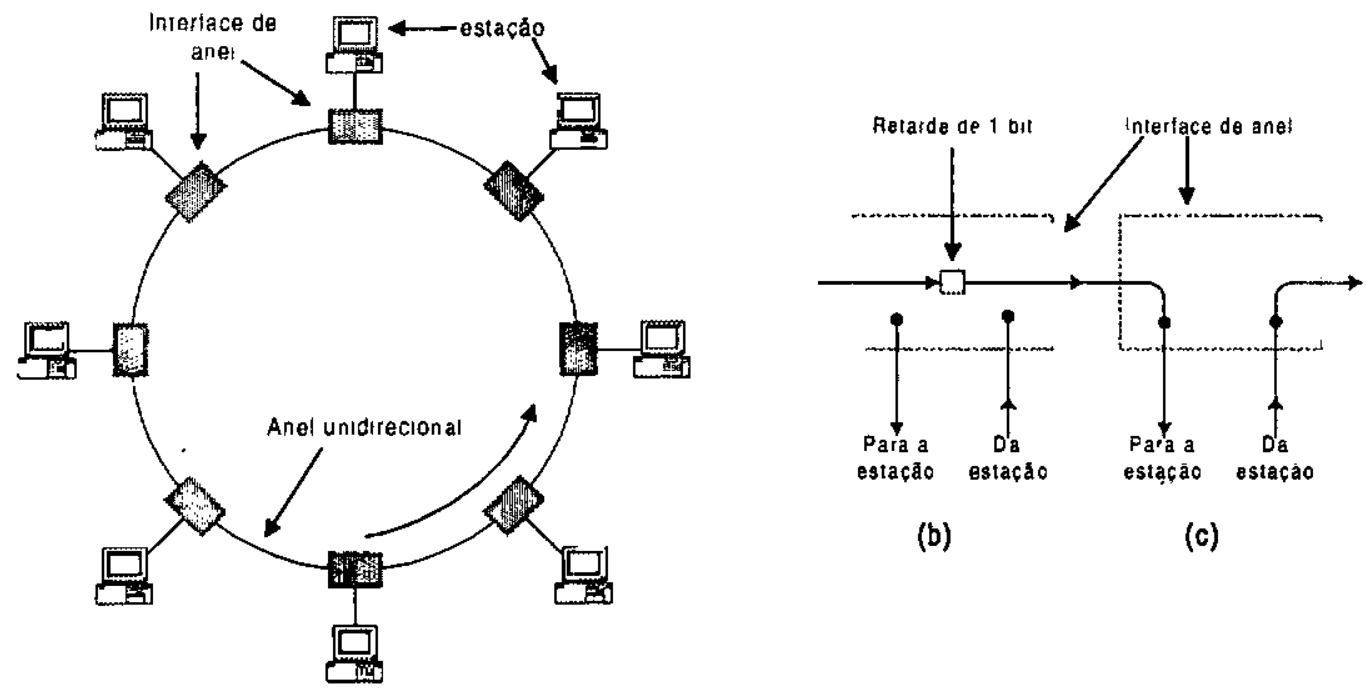

(b)

(c)

(a)

Figura 3.17: (a) Uma rede em anel. (b) Modo de escuta. (c) Modo de transmissão

Depois da transmissão, os dados retornam para o transmissor, que pode pegar os dados para verificar a confiabilidade da rede ou simplesmente descartá-los. Depois de retirar os dados transmitidos, a estação deve regenerar o token e devolvê-lo a rede para que outra estação possa utilizá-lo. Para que a estação transmissora saiba que a mensagem chegou ao destino, é preciso apenas incluir no quadro um campo com um bit em que a estação destino deve modificar para confirmar que recebeu a mensagem.

Para cargas leves, o token fica apenas circulando pelo anel. E para cargas altas, o token assim que é liberado por uma estação, é pego pela estação seguinte e assim sucessivamente, com um revezamento do uso da rede pelas estações. A eficiência pode chegar a $100 \%$ com cargas altas [TAN94].

Um dos problemas das redes em anel é que se ocorre um problema no cabo, a rede fica fora do ar. Isso pode ser resolvido através de um centro de cabeamento, em que cada estação 
está conectada a esse centro por dois pares de fios. Quando o anel se rompe, existem relés que desligam a estação com problemas, de modo a não afetar a rede para as demais estações.

O funcionamento do anel é bastante simples. Quando não há estações transmitindo, um token de 3 bytes fica circulando pela rede esperando que alguma estação tenha algo a transmitir. Se tiver, a estação deve modificar um bit específico do segundo byte de 0 para 1 . Isso faz com que os dois primeiros bytes sejam convertidos para início de quadro. Os dados então são colocados na rede no formato da Figura 3.18.

Normalmente, o primeiro bit do quadro dará a volta na rede e retornará ao transmissor antes dele terminar a transmissão. Isso implica que a estação deve continuar transmitindo e ir retirando o que já foi transmitido simultaneamente.

Os campos delimitador de início e delimitador de fim marcam o início e o fim do quadro. O campo controle de acesso contém o bit do token, o bit do monitor, os bits de prioridade e os bits de reserva. O controle de quadro determina se o quadro é de dados ou de controle. Os campos endereço de destino, endereço de origem e soma de verificação são iguais ao 802.3 e 802.4 .

(a)

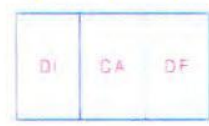

(b)

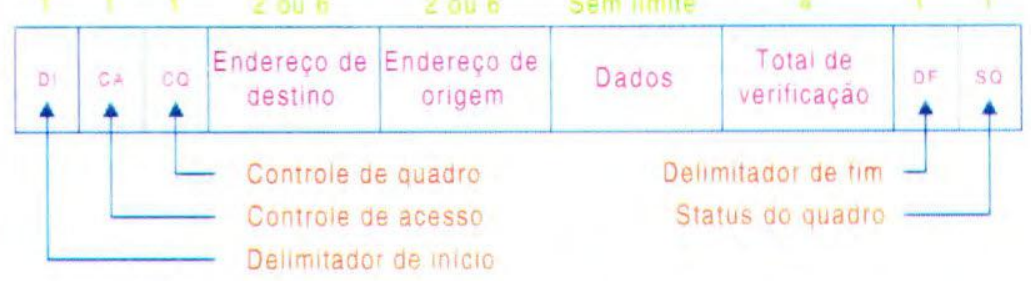

Figura 3.18: (a) Formato do token. (b) Formato do quadro de dados

O byte status do quadro contém dois bits, chamados A e C. O primeiro bit é ligado pelo destino se ele reconhecer que é para ele a mensagem. E o segundo bit é ligado quando o destino copia o quadro para ele. Assim, têm-se três combinações possíveis:

1. $A=0$ e $C=0$ : a estação de destino não está presente ou não está ligada.

2. $\mathrm{A}=1$ e $\mathrm{C}=0$ : a estação de destino está presente, mas não aceitou o quadro. 
3. $A=1$ e $C=1$ : a estação de destino está presente e aceitou o quadro.

Esse esquema facilita ao transmissor verificar se o receptor recebeu a mensagem, pois se a estação destino está presente, mas não aceitou o quadro, o transmissor pode tentar enviar a mensagem novamente depois de algum tempo.

\subsection{Interconexão de redes}

Uma das maiores motivações para o emprego de redes é o compartilhamento de recursos de hardware e de software. Porém, as redes em geral não são homogêneas, possuem características diferentes e limitações de tamanho. Para a interconexão dessas redes é preciso então inserir um módulo de interconexão e conversão para que as redes possam mover pacotes entre si. Diferentes módulos de interconexão estão disponíveis: [SOA90a, TAN94]

- Repetidores: copiam os bits individuais entre segmentos de cabos. Servem apenas para amplificar os sinais e são necessários para estender redes a distâncias maiores que o cabo pode operar.

- Pontes: armazenam e copiam dados entre redes locais. As pontes são dispositivos que podem fazer pequenas modificações no quadro, como retirar trechos do cabeçalho, ou verificar se a soma de verificação está correta.

- Gateways: armazenam e encaminham quadros entre redes não semelhantes. As redes conectadas por um gateway podem ser mais diferentes que as conectadas com pontes, além de poderem conectar redes com formatos de endereçamento incompatíveis.

- Conversores de protocolos: fornecem a interface das camadas mais altas. Possui um trabalho mais complexo que os gateways, pois devem converter protocolos sem perdas. Um exemplo é o conversor que traduz o protocolo de transporte OSI para o protocolo TCP ${ }^{7}$.

A seguir, cada um desses tipos de interconexão será discutido. 


\section{7:1 Repetidores}

Os repetidores são estações especiais utilizadas para a interligação de duas ou mais redes que utilizam o mesmo protocolo de comunicação. Eles atuam no nível 1 (físico) do modelo ISO/OSI. A função dos repetidores é receber os paçotes de cada uma das redes que está interligando e enviá-los para as demais redes, sem fazer qualquer tratamento sobre esses pacotes [SOA90a].

Em redes em anel, pode ser tarefa do repetidor retirar as mensagens da rede, quando ele atua como retransmissor. Outra tarefa é a deteç̧ão de colisão em redes baseadas em disputa.

Deve-se sempre considerar que podem existir diversos repetidores em uma rede e o projeto deve ser cuidadoso para evitar duplicações de pacotes, no caso de implementação de um caminho fechado entre dois repetidores. Outro ponto a ser considerado nos repetidores é que eles repetem o sinal para todas as redes que interliga, gerando sinais para redes ao qual não são destinados mensagens, com um conseqüente tráfego inútil na rede. Nesses casos, deve ser considerado o uso de pontes ao invés de repetidores.

\subsubsection{Pontes}

As pontes operam no nível 2 do modelo ISO/OSI e possuem diversas funções: filtro de entrada (apenas recebe as mensagens que são endereçadas às redes que ela interliga), armazenamento (necessário em caso de tráfego intenso entre as redes), e transmissão de dados (como nos repetidores) [SOA90a, TAN94].

A ponte, como o repetidor, possui a vantagem de que a falha de uma rede não prejudica a outra rede. Através disso, pode-se aumentar a confiabilidade de um sistema implementando diversas sub-redes interligadas por pontes ou repetidores. $O$ uso de pontes pode ser adotado para isolar certas partes da rede, aumentando a segurança contra espiôes.

\footnotetext{
${ }^{7}$ O TCP é um protocolo baseado em conexões que se assemelha ao protocolo de transporte OSI no estilo geral, mas difere em formato e detalhes. O TCP é utilizado no Berkeley UNIX.
} 
As pontes devem ser capazes de resolver diversos problemas para efetuar a comunicação entre as diferentes redes. Um dos problemas é o formato do quadro das redes. Cada rede pode possuir um formato diferente de quadro que deve ser convertido para que sejam legiveis pela rede. Outro problema é a taxa de transmissão de dados, pois cada rede dá suporte a um intervalo de velocidade diferente e a ponte deve ser capaz de armazenar os dados. Isso acontece quando a ponte está passando quadros de uma rede mais rápida para uma mais lenta. Outro problema é o tamanho do quadro ser diferente para cada rede.

\subsubsection{Gateways}

Os gateways operam em nível de rede ( 3 do modelo ISO/OSD) e têm como função interligar duas ou mais redes distintas, adaptando e convertendo protocolos de uma rede para outra. São mais flexíveis que as pontes, porém, são mais lentos, sendo normalmente utilizados em redes de longa distância [TAN94].

Um gateway funciona da seguinte maneira: ele recebe um pacote, trata o cabeçalho de modo a descobrir o roteamento necessário e então constrói um novo pacote com novo cabeçalho, se necessário, e envia esse pacote ao próximo destino segundo o protocolo de rede local em que se encontra.

A estrutura de ligação em cada uma das redes é completamente independente, e para facilitar a sua implementação normalmente essas entidades são separadas fisicamente. A cada uma das interfaces é dado o nome de "half-gateway". As metades se comunicam através de um sistema de comunicação adequado à velocidade de comunicação e à distância entre as redes.

Através da divisão do gateway, o projeto se torna mais simples e estruturado, e a distância entre as redes se torna mais flexível. Porém, a desvantagem dos gateways é a sua complexidade, a exigência de um protocolo inter-redes e seu custo de interligação [SOA90a]. 


\subsubsection{Conversores de protocolos}

A função dos conversores de protocolos é traduzir mensagens de uma rede em mensagens que contenham a mesma semântica do protocolo da outra rede. Um exemplo seria a tradução de um "open" em uma rede para "call request" em outra rede ao passar pelo conversor. Deve-se notar que nem todos os protocolos podem ser mapeados entre si. E o grande problema na tradução dos protocolos é a complexidade que ela exige e também a dificuldade de sua realização, o que aumenta o seu custo [SOA90a].

\subsection{Considerações finais}

Esse capítulo abordou os aspectos principais da conceituação de redes locais de computadores tais como topologia, meio de transmissão, protocolos, arquitetura da rede e interconexão de redes. A topologia descreve a estrutura física da rede, como ela está disposta fisicamente. As topologias abordadas foram estrela, anel, barramento, árvore, grafos e parcialmente conectada.

Os meios de transmissão mais comumente utilizados são o par trançado, o cabo coaxial e a fibra ótica. Cada meio tem suas características e cada aplicação deve ser cuidadosamente analisada para a definição do tipo de cabeamento a ser utilizado.

Os protocolos definem o tipo de comunicação que será implementada entre as estações, e definem as regras de funcionamento da rede. Diversos protocolos foram analisados, tanto os de acesso baseados em disputa quanto os de acesso sem disputa. Cada protocolo tem suas vantagens e desvantagens e somente a aplicação pode definir qual protocolo é o mais indicado para ser utilizado.

As redes são projetadas na forma de diversas camadas, cada qual com funções específicas. O modelo de sete camadas da OSI é formado pelas camadas: física, de enlace de dados, de rede, de transporte, de sessão, de apresentação e de aplicações [TAN94].

A camada fisica se preocupa com a parte física da rede, o cabeamento e os conectores, além das propriedades elétricas dos mesmos. A camada de enlace de dados faz a divisão dos 
dados em quadros para que eles sejam transmitidos pela rede. A camada de rede cuida do roteamento. A camada de transporte tem por função pegar os dados, dividi-los (se preciso) e enviá-los corretamente. A camada de sessão tem diversas facilidades para recuperação de falhas. A camada de apresentação se preocupa com a padronização dos dados. E a camada de aplicações contém as aplicações do usuário.

Diferentes motivos levam a subdividir as redes, tais como: distância entre os computadores, tamanho da rede, tipos de redes distintas, etc. Para garantir compartilhamento de recursos e informações torna-se necessário a interligação entre essas redes. Para a interconexão de redes podem ser utilizados diversos dispositivos que são os repetidores, as pontes, os gateways e os conversores de protocolo, que são necessários devido à característica não homogênea das redes.

A escotha de uma rede deve ser determinada através da análise crítica do problema a ser resolvido, dos custos e das características do ambiente em que ela será implementada. Cada rede tem características particulares e o seu desempenho dependerá da sua adequabilidade ao sistema proposto.

A análise de redes de computadores torna-se imprescindível à medida que ela vem sendo mais e mais utilizada em todos os tipos de aplicação. Desse modo, uma ferramenta de simulação de redes de computadores pode auxiliar o analista na escotha da rede mais adequada ou encontrar gargalos em redes já existentes.

O próximo capítulo traz alguns ambientes de simulação e dentre eles o sistema desenvolvido pelo grupo de Sistemas Distribuídos e Programação Concorrente do ICMC, o ASiA, que é o objeto de estudo desse trabalho. 


\section{Ambientes de Simulação}

Nesse capitulo são apresentados diversos ambientes de simulação, BONeS, COMNET3, ARENA e ASIA. O BONeS e o COMNET3 são ambientes específicos para simulação de redes de computadores. O ARENA e o ASiA são sistemas de simulação de propósito geral.

\subsection{Introdução}

A utilização de ambientes de simulação é atrativa, pois facilita a escolha entre soluções para resolução de problemas, podendo representar diminuição de custos em relação a implementação propriamente dita. A literatura [ALT96, CAC97, CAD98, CUB95, IMA97] apresenta diversos ambientes de simulação que podem ser utilizados, alguns deles bastante específicos para algum tipo de simulação, como simulação de redes de computadores.

Um conceito bastante importante nos ambientes de simulação é a programação visual [BRU97]. Com este tipo de programação é possível a criação do modelo através de recursos gráficos, possibilitando ao usuário uma melhor visualização do sistema sendo representado. A partir desse modelo e de parâmetros fornecidos pelo usuário é gerado então, automaticamente, o programa de simulação. A utilização de saídas gráficas para a visualização dos resultados também é benéfica, pois o usuário pode observar melhor o comportamento do sistema do que se os dados fossem apresentados em tabelas, por exemplo.

A animação do processo de simulação também tem sido utilizada para melhorar a visualização de problemas no sistema, que algumas vezes podem não ser perceptíveis nos resultados da simulação.

Uma ferramenta bastante importante é a análise de saída, pois é uma ferramenta que permite saber se os dados gerados pelo programa de simulação são confiáveis. 
Nas próximas seções são apresentados alguns ambientes de simulação e o ASiA (Ambiente de Simulaçāo Automático) desenvolvido pelo grupo de Sistemas Distribuídos e Programação Concorrente do Departamento de Computação e Estatística do ICMC - USP.

\subsection{BONeS}

BONeS (Block Oriented Network Simulator) [ISR97] é um ambiente de simulação para projeto e análise de sistemas arquiteturais, redes de comunicação e protocolos. Ele provê um ambiente gráfico para a modelagem de redes, topologia, tráfego, estruturas de pacotes de dados, e funções de protocolo. O modelo é construído hierarquicamente e graficamente, utilizando os blocos prontos da biblioteca de modelos do $\mathrm{BONeS}$, ou utilizando modelos construídos a partir da linguagem $C$.

O BONeS modela um sistema como uma coleção de recursos compartilhados (CPU, barramento, memória, etc.). O modelo criado descreve o fluxo de transações através dos vários elementos de processamento. E, através da execução da simulação no modelo, pode-se fazer avaliações do desempenho como tempo de resposta, throughput, utilização e probabilidade de erros. Baseando-se nos resultados da simulação, é possível modificar o sistema de modo a ter o melhor desempenho ao menor custo [CAD98, CAD98a].

O BONeS possui a facilidade de animação da simulação que permite uma análise de todos os passos da simulação e visualização de possíveis gargalos do sistema.

\subsection{COMNET III}

COMNET III [KIA96] é uma ferramenta para análise de desempenho de redes de comunicação orientada a objetos, que simula a operação de uma rede baseada na descrição da rede e nos algoritmos de roteamento, e provê medidas de desempenho da rede. Este ambiente utiliza metodologia de simulação discreta de eventos e pode simular uma variedade de topologias de rede e algoritmos de roteamento tais como LANs, WANs e sistemas de interconexão, tráfego orientado a conexão e sem conexão, entre outros [ISR97]. 
COMNET III possui uma interface gráfica, fácil de utilizar, que não requer programação para obter medidas de desempenho tanto de topologias de redes já existentes quanto para modelagem de redes ainda em fase de projeto (Figura 4.1). Permite a simulação desde redes Ethernet simples até redes locais e de longa distância mais complexas [KIA96].

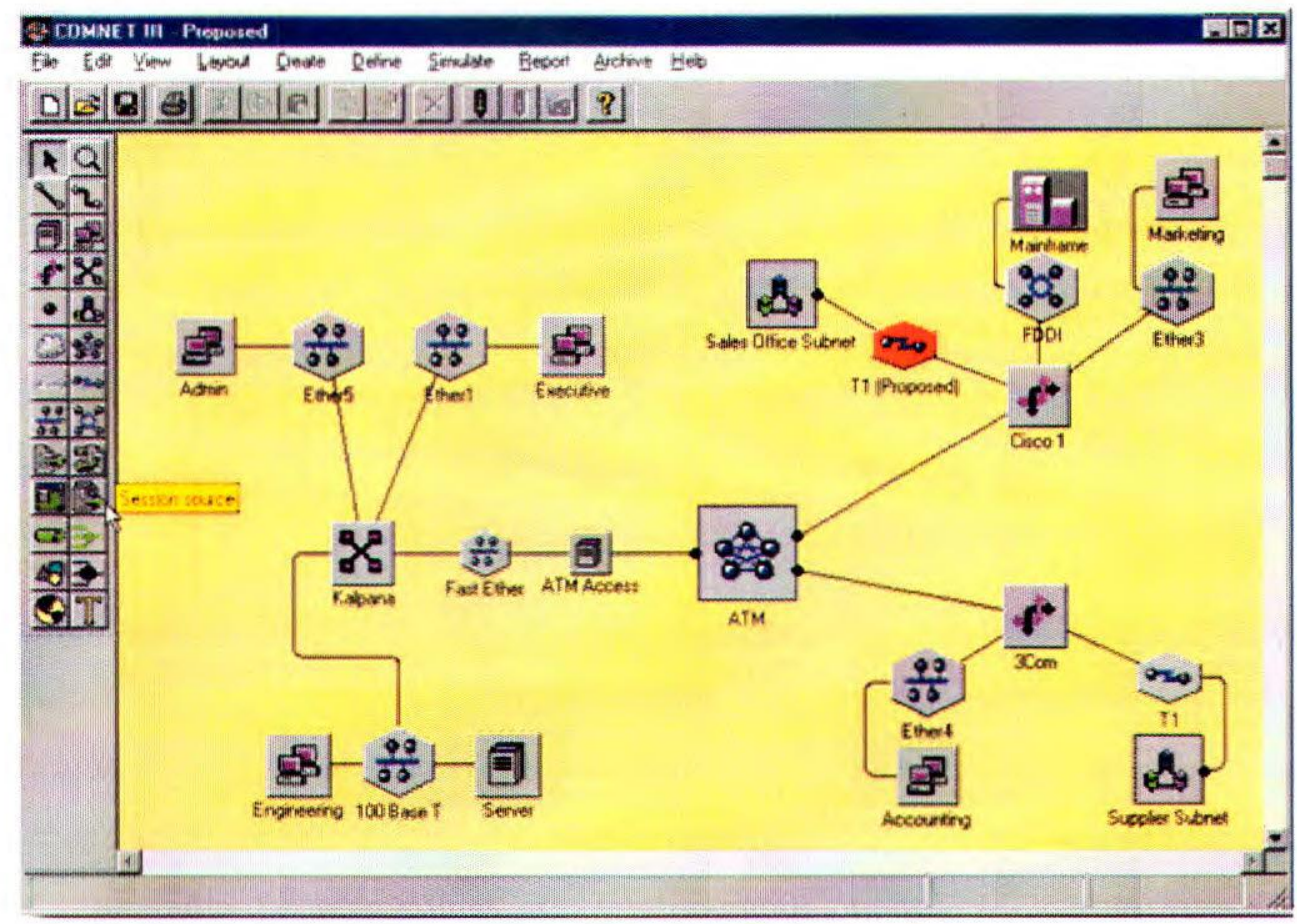

Figura 4.1: O sistema de simulação COMNET3

Problemas de gargalos e áreas de congestionamento em redes locais atuais são dificeis de rastrear sem o equipamento apropriado disponível. Utilizando-se o COMNET III, problemas em redes existentes podem ser isolados e corrigidos facilmente. As áreas com problemas podem ser detectadas através da animação da simulação e através dos relatórios de desempenho gerados.

O COMNET III foi desenvolvido utilizando o MODSIM II, que é uma linguagem orientada a objetos que suporta diversos paradigmas da engenharia de software como modularidade e estrutura em blocos. O MODSIM é uma linguagem estruturada em blocos, modular e de propósito geral, que provê programação orientada a objetos e simulação discreta orientada a eventos em máquinas com arquitetura seqüencial e em sistemas computacionais paralelos [KIA95]. 


\subsection{ARENA}

O sistema de simulação ARENA [SYS98] cria modelos computacionais animados que representam com fidelidade qualquer tipo de sistema. Ele possui um projeto orientado a objetos e pode ser utilizado para praticamente todas as áreas de aplicação.

Para se construir um modelo, o ARENA fornece módulos pré-definidos que podem ser utilizados para descrever uma aplicação. Esses módulos são separados logicamente em três grupos que compõe o gabarito do ARENA.

De modo a facilitar a construção de um modelo, é utilizada uma interface gráfica de usuário (GUI). A GUI automatiza o processo de construção do modelo e reduz a utilização do teclado e do mouse que seria necessário sem essa interface gráfica.

Como o processo de construção de um modelo é gráfico, os módulos prontos disponíveis que vão sendo desenhados são facilmente identificados pelos ícones que os representam. Por exemplo, o módulo que representa um processo servidor simples (isto é, obtém um recurso, espera pelo processamento, libera o recurso) é representado pela figura de uma caixa azul (retângulo) com um quadrado entrando (a esquerda do retângulo) e uma parte redonda saindo (a direita do retângulo) (Figura 4.2). Para adicionar o módulo servidor no modelo, deve-se apertar o botão esquerdo do mouse sobre o ícone server da barra de ferramentas da biblioteca comum, mover o cursor sobre a área de trabalho, e apertar o botão no local onde se quer posicionar o módulo. O ARENA possui a facilidade de reposicionar qualquer desenho dentro da área de trabalho, bastando arrastá-lo pela tela com o botão esquerdo do mouse pressionado.

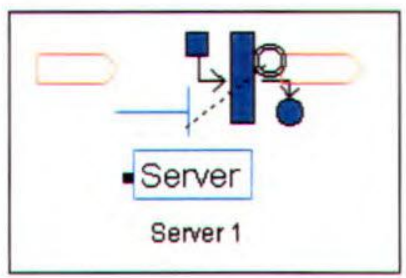

Figura 4.2: Exemplo de um módulo servidor simples 
Junto com a construção de modelos de simulação, pode-se querer especificar dados no início da simulação e analisar informações coletadas no fim da execução da simulação. $O$ ARENA possui dois sistemas integrados para manipular estas situações, os Processadores de Entrada e os Processadores de Saída.

O Processador de Entrada permite que se pegue dados novos e importantes (por exemplo, estudos de tempo em análise de processos) e adapte uma distribuição estatística a ele. Esta distribuição pode ser incorporada diretamente aos modelos.

O Processador de Saída é uma ferramenta de análise completa que permite a representação gráfica e a comparação estatística dos dados que foram coletados durante a execução do modelo de simulação [SYS94, SYS95, SYS95a].

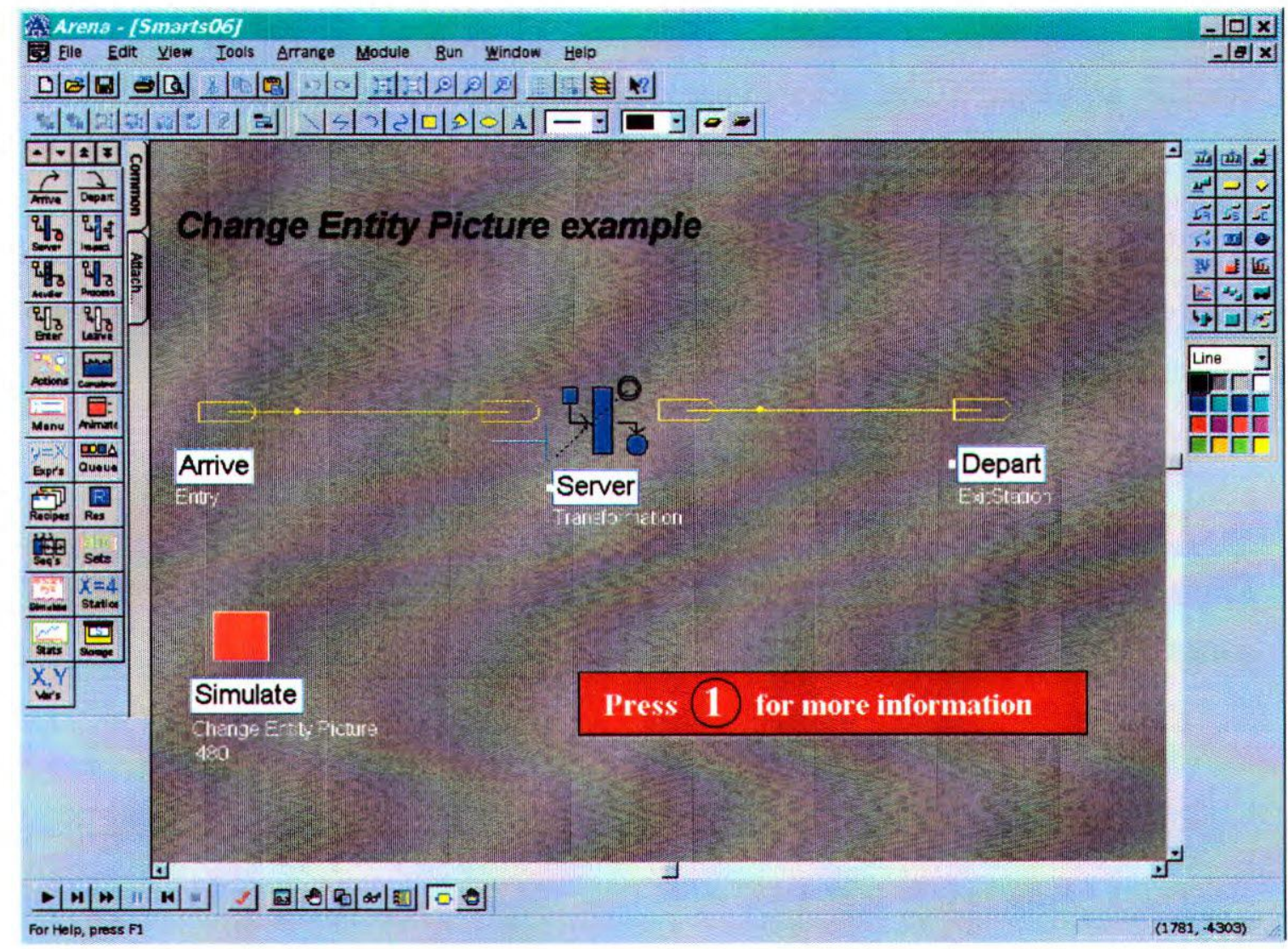

Figura 4.3: Tela do Sistema ARENA com um exemplo de modelo. 
Como pode ser visto na Figura 4.3, a interface do ARENA é composta de uma tela de edição gráfica, uma barra de menus e barras de ferramentas. A interface possui nove tipos diferentes de barra de ferramentas:

- Padrão - responsável por manipular arquivos, repetir operações, help sensível ao contexto e outras operações padrão, conforme visto na Figura 4.4.

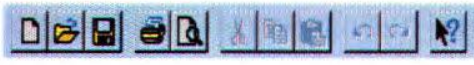

\section{Figura 4.4: Barra de ferramentas PADRÃO}

- Visualização - responsável por aumentar ou diminuir o tamanho do modelo dentro da janela de edição gráfica e por colocar linhas de grade para facilitar a confecção do modelo (Figura $4.5)$.

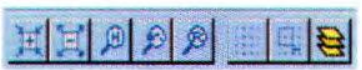

Figura 4.5: Barra de ferramentas VISUALIZAÇÃo

- Arranjo - responsável pela manipulação do modelo, tal como agrupar ou desagrupar um desenho, posicionar o objeto para primeiro ou para segundo plano (Figura 4.6).

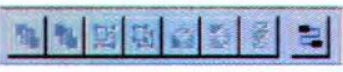

Figura 4.6: Barra de ferramentas ARRANJO

- Desenho - responsável por desenhar linhas retas, curvas, circunferências, retângulos na tela de edição gráfica e pela seleção do tipo de linha e sua espessura (Figura 4.7).

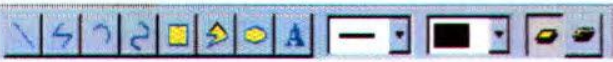

Figura 4.7: Barra de ferramentas DESENHO

- Cores - responsável pela escolha de cores, seja para preenchimento de um objeto quanto para a linha de contorno (Figura 4.8).

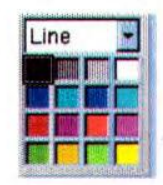

\section{Figura 4.8: Barra de ferramentas CORES}

- Animação - responsável pelos objetos que serão animados durante a simulação, ou seja, representa os objetos, a sua rota, tudo relacionado à animação (Figura 4.9). 


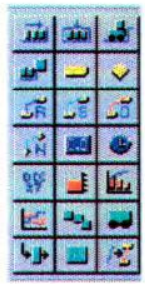

Figura 4.9: Barra de ferramentas ANIMAÇÃO

- Bibliotecas - possui os módulos prontos para construção de modelos. É formado pelas bibliotecas comum, suporte e transferência que serão abordados nos próximos parágrafos (Figura 4.10).

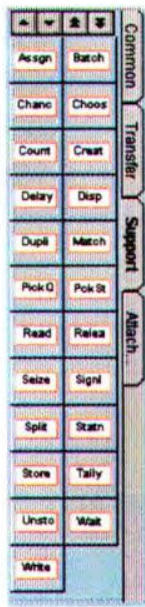

Figura 4.10: Barra de ferramentas BIBLIOTECAS

- Executar - responsável pela execução, parada, pausa, retrocesso e avanço da simulação do modelo (Figura 4.11).

\section{$\nabla|M| M|\|| \mathbf{M}|=|$}

Figura 4.11: Barra de ferramentas EXECUTAR

- Executar interativamente - responsável por rastreamento, checagem do modelo, relatório, janela de linha de comando (Figura 4.12).

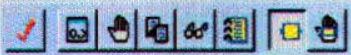

Figura 4.12: Barra de ferramentas EXECUTAR INTERATIVAMENTE

O Gabarito do ARENA é uma coleção de módulos que podem ser utilizados para modelar uma ampla variedade de sistemas. Os módulos do gabarito capturam a lógica e os elementos de sistema mais comumente encontrados na modelagem de simulações, tal como chegadas, servidores, processo de inspeção, e sistema de transporte de material. Através de 
ferramentas para representar esses processos, o gabarito do ARENA habilita o usuário a construir rapidamente, modelos gráficos e animados completos no ambiente Windows [SYS95].

O gabarito do ARENA foi também projetado para facilitar certas representações de sistema. Os construtores de modelos do gabarito são supridos por um conjunto de módulos flexíveis que podem ser combinados para capturar em detalhes, a lógica do sistema e as suas interações. Esses módulos são utilizados no mesmo ambiente gráfico como os módulos já descritos, desse modo a modelagem de sistemas complexos pode ser feita completamente dentro da interface interativa do ARENA - nenhuma programação é necessária. Além disso, a animação encontrada no ARENA permite ao usuário criar representações gráficas realísticas de um sistema.

Três bibliotecas compõe o gabarito do ARENA:

- COMUM, que contém módulos representando os processos fundamentais em simulação tais como chegada, serviço, saída;

- SUPORTE, que contém módulos suplementares para modelar ações específicas tais como capturar um recurso ou mandar um sinal;

- TRANSFERÊNCIA, cujos módulos são utilizados para modelar a transferência de entidades através do sistema e a representação dos dispositivos de transferência de material (isto é, transporte).

Os módulos dessas bibliotecas podem ser combinados em um mesmo modelo ou podem ser utilizados com outros gabaritos.

Existe um relacionamento hierárquico entre os módulos no gabarito do ARENA. Por exemplo, o modelo de servidor avançado no painel comum incorpora três passos (entrada no servidor, processamento no servidor, e saída do servidor) que são definidos individualmente pelos módulos entrada, processamento, e saída (também do painel comum). Cada um desses módulos é definido por uma seqüência de atividades que são capturados nos módulos contidos nos painéis de Suporte e de Transferência. Pode-se utilizar ambas estruturas no desenvolvimento e compreensão da construção de modelos do gabarito do ARENA e na criação de modelos [SYS95a]. 
Os modelos do ARENA são implementados na linguagem SIMAN (SIMulation Analysis), que é uma linguagem de simulação que modela sistemas de eventos discretos, contínuos ou a combinação dos dois. Utiliza um diagrama de blocos direcionado que consiste de diversos tipos de blocos, cada um dos quais com função única. Em uma visão geral, as entidades fluem através dos blocos, definindo os componentes do sistema [HOO90, SCH95].

O SIMAN é uma linguagem baseada no Fortran que simula sistemas bastante complexos, requerendo assim, uma especificação detalhada do modelo.

\subsection{ASiA}

ASiA ou Ambiente de Simulação Automático, consiste de um sistema que permite a geração automática de um programa de simulação, a partir da descrição de um modelo em um ambiente gráfico [SAN94]. O ASiA tem por objetivo afastar o usuário da tarefa de transcrição do modelo em um programa de simulação. Esse ambiente está em desenvolvimento no grupo de Sistemas Distribuídos e Programação Concorrente do ICMC - USP.

No ambiente de simulação proposto, o usuário descreve seus modelos através de um editor gráfico, define os pontos de coleta de dados para análise estatística, seleciona os tipos de gráficos a serem apresentados no relatório final e escolhe qual o sistema de simulação a ser utilizado (o ambiente automático pode oferecer diversos sistemas para a escolha do usuário). A partir disso, o sistema, automaticamente, compila todas as informações contidas no modelo do sistema em estudo, inclui as opções definidas pelo usuário e gera (através de um gerador de aplicações) o programa de simulação correspondente. Dentro do mesmo ambiente, o usuário compila e executa o programa gerado [OGA97b].

Como uma opção adicional, o ASiA deverá incluir a possibilidade de se analisar os dados coletados durante a execução do programa de simulação. Assim, o sistema cobre todas as etapas fundamentais do processo de elaboração e análise de simulação.

Quatro estágios básicos são necessários para a implementação do sistema de simulação automático (Figura 4.13):

- Editor Gráfico - captura o modelo através de uma interface amigável 
- Gerador de Aplicações - geração automática do programa de simulação

- Execução da Simulação - obtenção dos resultados

- Estágio de saída - análise dos dados e visualização gráfica dos resultados

A função do editor gráfico é oferecer para o usuário uma interface amigável onde será definido o modelo a ser simulado e seus parâmetros através da utilização de barras de ferramentas e menus, janelas, ícones, etc. Além da interface com o usuário, o Editor Gráfico analisa, organiza e grava em arquivos os dados fornecidos pelo usuário, que serão utilizados pelo Gerador de Aplicações. Esse módulo foi desenvolvido em um programa de mestrado [SPO94a] e aprimorado em um programa de Iniciação Científica [OGA95, OGA96, OGA97a, OGA97b]

A segunda fase do sistema de simulação automática não depende da interferência direta do usuário. As informações coletadas e organizadas pelo editor gráfico em estruturas de dados previamente definidas, alimentam um gerador de aplicações que fornecerá como saída um programa de simulação. Esse programa é gerado de acordo com a linguagem de simulação adotada. Esse segundo módulo foi desenvolvido no programa de mestrado de Roberta Spolon [SPO94e].

A terceira fase consiste na execução do programa de simulação gerado. Em princípio, qualquer sistema de simulação pode ser utilizado, sendo possível até mesmo oferecer ao usuário diversas opçōes. Na versão atual do ASiA foi utilizada a extensão funcional SMPL [MAC87].

O módulo de análise dos resultados permite que sejam feitas aferições sobre a validade dos resultados gerados através da execução de testes estatísticos. Este módulo foi desenvolvido no programa de mestrado de Laís Lemos de Oliveira [OLI98].

O último estágio do sistema de simulação automático oferece ao usuário a possibilidade de visualização gráfica dos resultados obtidos na simulação. Esse último módulo constitui a tese de mestrado de Walter Pedroso [PED96]. 


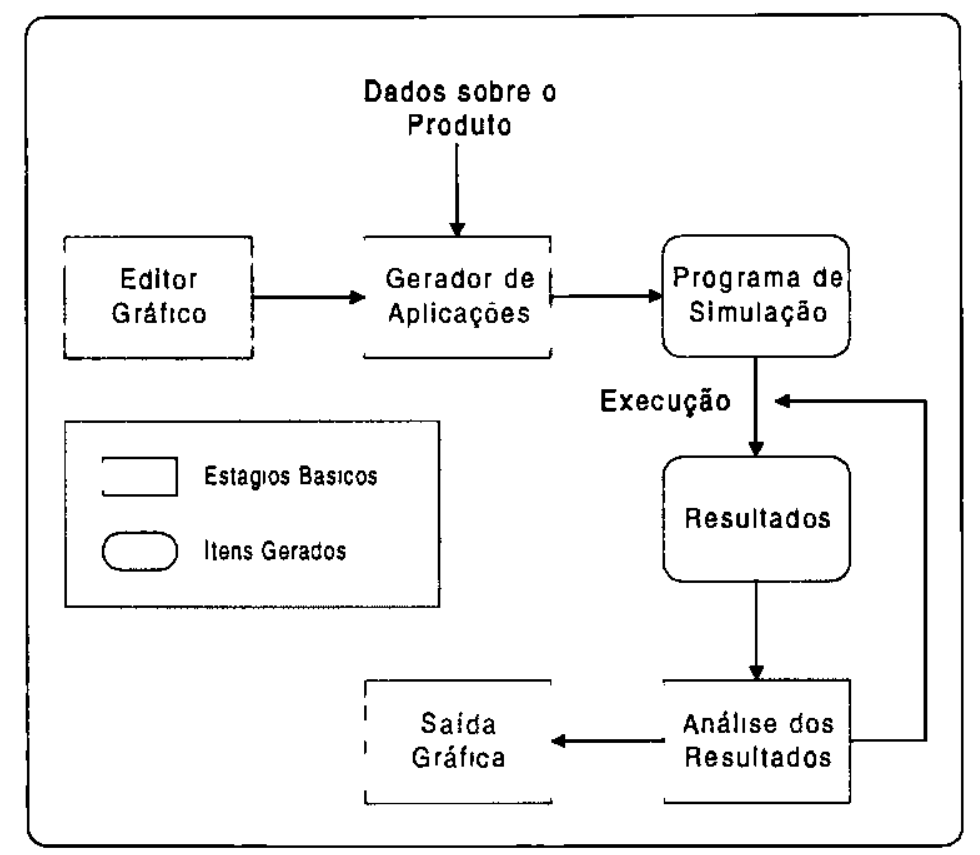

Figura 4.13: Estrutura geral do Ambiente de Simulação Automático.

De modo a aperfeiçoar o ASiA, alguns módulos, para utilização em áreas específicas, estão em desenvolvimento. Um módulo de análise de desempenho de arquiteturas de computadores, denominado Módulo Arquitetura, foi desenvolvido no programa de mestrado de Sarita Mazzini Bruschi [BRU97]. O projeto de mestrado, descrito no capítulo 5 desta monografia, considera o desenvolvimento de um módulo para simulação de redes de computadores. Outros programas de mestrado e de doutoramento estão em desenvolvimento, com o intuito de aprimorar ou de expandir a funcionalidade do ASiA:

- Redefinição dos processos do ASjA [PIE97]: espera-se obter um código final otimizado através do estudo detalhado da implementação do ASiA e da especificação geral do ambiente definido no projeto inicial.

- Suporte para modelagem de redes de petri [NON97]: o usuário terá a opção de modelar seus sistemas em redes de petri, ao invés de utilizar redes de filas (como está implementado o ASiA atualmente).

A seguir são descritos os estágios básicos e módulos que compõem o ASiA. 


\subsubsection{Editor Gráfico}

O Editor Gráfico constitui o módulo de interface entre o usuário e o Gerador de Aplicações e tem como função primária fornecer ao usuário uma interface gráfica e amigável para a definição do modelo em um programa de simulação [SPO94a, SPO94b, SPO94c, SPO95, OGA95, OGA96, OGA97a, OGA97b].

O Editor Gráfico é responsável ainda por gerar uma tabela que deve conter todos os dados para que o gerador de aplicações construa o programa de simulação.

A interface com o usuário permite que os elementos do modelo que representam o sistema a ser simulado (basicamente um modelo de redes de filas) sejam desenhados na tela de um monitor de vídeo. $O$ editor oferece facilidades para o desenho do modelo, permitindo modificações imediatas. Uma vez fornecido o modelo, o editor requisita do usuário os parâmetros necessários para a simulação e os pontos de coleta de dados. As demais tarefas são executadas automaticamente pelo sistema.

Assim, o editor gráfico é responsável por um conjunto de funções que são executadas através das seguintes etapas:

Definição de uma interface com o usuário: A interface gráfica oferecida pelo sistema de simulação automático segue os requisitos básicos para o projeto de interfaces (facilidade de aprendizagem, velocidade de utilização, baixa taxa de erros, etc.). A interface segue a abordagem WYGiWYS (What You Get is What You See), isto é, o usuário obtém na tela o modelo que está sendo definido, passo a passo, através de pop down menus e por manipulação direta da tela.

Definição do modelo a ser simulado: A definição do modelo é feita através da seleção de blocos básicos que representam os elementos básicos existentes em modelos de redes de filas, isto é, recursos, recurso com uma fila, recurso com diversas filas, etc.

Definição e verificação dos parâmetros do modelo: $O$ usuário deverá fornecer os parâmetros necessários para a caracterização do sistema em estudo, isto é, a política de escalonamento das filas, o tempo de serviço e a distribuição de chegada, entre outros. 
Formação da tabela de especificações: $O$ último passo executado pelo editor é a implementação de uma tabela contendo todas as informações necessárias para que o gerador de aplicações gere o programa de simulação, isto é, identificação dos recursos e eventos, interrelacionamento entre os recursos, parâmetros básicos, etc.

O EdGraf (Editor Gráfico) foi desenvolvido utilizando-se a linguagem C, com o compilador Borland C++ (versão 3.1), em microcomputador IBM-PC 386. Para a interface ser mais amigável, fez-se uso dos recursos oferecidos pela interface gráfica do MS-Windows. O Windows oferece inúmeras rotinas internas que permitem o uso de menus, caixa de diálogos, ícones, cursores e outros componentes de uma interface amigável.

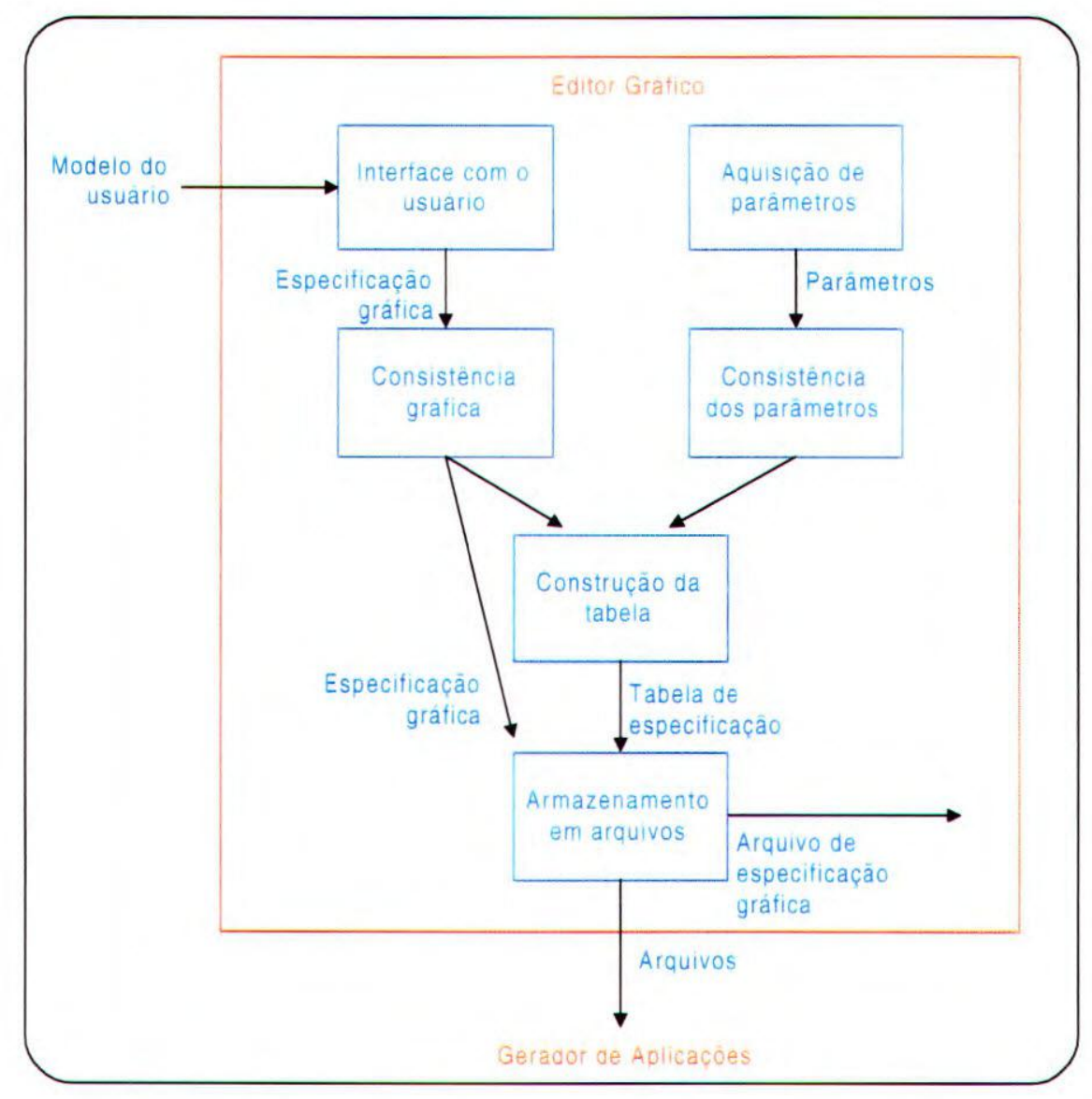

Figura 4.14: Visão geral do Editor Gráfico

A Figura 4.14 apresenta uma visão geral dos módulos que compõem o Editor Gráfico e o inter-relacionamento entre eles. Como pode ser observado, o usuário fornece ao editor, 
através da interface com o usuário, o seu modelo, desenhando-o através das primitivas gráficas presentes no editor. A consistência do modelo gráfico é verificada para que o usuário possa então fornecer os parâmetros do modelo. $O$ usuário parametriza o modelo e é feita a verificação da consistência dos parâmetros para que a tabela de especificação possa ser construída. Por fim, os dados da especificação gráfica e os parâmetros são gravados em arquivos.

O EdGraf transforma todas as informações vindas do modelo de simulação em um conjunto de dados consistente e organizado de forma que possa ser utilizado pelo Gerador de Aplicações.

A Figura 4.15 mostra a tela principal do ASiA, onde tem-se a barra de ferramentas, a barra de menus e a tela de edição gráfica. Através da barra de ferramentas o usuário pode desenhar os recursos do modelo (centros de serviço com um ou vários servidores e com uma ou várias filas), pode selecionar um recurso para ser parametrizado, pode apagar qualquer símbolo desenhado, pode mover os recursos pela tela de edição gráfica e pode também definir os caminhos dos clientes pelo sistema sendo modelado.

A barra de menus permite operações relacionadas com arquivos (salvar arquivo, abrir arquivo, etc.), permite a parametrização do modelo e dos recursos, permite a geração do programa de simulação e execução do mesmo, além da visualização dos resultados obtidos. $O$ ASiA também possui na barra de menus um sistema de ajuda.

Na tela de edição gráfica o usuário pode desenhar seu modelo sem se preocupar com a área que está ocupando pois existem barras de rolagem que permitem ao usuário exceder o limite de espaço da tela do computador. 


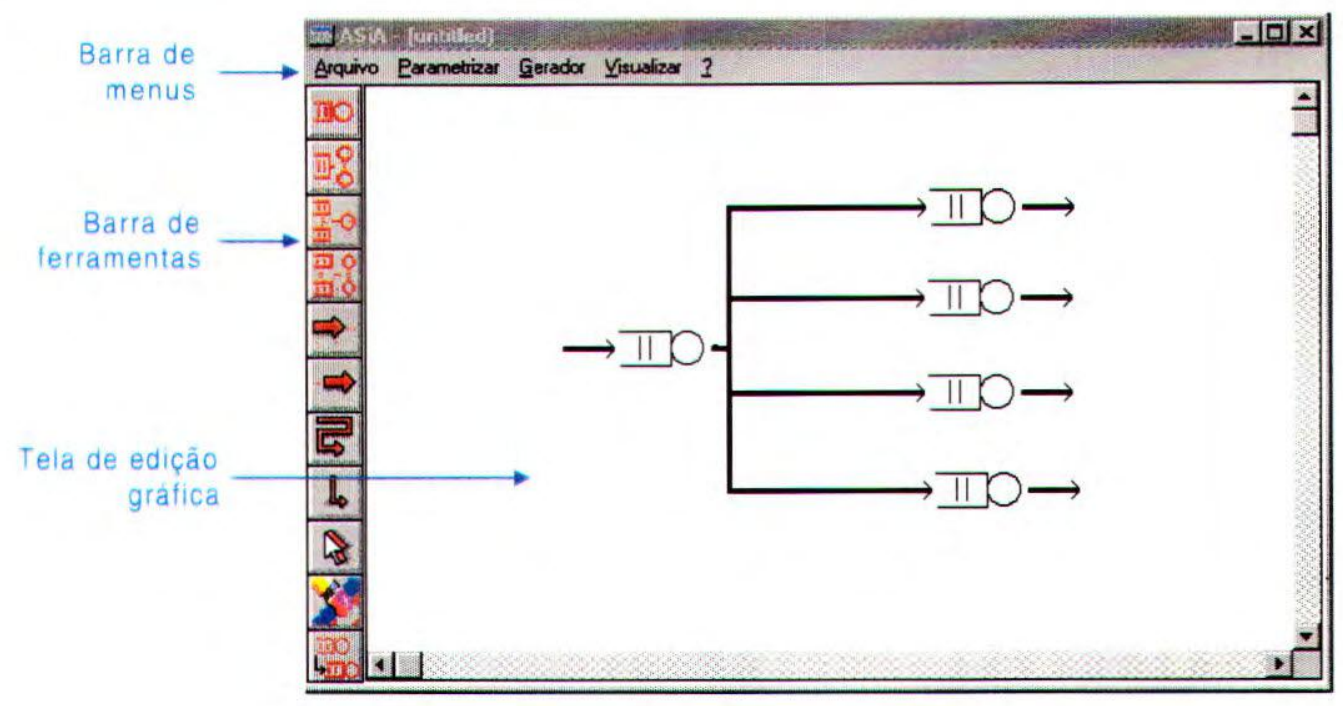

Figura 4.15: Tela principal do Editor Gráfico

\subsubsection{Gerador de Aplicações}

O gerador de aplicações é um módulo que não depende da interferência do usuário. As informações colhidas pelo editor alimentam o gerador que irá fornecer como saída um programa de simulação. Esse programa é gerado de acordo com o sistema de simulação adotado, e no caso do ASiA, optou-se pela geração do código em SMPL [MAC87].

A utilização de geradores de aplicação é bastante atrativa pois possibilita que usuários menos experientes desenvolvam seus programas de modo eficiente e também facilita a tarefa de programadores experientes no desenvolvimento de programas em geral [SAN94].

O gerador é constituído por um conjunto de primitivas que definem o núcleo do Gerador de Aplicações, e cada uma dessas primitivas é responsável por um trecho específico de código do programa de simulação [SPO94e, SPO94d, SPO95a].

No ASiA, o gerador produz um programa de simulação baseado nas tabelas fornecidas pelo editor e no conjunto de regras definidas pela linguagem de simulação adotada. O Gerador de Aplicações analisa a tabela e para cada componente da tabela são gerados os comandos necessários para a sua simulação. 


\subsubsection{Análise dos Resultados}

Este módulo é responsável pelo controle da precisão dos dados obtidos na simulação através da execução de testes estatísticos. Ėsta etapa é de grande importância devido ao fato dos resultados serem produto de uma simulação estocástica, que se baseia em um conjunto de números aleatórios fornecendo portanto resultados não exatos. Essa análise indica se alguns parâmetros (por exemplo, tempo total da simulação) são suficientes para se ter uma precisão adequada. Os testes são feitos através de ferramentas estatísticas que utilizam intervalos de confiança, análise de batch means, replicações, etc. Este módulo foi desenvolvido no projeto de mestrado de Laís Lemos de Oliveira [OLI98].

Os testes são executados para que a simulação alcance a precisão desejada, e a simulação é considerada válida quando isso acontece. Porém, quando não se obtém essa precisão, os parâmetros pertinentes devem ser alterados e a simulação e os testes devem ser refeitos para atingir a precisão desejada.

\subsubsection{Estágio de Saída}

Este módulo, chamado Módulo Visual, oferece ao usuário a possibilidade de visualizar, através de gráficos, alguns pontos de coleta de dados estabelecidos na fase de definição do modelo [SAN94].

O Módulo Visual tem o objetivo de facilitar a coleta e análise dos resultados do sistema simulado, disponibilizando para o usuário, ferramentas que irão auxiliá-lo no trabalho de verificação e validação do modelo e visualização do processo de simulação [PED96, PED95]. O tempo de simulação elevado e a visualização da simulação em diversos níveis são alguns dos fatores que tornam o uso do Módulo Visual atrativo, reduzindo o tempo verificação, aumentando a produtividade, e antecipando a análise de resultados do modelo simulado. 


\subsubsection{Módulo Arquitetura}

O módulo Arquitetura, desenvolvido no programa de mestrado de Sarita Mazzini Bruschi [BRU97], tem como objetivo facilitar a construção de modelos que representem arquiteturas de computadores, utilizando a simulação para validação e avaliação de desempenho dessas arquiteturas. Pode ser utilizado também como ferramenta de auxílio para o ensino de arquiteturas.

O usuário pode definir diferentes tipos de arquiteturas, utilizando recursos básicos, como processador, disco, memória, etc., ou então escolher entre os modelos de arquiteturas pré-definidos: arquitetura de Von Neumann, arquitetura de Von Neumann com pipeline, arquitetura MIMD com memória distribuída e arquitetura MIMD com memória compartilhada.

\subsection{Tabela Comparativa}

A Tabela 4.1 mostra dados comparativos entre os ambientes de simulação estudados neste capítulo.

Tabela 4.1: Tabela comparativa entre os ambientes de simulação.

\begin{tabular}{|c|c|c|c|c|}
\hline 4 & & Oritign: ITin & ASthol & 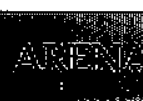 \\
\hline $\begin{array}{l}\text { Especifico para } \\
\text { redes? }\end{array}$ & S & $S$ & $\mathrm{~N}$ & $\mathrm{~N}$ \\
\hline * Añimação & $\mathbf{S}$ & $\mathbf{S}$ & $\mathrm{N}$ & $\mathrm{S}$ \\
\hline $\begin{array}{l}\text { Modelagem } \\
\text { gráfica }\end{array}$ & $S$ & $\mathbf{S}$ & $\mathbf{S}$ & $\mathbf{S}$ \\
\hline $\begin{array}{l}\text { Linguagem } \\
\text { utilizada }\end{array}$ & $\mathrm{C}$ & MODSIM & $C(\mathrm{SMPL})$ & SIMAN \\
\hline
\end{tabular}




\subsection{Considerações finais}

A simulação de sistemas tornou-se uma tarefa mais simples devido ao surgimento dos ambientes de simulação, pois o usuário deve apenas saber transcrever o modelo graficamente e parametrizar esse modelo. $O$ ambiente se encarrega de gerar o programa de simulação e os resultados podem ser analisados através de gráficos ou animações. A modelagem de sistemas sem a preocupação de aprendizado de linguagens de simulação e a gama de ferramentas encontradas atualmente torna a tarefa de simular bastante simples.

Existem diversos sistemas de simulação, e foram apresentados nesse capítulo o BONeS, o COMNET III, o ARENA e o ASiA. O ASiA é um sistema que está em desenvolvimento e de modo a aperfeiçoá-lo, está sendo proposto a inclusão de ferramentas para a modelagem de redes de computadores. No próximo capítulo são apresentados os detalhes de implementação do módulo de simulação de redes de computadores. 


\section{Modificações Introduzidas no ASiA}

Este capitulo discute as modificações implementadas no ASiA para adequá-lo a inclusão do Módulo de Redes.

\subsection{Introdução}

$\mathrm{O}$ ambiente de simulação $\mathrm{ASiA}$ provê para o usuário um ambiente completo de simulação, onde o usuário pode descrever seu modelo através de primitivas gráficas, parametrizar esse modelo, gerar um código de simulação e visualizar os resultados. Porém, o usuário se encontrava limitado na sua capacidade de desenvolvimento devido à falta de alguns recursos específicos.

A versão original do ASiA possui centros de serviço com uma ou mais filas e um ou mais servidores, além do recurso entrada, saída, ligação e ramificação. Apesar destes recursos possibilitarem a representação de um grande número de modelos, estes recursos não são suficientes para a representação de sistemas mais complexos.

A estrutura de redes de fila básica é usada apenas para resolução de problemas de sistemas simples. Para a representação de características mais complexas é necessária a utilização de extensões do modelo de filas.

Uma abordagem que pode ser considerada é a utilização de novas estruturas que estendam as redes de filas básicas, tais como as sugeridas no pacote para simulação RESQ [SOA92]. O RESQ é uma linguagem de simulação que emprega a estrutura de redes de fila e introduz recursos adicionais às redes de fila básicas. A seção 5.2 apresenta as estruturas da linguagem RESQ, utilizadas neste trabalho.

São utilizadas neste trabalho as estruturas do RESQ para representar os seguintes recursos: servidor sem fila, posse múltipla de recursos e servidor infinito. Com esses recursos aumenta a quantidade de modelos que o usuário pode representar. Adicionando-se estas novas 
funcionalidades ao ASiA, o usuário tem a possibilidade de criar modelos mais complexos, permitindo que usuários mais avançados tenham mais ferramentas para implementação dos seus sistemas.

O SMPL implementa os novos recursos adicionados, tanto o servidor passivo (posse múltipla de recursos) quanto o servidor infinito. Quanto ao servidor sem fila, foi preciso implementar uma política de reescalonamento para esse servidor, que o SMPL não implementa. Essa política de reescalonamento já encontra-se implementada [SPO94e].

As características introduzidas às redes de filas neste trabalho são especialmente importantes para a simulação de redes de computadores. Os três recursos acrescentados às redes de fila possibilitam a representação de tipos de centros de serviço que modelam importantes características das redes de computadores. Uma descrição detalhada das funcionalidades introduzidas ao ASiA é dada na seção 5.2.

Essas modificações foram implementadas no ASiA. O módulo de redes (descrito no Capítulo 6) foi implementado utilizando essas funcionalidades acrescentadas ao ASiA. Através desta abordagem, além de implementar o módulo de redes de computadores, também se ampliou as funcionalidades do ASiA.

Todas as modificações efetuadas no ASiA para ampliar suas funcionalidades são detalhadas nas próximas seções.

\subsection{Inclusão de Novas Funcionalidades no Ambiente ASiA}

Conforme descrito na introdução deste capítulo, a versão original do ASiA considera os recursos disponíveis em uma rede de filas básica. Quando os modelos para diferentes tipos de redes de computadores foram considerados, observou-se que estes recursos básicos não são suficientes para modelar algumas das características das redes de computadores. Desse modo foram implementados os seguintes recursos adicionais: servidor sem fila, posse simultânea de recursos e servidor infinito. 
Duas possibilidades foram avaliadas para o desenvolvimento destes recursos: 1 . incluílos no módulo de redes ou 2. disponibilizá-los na tela principal do ASiA. Como a segunda possibilidade permite a utilização destes novos recursos tanto para simulações no módulo de redes de computadores quanto em outras simulações, optou-se por disponibilizar os recursos na tela principal do ASiA. Nas próximas seções, a implementação de cada um destes recursos é detalhada.

\subsubsection{Servidor sem fila}

Nas redes de filas básicas, todo recurso tem uma fila associada ao mesmo, e um número variado de servidores. Entretanto, existem muitos modelos em que seus recursos não possuem fila, necessitando de um tratamento diferenciado dos demais. Nesses recursos, quando um cliente chega e não há servidores disponíveis para atendê-lo, deve-se definir uma política para nova tentativa de utilização desse recurso. Essa política chamada política de reescalonamento é determinada pelo usuário através de uma tabela onde são especificados os tempos para escalonar uma nova tentativa de utilização do recurso. Através dessa tabela, a cada tentativa mal sucedida de utilização de um recurso, um novo tempo é utilizado para escalonar a próxima tentativa.

Um exemplo de utilização de servidor sem fila pode ser vista na Figura 5.1 [ULS99]. Nessa figura está ilustrado o Modelo do Servidor de Arquivos do Sistema Distribuído Trice [SAN90]. Trice (Transportable Integrated Computing Environment) é um sistema computacional distribuído fracamente acoplado baseado em redes locais [SAN90] constituído por sub-redes conectadas a um anel central. O sistema de comunicação é organizado segundo o paradigma cliente-servidor, onde as estações de trabalho dos usuários operam como clientes, requisitando serviços específicos a um conjunto de servidores especializados.

O Modelo do Servidor de Arquivos do Sistema Distribuído Trice é representado por quatro recursos: os processadores Front-End, o processador central (CPU) e a unidade de disco.

A ação executada no servidor de arquivos, quando chega um novo pacote, consiste na requisição para utilização do PFEin. Se esse estiver ocupado, o pacote é descartado e deve ser 
reenviado ao servidor após um tempo específico. Existe um limite quanto ao número de tentativas para a transmissão de um pacote, uma vez que não existe fila de pedidos pendentes (o PFEin é representado por um recurso sem fila). Caso esteja disponível, o PFEin é reservado para o recebimento do pacote. Assim que o pacote for recebido, o PFEin é liberado. Após essa etapa, o processador central é requisitado para processar o pedido. Se estiver ocupado, o pedido é inserido na fila de espera, caso contrário seu processamento tem início.

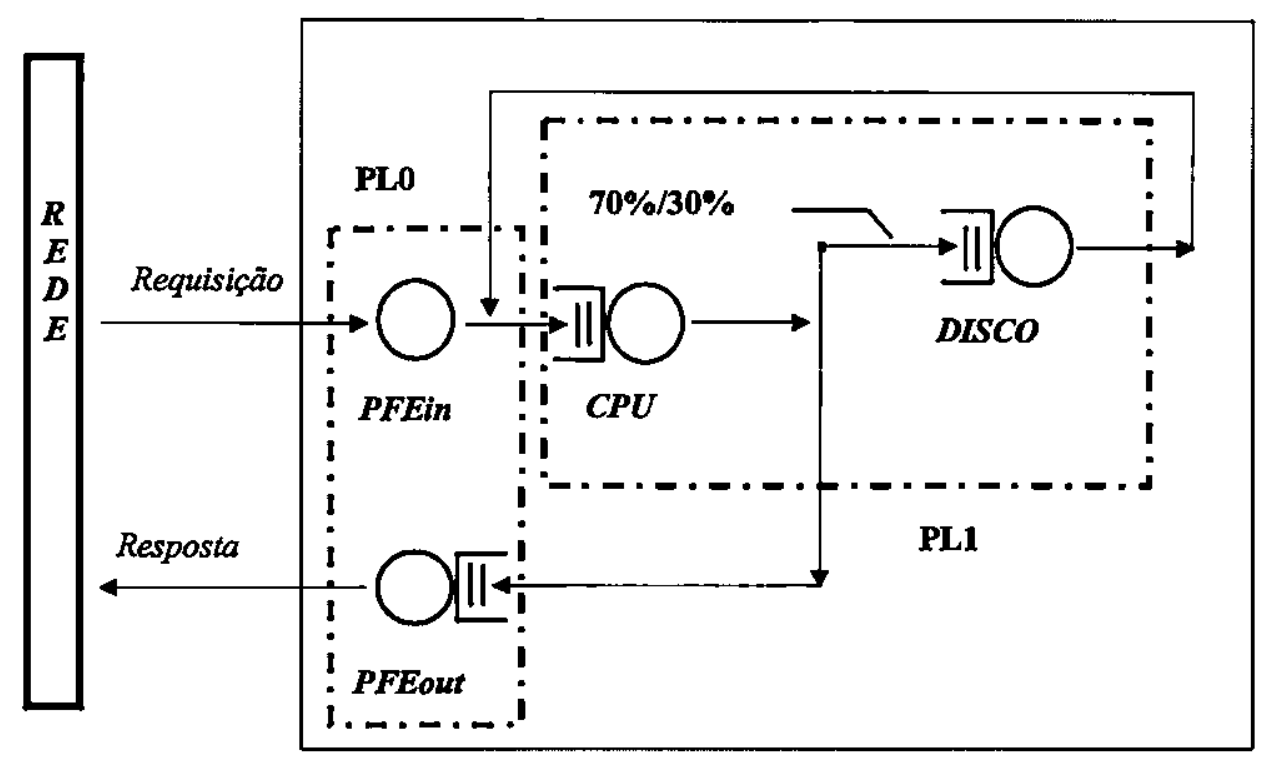

Figura 5.1: Modelo de Redes de Filas: Servidor de Arquivos do Sistema Distribuído Trice. Nessa configuração os processadores Front-End são agrupados em um processo lógico, e as unidades de processamento e disco são representadas em outro processo

Durante o processamento, pode ocorrer a necessidade de operações com a unidade de disco. Nesse caso, o processador central bloqueia o processamento do pedido e o transfere para o disco, prosseguindo sua atividade com o próximo pedido. O pedido é então inserido na fila de espera do disco e assim que o disco concluir as tarefas pendentes o mesmo é processado. Concluídas essas etapas, o PFEout é requisitado para efetuar a transferência de dados e a resposta é inserida em uma fila de espera de respostas a serem enviadas pela rede.

Assim, o comportamento do Processador "Front-End" de entrada ilustra a utilização de um servidor sem fila. 
$\mathrm{Na}$ versão original do $\mathrm{ASiA}$, a modelagem de servidor sem fila e os mecanismos de reescalonamento para esse tipo de recurso encontravam-se implementados no gerador de aplicações [SPO94a] , porém, não estavam disponíveis ao usuário no editor gráfico [SPO94b]. O editor gráfico foi então modificado acrescentando-se o recurso servidor sem fila e a parametrização dos mecanismos de reescalonamento.

Para isso foram implementadas todas as modificações necessárias à inclusão do ícone na barra de ferramentas e ao desenho do recurso na tela de edição gráfica e as interfaces para a geração da tabela de reescalonamento do recurso.

A inchusão de um servidor sem fila no ASiA envolve as seguintes modificações:

I. Inclusão de um ícone representando o recurso na barra de ferramentas e no desenho do recurso na tela de edição gráfica

O símbolo utilizado para a representação de servidor sem fila pode ser visto na Figura 5.2 onde a circunferência representa o servidor.

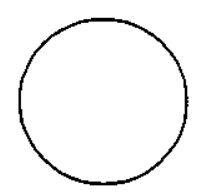

Figura 5.2: Servidor sem fila

O ícone deve inicialmente ser desenhado no Resource Workshop do compilador Borland C++ [BOR96]. O Resource Workshop é uma ferramenta que permite a geração de recursos gráficos que são os componentes da interface com o usuário. Esses componentes podem ser: caixas de diálogo, menus, bitmaps, ícones, dentre outros.

Uma vez desenhado o ícone, ele deve ser inserido na barra de ferramentas. $E$ todo o código referente ao posicionamento dos ícones, tratamento das ações do mouse sobre a barra de ferramentas e desenho dos ícones deve ser modificado para a inserção de um novo ícone. $O$ código para o desenho do ícone na tela de edição gráfica e o tratamento referente a inserção do desenho nas tabelas de especificação gráfica devem também ser implementados. 


\section{Inclusão de uma interface (através de caixa de diálogo) para parametrização do recurso.}

A Figura 5.3 mostra a utilização do recurso sem fila no ASiA e sua parametrização. Na caixa de diálogo "Parametrização do Recurso", o item "Tabela de Tempos" sublinhado em vermelho, indica que o usuário irá utilizar reescalonamento. Quando o usuário pressiona o botão "Gerar", abre-se a caixa de diálogo "Reescalonamento" que pede os valores (tempos) para a geração de uma tabela. Quando o usuário coloca um valor, ele deve pressionar "Ok". Depois do último valor da tabela que o usuário deseja gerar ele deve pressionar "Fim", que irá fechar essa caixa de diálogo. Essa tabela de reescalonamento contém os tempos em que serão feitas as novas tentativas de uso do servidor. Para um cliente que tenta usar o servidor e ele está ocupado é utilizado o primeiro tempo da tabela para reescalonar o cliente. Se o cliente novamente não foi atendido, um novo tempo (o próximo da tabela) é utilizado para nova tentativa, e assim sucessivamente até que o cliente seja atendido ou sejam utilizados todos os tempos da tabela e o cliente não obteve sucesso e sai do sistema.

A caixa de diálogo "Reescalonamento" (Figura 5.3) foi criada no Resource Workshop e ela faz a captação dos valores que serão utilizados para reescalonar o cliente. Esses valores são guardados em um arquivo de extensão ".DAT". Os códigos para tratamento de arquivo foram inseridos nos locais adequados e foi criado um novo arquivo "REESC.CPP" que contém as funções que manipulam a lista de dados da tabela de tempos. 


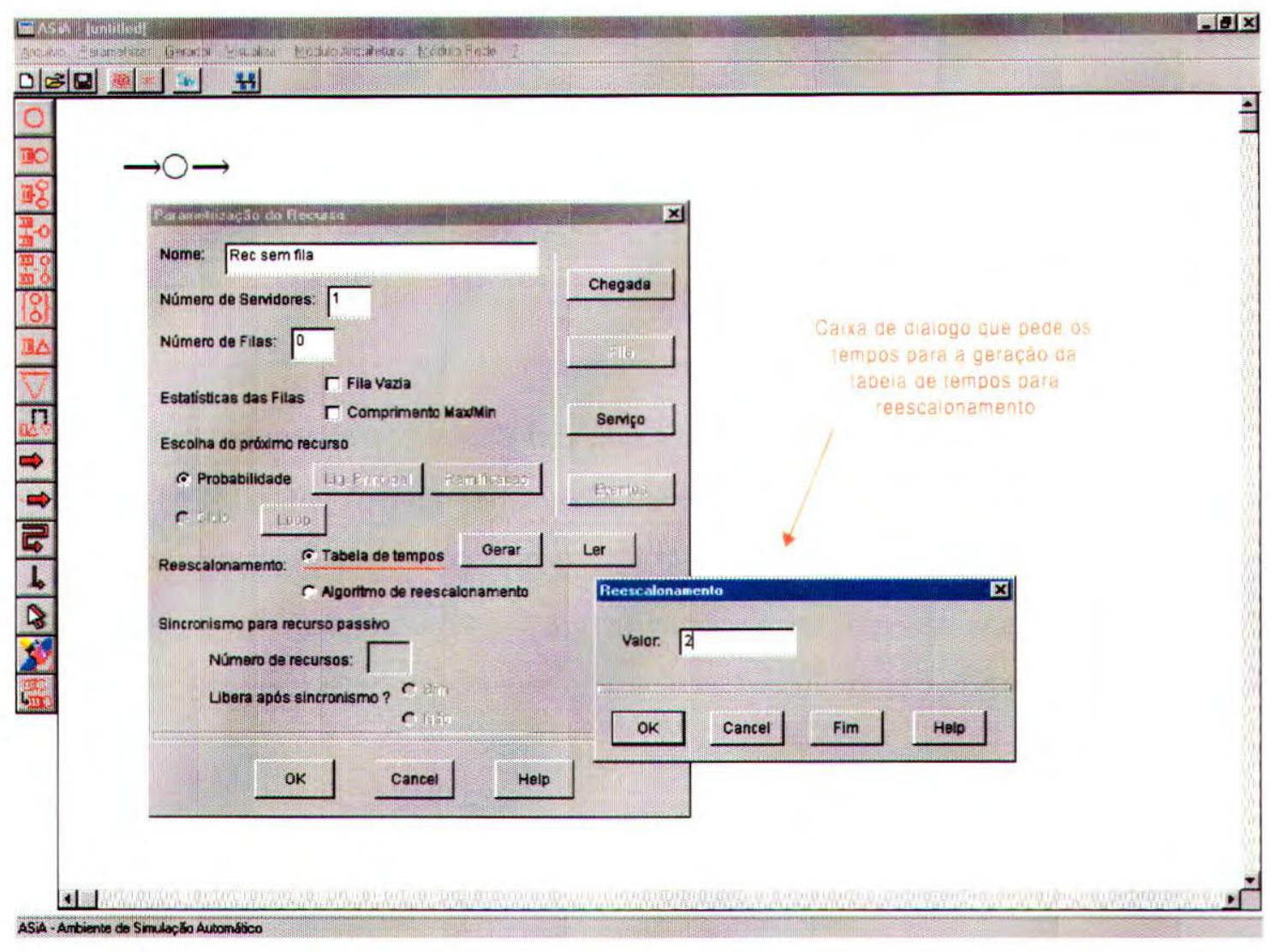

Figura 5.3: Tela do ASiA

\section{Inclusão dos dados a serem enviados para o gerador de aplicações.}

Os parâmetros obtidos pela caixa de diálogo são enviados para o Gerador de Aplicações através de arquivos, conforme descrito na seção 4.5.2.

Inseriu-se o código necessário para obtenção dos tempos de reescalonamento, para verificação de consistência dos dados fornecidos pelo usuário e ativou-se o código que indicava a presença de recurso sem fila. $\mathrm{Na}$ versão original do ASiA o Editor não implementava o recurso sem fila, mas possuía os dados que indicavam a presença deste recurso. Esses dados estavam inativos e foram modificados de modo a receberem os valores fornecidos pelo usuário.

Com a implementação dessas modificações, o recurso servidor sem fila torna-se disponível no ASiA. Na tela de fundo da Figura 5.3, pode-se observar a existência do ícone 
para o recurso incluído ( $1^{\circ}$ ícone da barra de ferramentas vertical) e a sua "presença" na tela de edição gráfica.

\subsubsection{Posse simultânea de recursos}

Posse simultânea de recursos significa que vários recursos podem estar alocados a um mesmo usuário ao mesmo tempo. A posse simultânea de recursos em redes de filas ocorre, por exemplo, em modelos de sistemas de "I/O", nos quais um cliente requer o serviço de um disco além do serviço adicional de um canal para a transferência dos dados. Neste caso, o cliente deve estar de posse tanto do disco quanto do canal de comunicação para então iniciar a transferência de dados.

No modelo da rede Ethernet [SOA90] da Figura 5.4 pode-se observar a utilização deste recurso. Este modelo detalha os eventos que ocorrem no protocolo CSMA/CD e ilustram o uso de posse simultânea em redes de computadores.

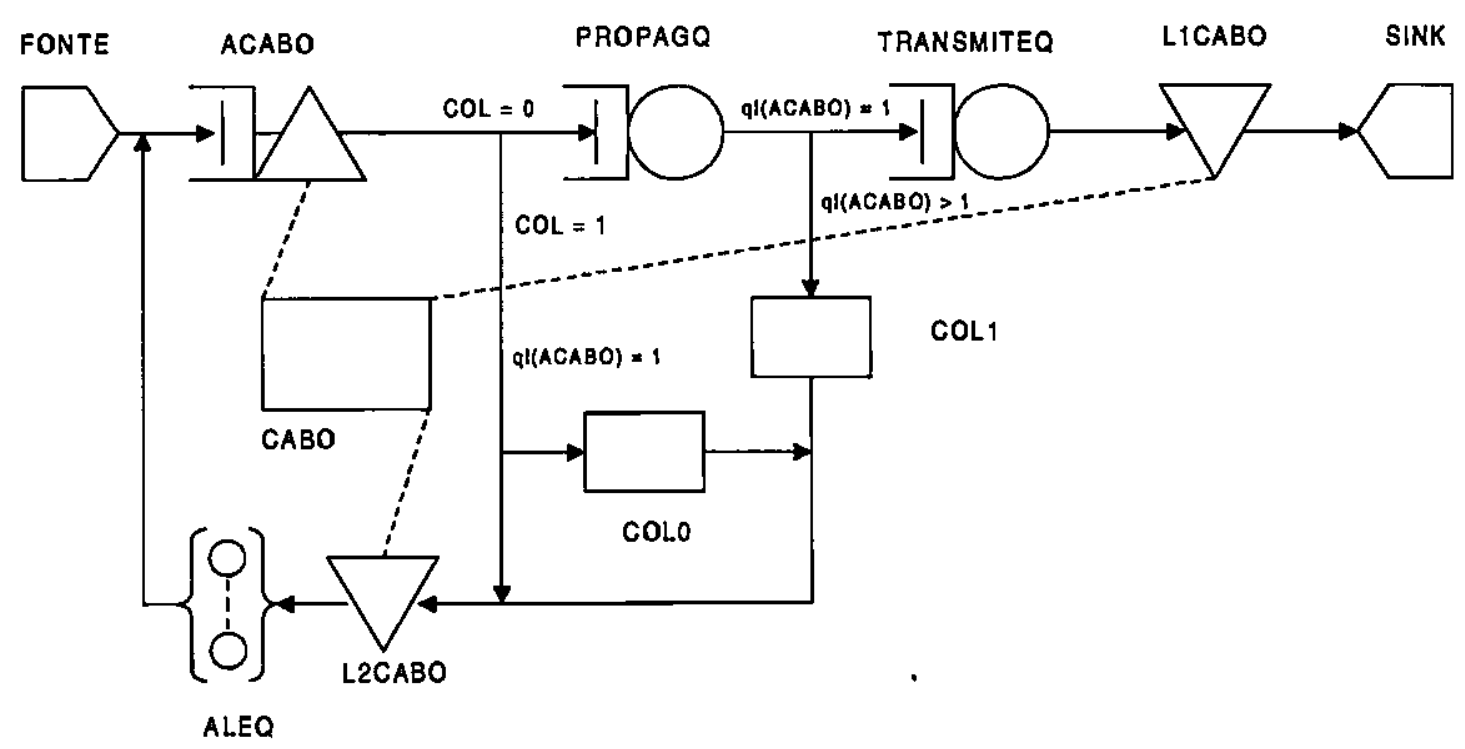

Figura 5.4: Modelo de rede Ethernet 
Neste modelo, o canal de transmissão é representado por um centro de serviço passivo (CABO), o retardo de propagação pelo centro ativo PROPAGQ, e o retardo de transmissão pelo centro ativo TRANSMITEQ. COL é uma variável global que quando igual a 1 representa que duas ou mais estações estão transmitindo simultaneamente. Quando o canal está livre, um usuário pode alocá-lo, passando em seguida para o nó do retardo de propagação. Se algum outro usuário chegar durante o retardo de propagação, $\mathrm{ql}(\mathrm{CABO})>1$, a variável $\mathrm{COL}$ é levada a 1 , indicando colisão. Se, por outro lado, um usuário chegar enquanto o canal está em uso, mas depois do retardo de propagação, ele simplesmente espera a liberação do cabo. Depois que um usuário termina seu retardo de propagação, ele é encaminhado ao nó de transmissão, se não ocorreu colisão. Em caso contrário, ele libera o cabo e espera um tempo aleatório no nó ALEAQ, para depois tentar nova transmissão. Os outros usuários envolvidos na colisão liberam o cabo, passando também para o nó de espera ALEAQ, sendo que o último dos usuários leva a variável COL a 0.

O canal de transmissão (ACABO) é representado por um servidor passivo, pois ele não fornece serviços, mas deve ser alocado para o cliente para que este possa transmitir sua mensagem. $O$ canal de transmissão fica então alocado ao cliente até o término de envio da mensagem ou quando o cliente não conseguiu enviar a sua mensagem, desaloca o canal e entra em ALEQ até nova tentativa de transmissão.

Quando se representa um modelo através de redes de filas convencionais, a posse simultânea de recursos não pode ser especificada. Deve-se então recorrer a estruturas de redes de fila estendidas. Desse modo, uma possível representação é a utilização dos símbolos da ferramenta RESQ (RESearch Queuing Package) empregada na modelagem e simulação discreta orientada a processos [SOA92].

Para a representação de posse simultânea é necessária a utilização de recursos passivos que são utilizados para modelar um recurso com número limitado de elementos. Nos recursos passivos não existem servidores realizando serviços, mas apenas representando um número finito de elementos de um recurso, tais como "buffers", unidades de memória, canais de comunicação, etc. Os recursos que oferecem algum tipo de serviço aos clientes são denominados recursos ativos, tais como processadores, discos, etc. Os recursos passivos são alocados a um cliente enquanto o mesmo cliente recebe serviços em outros recursos e posteriormente são liberados em algum outro ponto do modelo. 
No exemplo do disco tem-se que o cliente requer um acesso ao disco, mas para utilizar este acesso necessita estar de posse do canal de comunicação. Neste caso, o canal seria representado por um recurso passivo e o disco por um recurso ativo.

A inclusão de posse simultânea no ASiA foi implementada seguindo os mesmos passos apresentados na seção anterior para a inclusão de recurso sem fila:

I. Inclusão de um ícone representando o recurso nạa barra de ferramentas e no desenho do recurso na tela de edição gráfica.

Neste caso é necessária a definição dos três ícones representados na Figura 5.5. O símbolo 1 indica a alocação do servidor ao cliente e o símbolo 2 representa a sua liberação. Um terceiro símbolo (3) é utilizado para estabelecer a relação entre a alocação e liberação de um recurso.

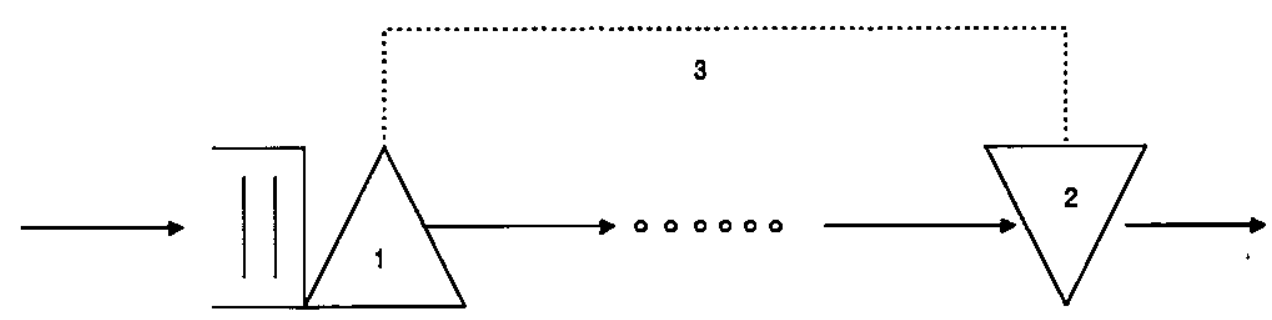

Figura 5.5: Posse simultânea de recursos

Os ícones inseridos na barra de ferramentas podem ser vistos na Figura 5.6, onde o primeiro ícone indicado representa a alocação do servidor, o segundo a liberação do servidor e o terceiro ícone é a linha pontilhada que une a alocação com a liberação do servidor. 


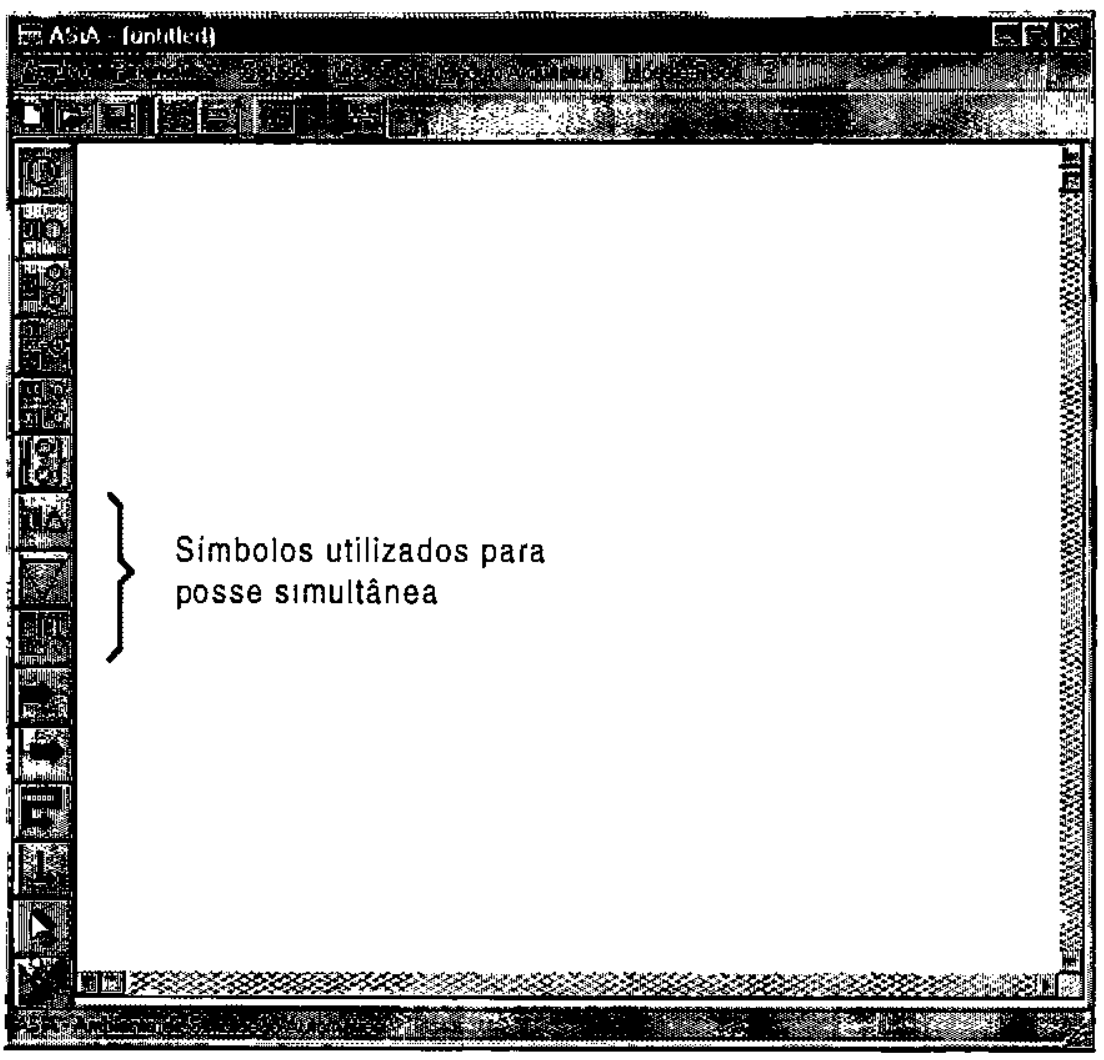

Figura 5.6: Tela do ASiA mostrando os ícones que representam posse simultânea de recursos

No exemplo do disco (Figura 5.7) o cliente quer utilizar o canal e o disco simultaneamente. Desse modo, o canal de comunicação (representado pelo servidor passivo) é alocado ao cliente, que também aloca o disco. Uma vez utilizado o disco e o canal, o cliente sai do sistema, liberando o canal e o disco (libera canal - Figura 5.7). 


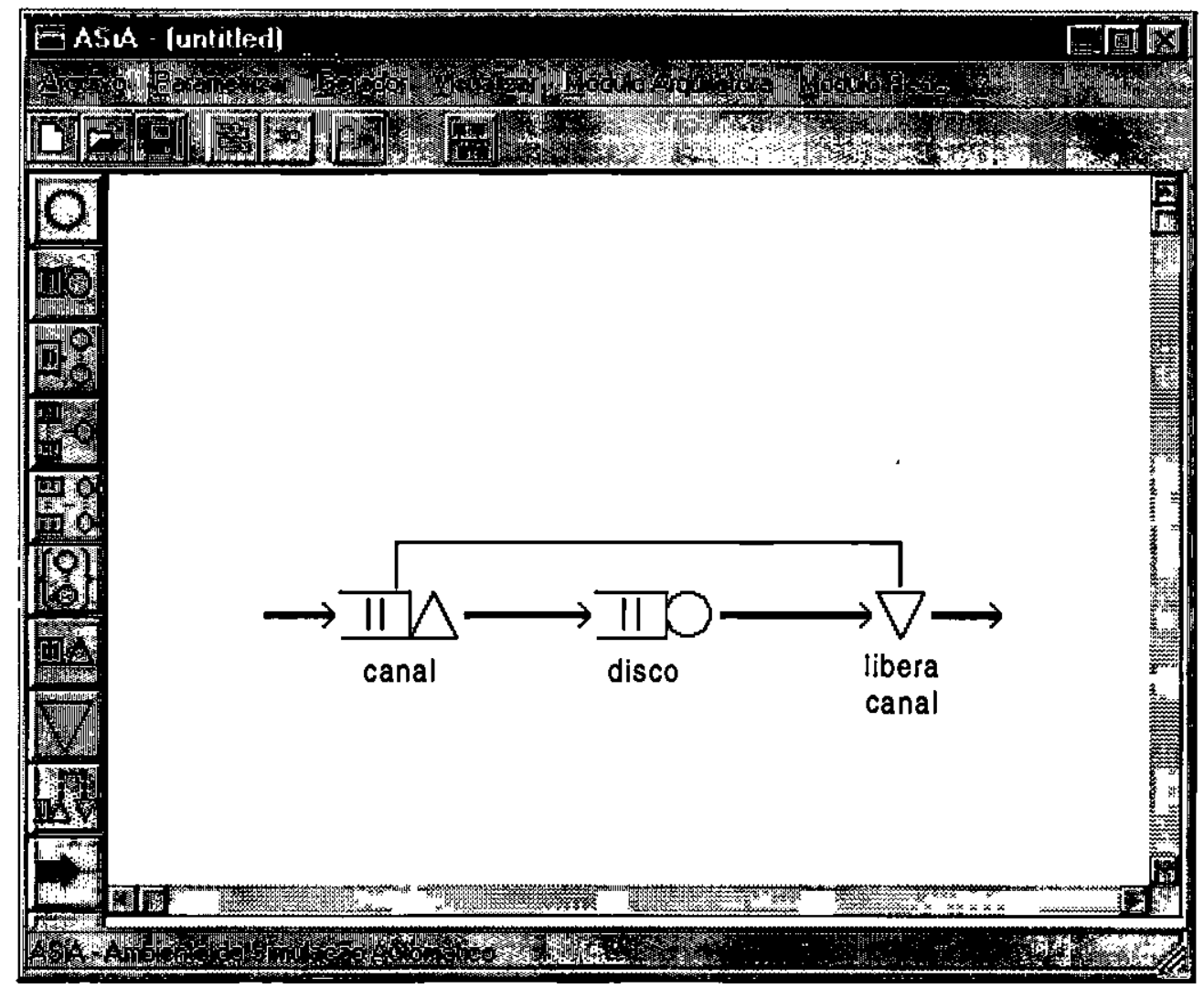

Figura 5.7: Tela do ASiA com um exemplo em redes de filas

Para a inclusão dos ícones da posse simultânea na barra de ferramentas foram feitas as mesmas ações descritas no item anterior.

\section{Inclusão de uma interface (através de caixa de diálogo) para parametrização do recurso}

A posse simultânea foi implementada no editor gráfico através da inclusão de dois novos itens na caixa de diálogo Parametrização do Recurso: "número de recursos" e "libera após sincronismo?" (indicados na Figura 5.8 em vermelho). Através desses parâmetros o usuário indica em "número de recursos" com quantos recursos está sincronizado (indicando 0 se não está sincronizado com nenhum recurso) e em 'Libera após sincronismo?” se o recurso deve ser liberado imediatamente após o sincronismo. 


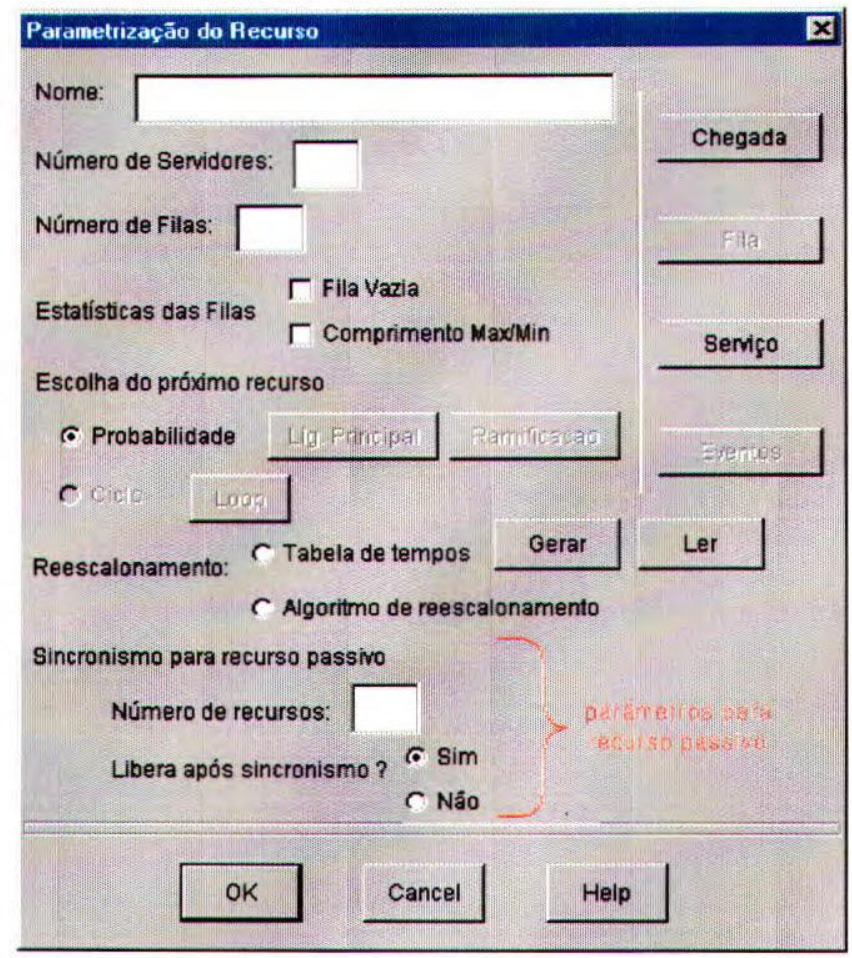

Figura 5.8: Caixa de diálogo de parametrização do recurso

Na Figura 5.9 tem-se um exemplo de uso de posse simultânea de recursos e a sua parametrização. No exemplo, um cliente chega e é atendido no recurso 1. Desse recurso ele vai para o recurso 2 (recurso passivo) que é alocado e então o cliente será servido pelo recurso 3 ou pelo recurso 4. Depois de servido o cliente vai para o recurso 5 (liberação do recurso 2) e sai do sistema.

A parametrização dos recursos 1, 3 e 4 continua do mesmo modo como na versão anterior do ASiA. A parametrização do recurso 2 pode ser vista na Figura 5.9, onde além dos dados comuns aos outros recursos, o usuário deve também fornecer os dados de sincronismo para recurso passivo. $\mathrm{O}$ recurso 5 não necessita de parametrização.

No exemplo dado, o usuário deve colocar o número 2 para Número de recursos e Sim para Deve liberar após sincronismo ?. O número 2 indica que existem 2 recursos, os recursos 3 e 4 entre os recursos de início de posse simultânea e fim de posse simultânea e o Sim indica que o recurso passivo deve ser liberado após o cliente ter utilizado os serviços dos recursos 3 ou 4. 


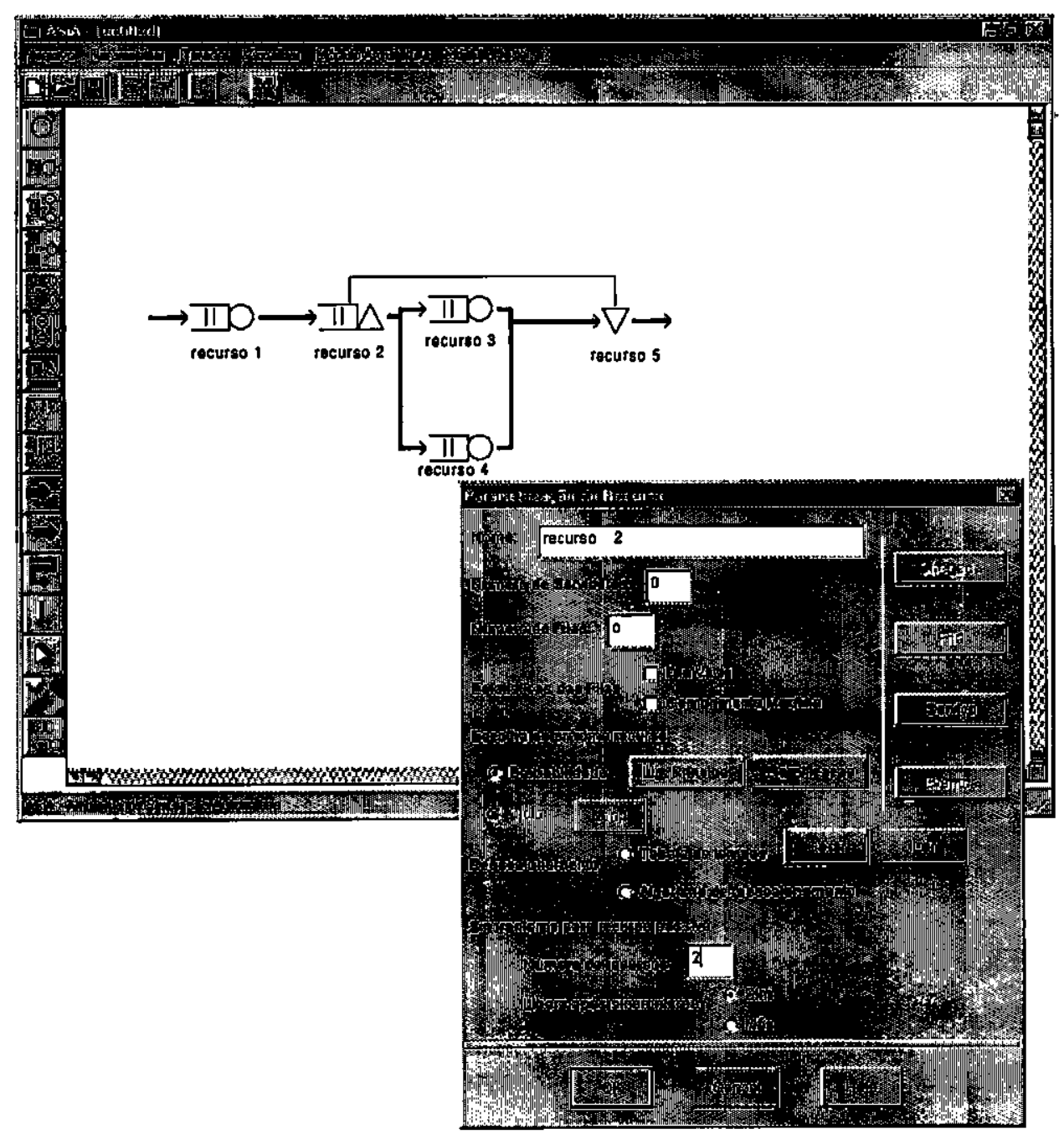

Figura 5.9: Tela do ASiA com um exemplo de posse simultânea e a parametrização do recurso passivo.

No gerador a posse simultânea de recursos já se encontrava implementada [SPO94a].

\section{Interface com o gerador de aplicações}

Os parâmetros obtidos pela caixa de diálogo Parametrização de recursos são enviados para o Gerador de Aplicações através de arquivos. O código necessário para obtenção dos dados: Número de recursos e Libera após sincronismo? e para verificação de consistência dos dados foi inserido no local apropriado e todos os dados referentes a posse simultânea foram 
inseridos de modo ao gerador de aplicações obter todos os dados para a geração do programa de simulação. Na versão original do ASiA o Editor não implementava a posse simultânea de recursos mas possuía os dados que indicavam a presença deste recurso. Esses dados estavam inativos e foram modificados de modo a receberem os valores fornecidos pelo usuário.

\subsubsection{Servidor infinito}

Servidor infinito é um recurso que sempre tem espaço para acomodar a demanda por servidores e, portanto não existe a formação de filas. As requisições que chegam são prontamente atendidas. Um exemplo de servidor infinito é a utilização de terminais de um sistema de tempo compartilhado. Ou mesmo o canal de comunicação na modelagem da rede Aloha, uma vez que todas as estações sempre imaginam que o canal de comunicação está livre e que a transmissão pode ser efetuada.

A Figura 5.10 apresenta um modelo [SOA90] para o protocolo Aloha. Nesse modelo vê-se a importância do servidor infinito para a modelagem de redes de computadores. A modelagem do protocolo Aloha constitui um conjunto de regras para a comunicação através de uma rede de rádio-difusão via satélite, chamada Aloha. Uma descrição mais detalhăda desse protocolo é dada na seção 3.5.1.

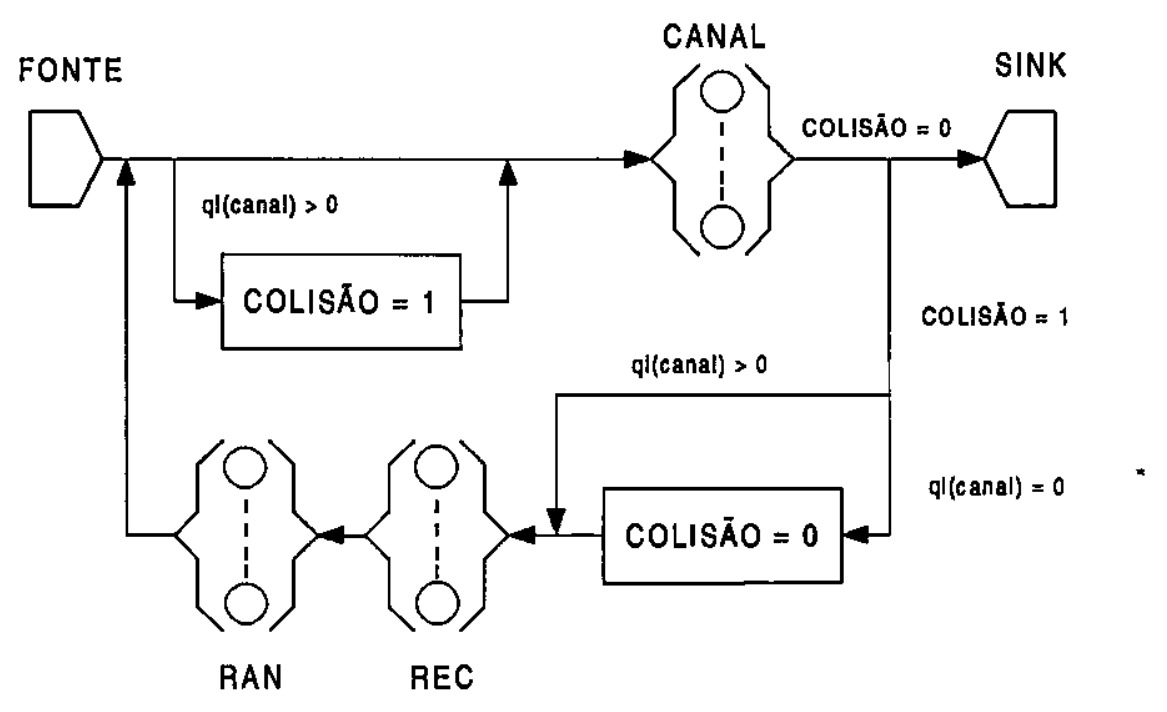

Figura 5.10: Protocolo Aloha 
Na Figura 5.10, COLISÃO é uma variável global que se igual a 1, indica duas ou mais estações transmitindo simultaneamente. Esta variável é levada a 1 sempre que o número de usuários no canal for maior que 0 (ql $(\mathrm{CANAL})>0)$. A variável é zerada, quando após a transmissão de um pacote, nenhum outro estiver sendo transmitido ( $1(\mathrm{CANAL})=0$ ). Após a transmissão de uma mensagem que colidiu, é necessário aguardar um tempo de reconhecimento (REC) e um tempo randômico (RAN), antes de tentar nova transmissão.

O CANAL é representado por um servidor infinito porque todas as estações podem tomar posse do canal, sem precisar entrar em uma fila. $O$ mesmo caso pode ser visto para REC (tempo de reconhecimento) e RAN (tempo randômico), pois as estações não precisam entrar em uma fila para aguardar esses tempos para tentativa de nova transmissão.

Duas abordagens podem ser consideradas para a implementação de um servidor infinito.

\section{a. Recurso com um número muito grande de servidores, de forma a não gerar filas.}

Nesta abordagem, a parametrização do recurso deve ser feita pelo usuário especificando um número de servidores tal que no sistema o número de clientes nunca exceda o número de servidores. Para um número de servidores preestabelecido (por exemplo, 10000) não há garantias de que não haverá formação de filas. Por outro lado, um número grande qualquer causa sobrecarga na simulação para sistemas cujo número de clientes nunca é maior que 10. Desse modo, a melhor solução é a parametrização feita pelo usuário.

\section{b. Utilização de "think time"}

Nesta abordagem os clientes ficam no servidor por um tempo aleatório até que seja completado o seu serviço. Um dos problemas dessa abordagem é que o usuário não terá como um dos resultados da simulação a utilização desse servidor.

A abordagem (a.) foi adotada na implementação do ASiA devido a maior flexibilidade apresentada. 
A inclusão do servidor infinito no ASiA foi implementada seguindo os mesmos passos apresentados na seção anterior para a inclusão de posse simultânea de recursos:

I. Inclusão de um ícone representando o recurso na barra de ferramentas e no desenho do recurso na tela de edição gráfica.

Para a implementação de servidor infinito foi incluído um ícone (Figura 5.11) no editor gráfico e todas as rotinas necessárias para o tratamento do desenho do recurso na tela.

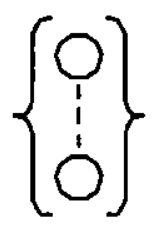

Figura 5.11: Servidor infinito

Os passos para a inclusão do ícone e para o desenho na tela são os mesmos descritos nas seções anteriores para o servidor sem fila e para posse múltipla de recursos.

\section{Inclusão de uma interface (através de caixa de diálogo) para parametrização do Recurso}

A caixa de diálogo Parametrização de recurso não precisou ser modificada para a parametrização de servidor infinito. Ela apenas foi adaptada para não permitir que o usuário forneça o número de filas, uma vez que a idéia de servidor infinito é a não existência de filas. Um número grande (99) está inicialmente colocado em número de servidores como sugestão. Cabe ao usuário modificá-lo de modo a adaptar esse múmero à simulação do sistema que está sendo modelado (Figura 5.12). 


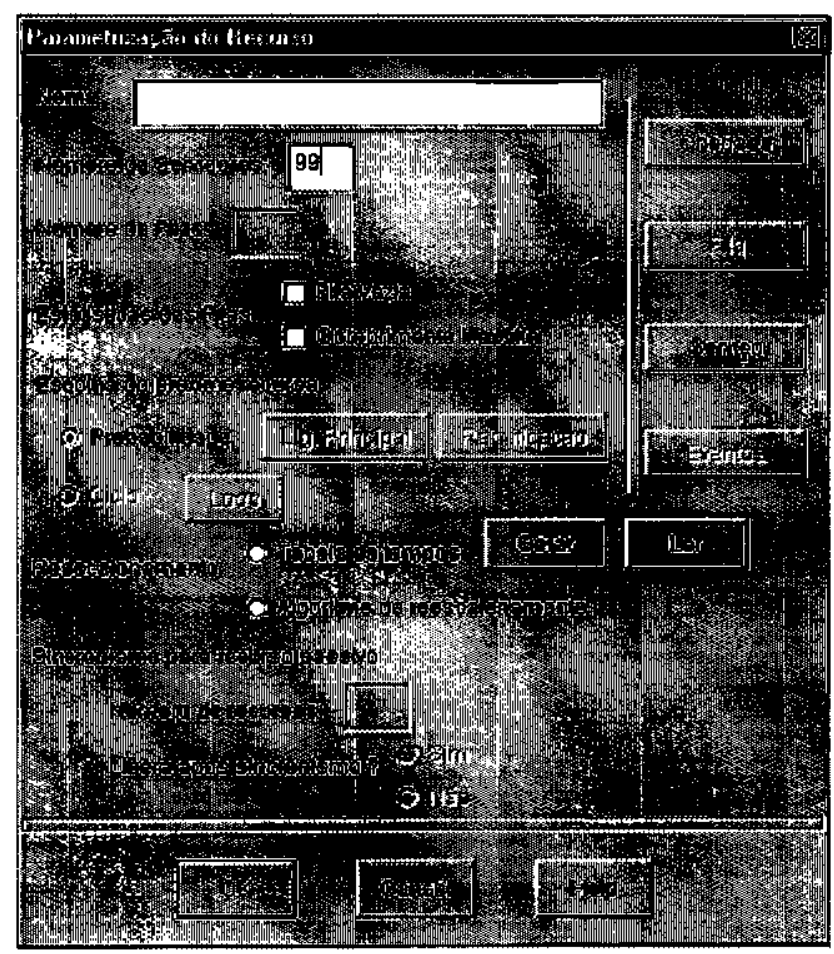

Figura 5.12: Caixa de diálogo Parametrização de recurso para o recurso servidor infinito

\section{Inclusão dos dados a serem enviados para o gerador de aplicações}

Os dados a serem enviados para o gerador de aplicações são os mesmos dados enviados pelos outros recursos (servidor com uma fila, vários servidores com uma fila, etc.). Desse modo não houve a necessidade de maiores alterações na interface com o gerador. Apenas foi inclúdo um novo recurso (servidor infinito) no tipo de recurso (um dos parâmetros dos dados do recurso). O tipo de recurso é um número, ou seja, o número 1 indica um servidor com uma fila, o número 2 indica uma fila com vários servidores e assim por diante. Um novo número foi incluído para indicar servidor infinito, o número 5.

Os novos botões inchuídos na barra de ferramentas podem ser vistos na Figura 5.13. Também está ilustrado um modelo ilustrando a utilização das novas funcionalidades do ASiA. 


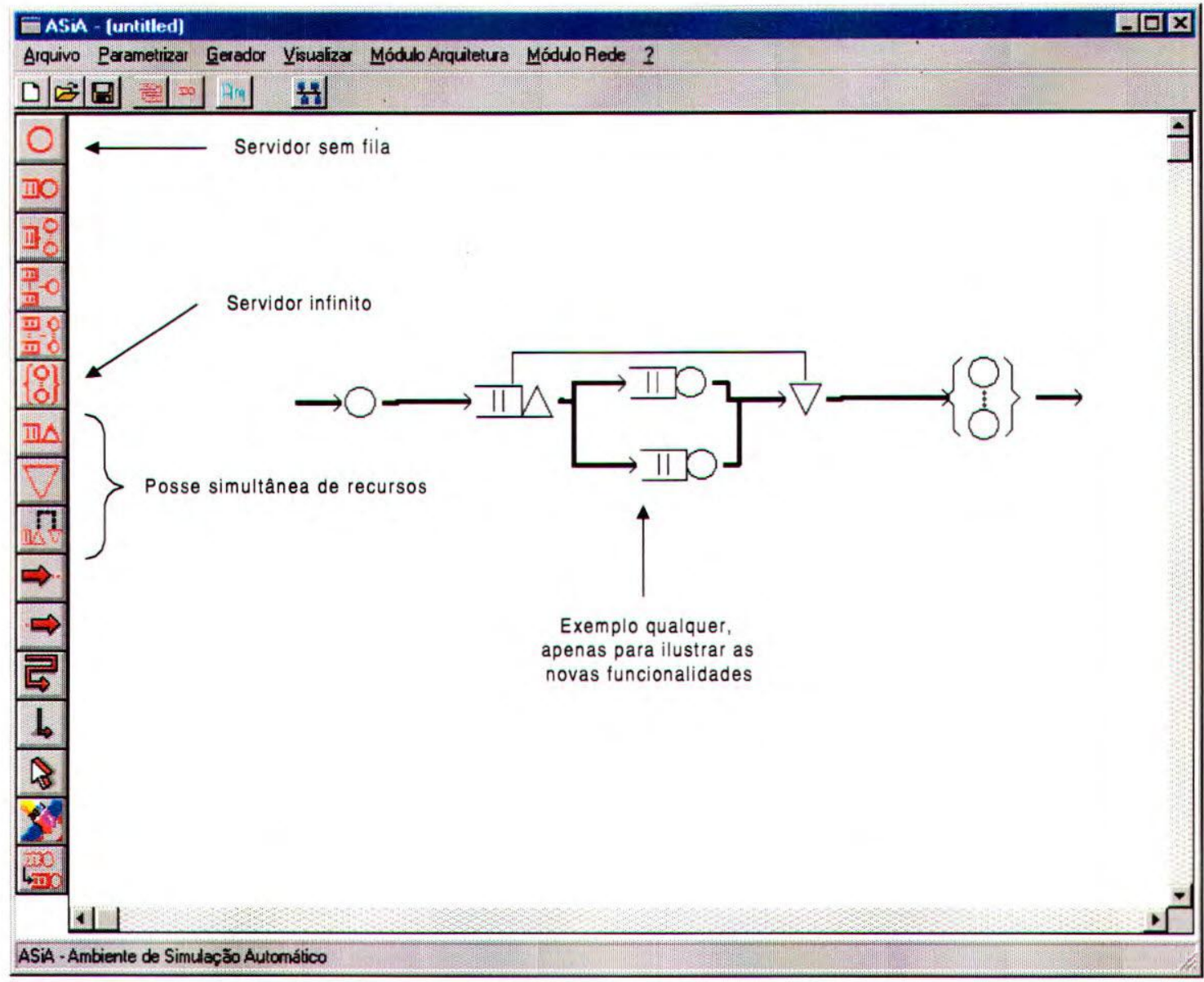

Figura 5.13: Tela do ASiA com as novas funcionalidades

\subsection{Considerações finais}

Neste capítulo foi detalhada a implementação de três novos recursos incluídos no ASiA: servidor sem fila, posse múltipla de recursos e servidor infinito. Com esses novos recursos os modelos que podem ser representados no $\mathrm{ASiA}$ foram significantemente ampliados uma vez que modelos mais complexos e com mais detalhes podem ser modelados na nova versão do ASiA.

No próximo capítulo está descrita a implementação do Módulo de Redes. 
. 


\section{Módulo de Redes}

Este capitulo discute a implementação do módulo de redes para simulação de redes locais de computadores.

\subsection{Introdução}

As modificações introduzidas no ASiA, detalhadas no capítulo anterior, tiveram como objetivo preparar o ambiente para a implementação do Módulo de Redes de Computadores.

Esse módulo, denominado Módulo Redes, tem como objetivo facilitar a construção de modelos que representem redes de computadores visando validação e avaliação de desempenho de redes de computadores através da simulação.

A avaliação de desempenho de redes de computadores vem tendo cada vez maior importância devido a crescente utilização de redes em todas as áreas do conhecimento humano. Assim é essencial a construção de ferramentas que facilitem o uso da avaliação de desempenho. E dentre as ferramentas de avaliação de desempenho a simulação tem destaque. O Ambiente de Simulação Automático ASiA que está em desenvolvimento no Grupo de Sistemas Distribuídos e Programação Concorrente do ICMC facilita o uso da simulação pois provê para o usuário facilidades gráficas para a construção do modelo e possui parametrização simples que simplifica a modelagem de um sistema.

No capítulo anterior foi descrita a inclusão de diversos recursos que não existiam na versão original do $\mathrm{ASiA}$, mas que são importantes para o trabalho de mestrado descrito aqui. Esses recursos foram adicionados aos recursos já existentes para que pudesse ser implementado o módulo de simulação de redes de computadores.

A nova versão do ambiente ASiA desenvolvido permite ao usuário, através do módulo de redes de computadores, fazer a escolha da rede que pretende simular, parametrizar os dados de rede de interesse, simular e obter os resultados que desejar. O módulo de redes 
permite que o usuário faça uso dos modelos já prontos dé redè, tornando a utilização do ASiA para simular redes de computadores mais simples para usuários que ainda não estão familiarizados com a teoria de redes de filas, simulação, etc. A flexibilidade do ASiA não é atingida pelo módulo implementado, uma vez que usuários mais experientes podem continuar a implementar seus próprios modelos ou até mesmo utilizar os modelos sugeridos pelo ASiA como base para implementações mais sofisticadas.

O ASiA foi preparado para a inclusão das simulações de redes de computadores, a partir de um botão na tela principal, onde o usuário aciona o módulo de redes e faz a escolha da rede que pretende simular. Foram incluídos novas caixas de diálogo e novos botões na barra de ferramentas. Foi criado um novo gabarito para o gerador de aplicações que contém as primitivas necessárias que não faziam parte do gabarito já existente. Esse novo gabarito foi incluído no gerador e foram criadas as funções necessárias para a simulação das redes no ambiente ASiA.

A parametrização das redes já definidas pode ser modificada, com o intuito de se determinar a influência de diferentes valores no desempenho de cada rede.

O Módulo Rede foi implementado utilizando-se as ferramentas já existentes no ASiA. Desse modo, o módulo foi desenvolvido na linguagem $C$, utilizando-se o compilador Borland $\mathrm{C}+5.01$ e o ambiente Windows95.

Nas próximas seções é detalhada a implementação do Módulo Rede.

\subsection{Implementação do módulo de redes no ASiA}

O Ambiente de Simulação Automático (ASiA) sofreu diversas modificações devido a necessidade de alterações em diversos pontos. Uma das modificações foi quanto a interface gráfica. Novos recursos foram colocados à disposição do usuário, como descrito no capítulo anterior e foram incluídos também botões para ativação do módulo de rede.

O Módulo Rede pode ser ativado através da tela principal do ASiA, utilizando-se a opção Ativar do memu Módulo Rede ou o ícone que ativa o módulo de rede da barra de 
acesso rápido (Figura 6.1). O módulo de redes é ativado do mesmo modo que o módulo Arquitetura [BRU97] que permite ao usuário a simulação de arquiteturas de computadores.

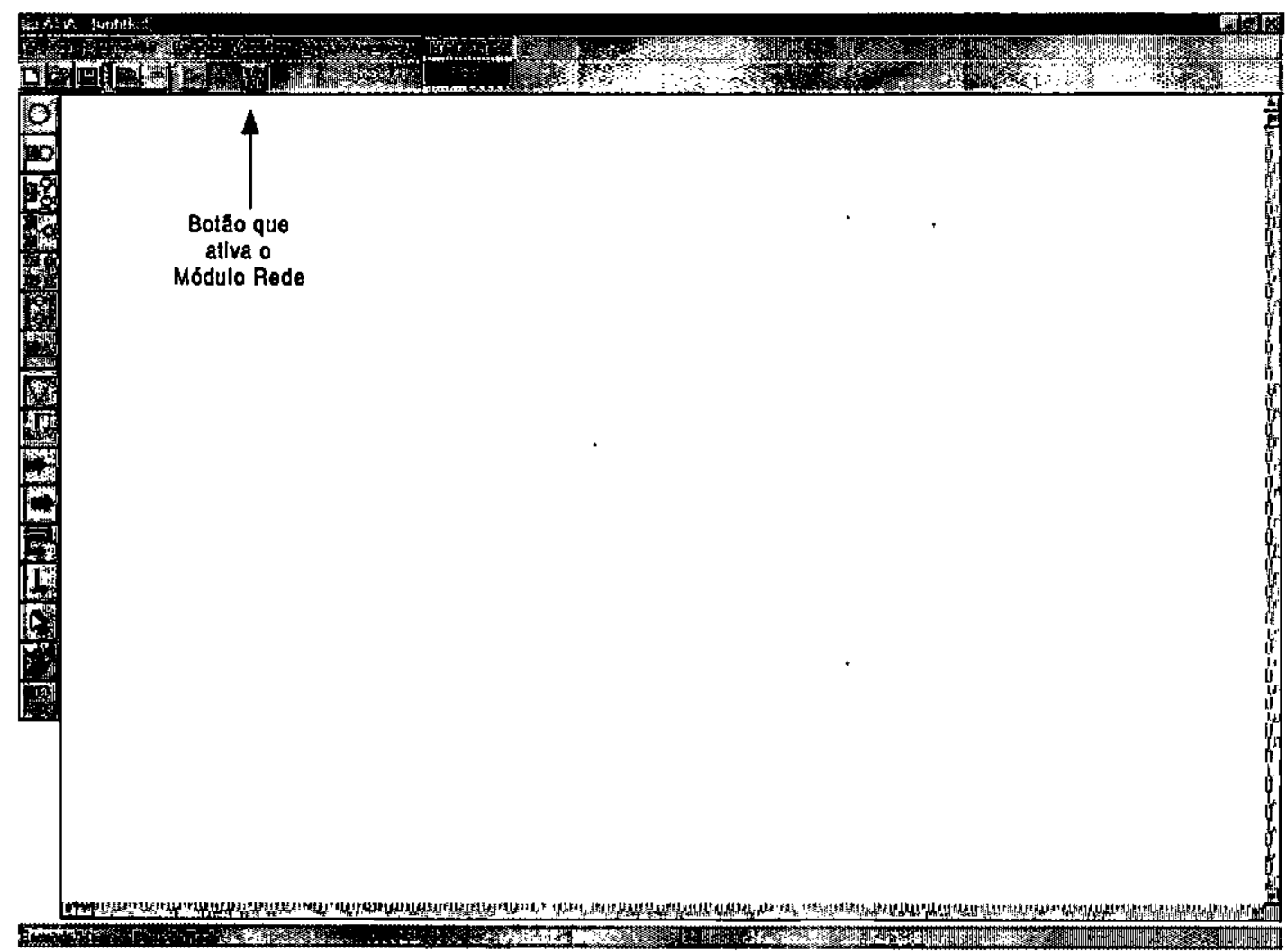

Figura 6.1:Tela principal do ASiA

Da tela principal do ASiA (Figura 6.1), o usuário acessa a interface do usuário do módulo de redes e faz a escolha do tipo de rede que quer simular, se alguma das redes já prédefinidas ou se pretende construir sua própria rede.

A Figura 6.2 mostra a visão geral do Módulo Rede, nele está descrito o fluxo das ações que ocorrem no ASiA quando o módulo rede é acionado. 


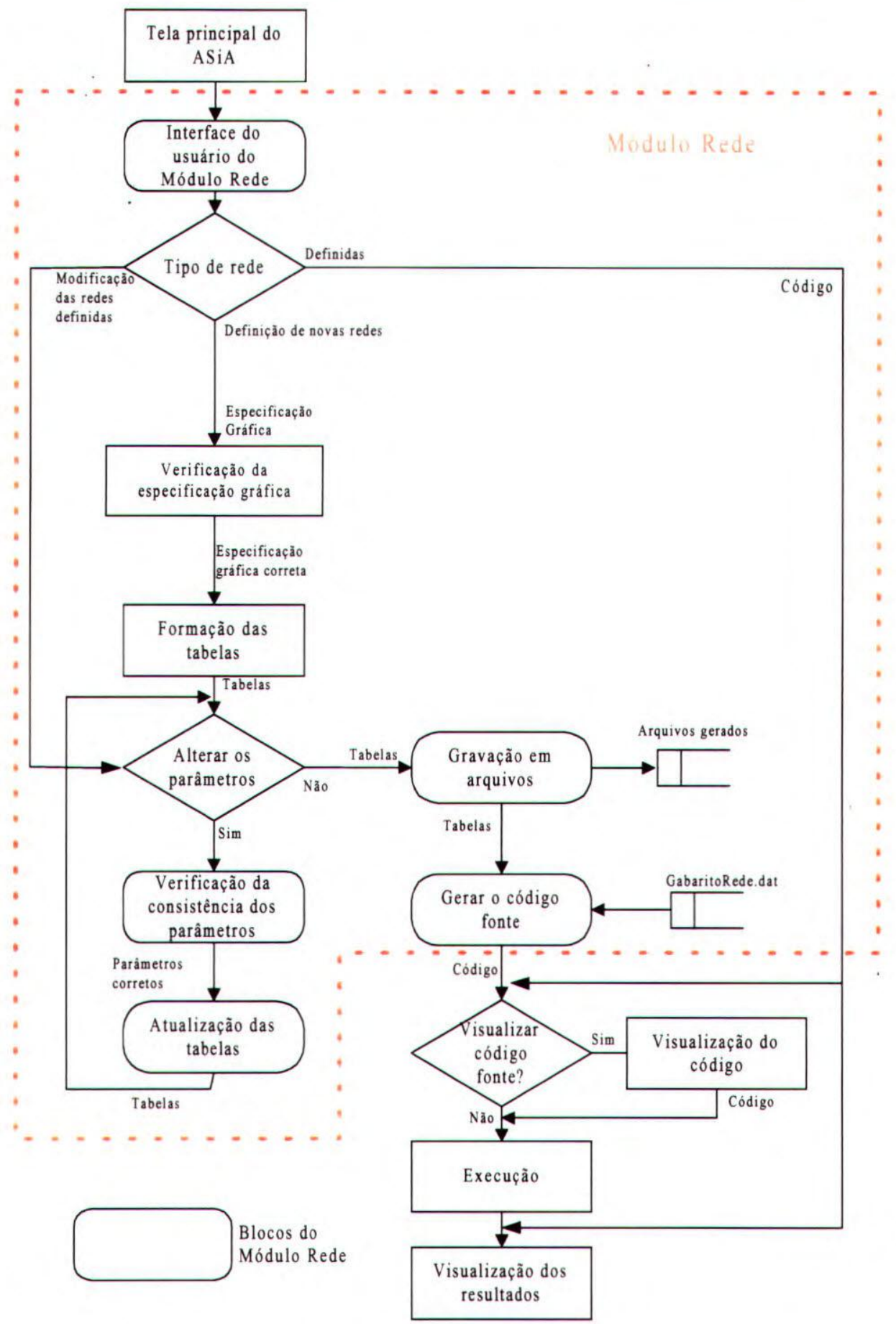

Figura 6.2: Visão geral do módulo de simulação de redes

As redes já definidas no Módulo Rede contêm o código fonte e resultados já elaborados. Os passos que devem ser seguidos pelo usuário para obtenção dos dados consiste 
simplesmente em escolher a rede e visualizar ou o código gerado (qué pode ser alterado por usuários mais experientes) ou os resultados.

Para o caso em que se pretende utilizar uma das redes definidas, mas com parâmetrso diferentes do padrão, deve-se escolher a rede e passar para os passos onde serão efetuadas modificações nos parâmetros da rede. A cada etapa de modificação dos parâmetros, o Módulo Rede faz uma verificação da consistência dos parâmetros e a atualização das tabelas. Uma vez encerrada a alteração dos parâmetros, estes são gravados em arquivos e o Módulo Rede passa para a geração do código fonte, baseando-se em um gabarito pré-definido.

$\mathrm{Na}$ definição de novas redes o editor gráfico do $\mathrm{ASiA}$ deve ser utilizado. Isto é, o modelo de rede deve ser desenvolvido utilizando os recursos padrões do ASiA (tanto aqueles que já existiam quanto os novos - servidor sem fila, servidor infinito e posse múltipla de recursos). Após a definição do modelo a sua consistência deve ser verificada (bloco Verificação da especificação gráfica - Figura 6.2). O usuário deve então fornecer os parâmetros, dos quais é verificada a consistência, e as tabelas são atualizadas e gravadas em arquivo. Os dados das tabelas são utilizados em conjunto com o GabaritoRede.dat para a geração do código. Após esse passo segue-se o fluxo definido no ASiA.

Nas próximas seções serão detalhados os blocos que compõe o Módulo Rede: Interface do usuário do Módulo Rede, Verificação da consistência dos parâmetros, Atualização das tabelas, Gravação dos arquivos e Gerar o código fonte.

\subsubsection{Interface com o usuário}

A Interface do usuário do Módulo Rede é responsável pela interface gráfica com o usuário, que é ativada quando o botão Módulo Rede é ativado ou quando o usuário escolhe Ativar no Módulo Rede na barra de menus (Figura 6.1).

Quando o usuário seleciona a ativação do "Módulo Rede", a caixa de diálogo "Tipos de Rede" (Figura 6.3) é aberta e o usuário seleciona qual rede quer simular. Se o usuário escolher as redes pré-definidas Ethernet ou Token Ring, a rede correspondente é desenhada na tela. Caso contrário o usuário pode especificar sua própria rede utilizando a barra de ferramentas do ASiA. 


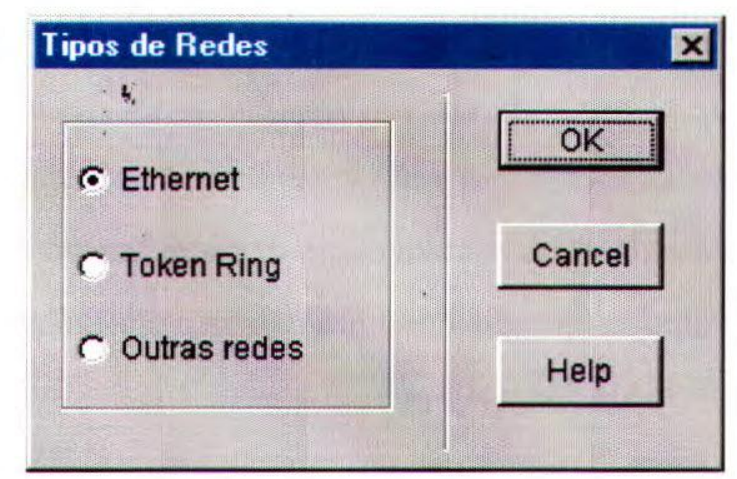

Figura 6.3: Caixa de diálogo "Tipos de Rede"

Se o usuário optar por um dos tipos de rede disponível, poderá ainda optar por utilização sem alterações ou com alterações, tanto no modelo quanto na parametrização.

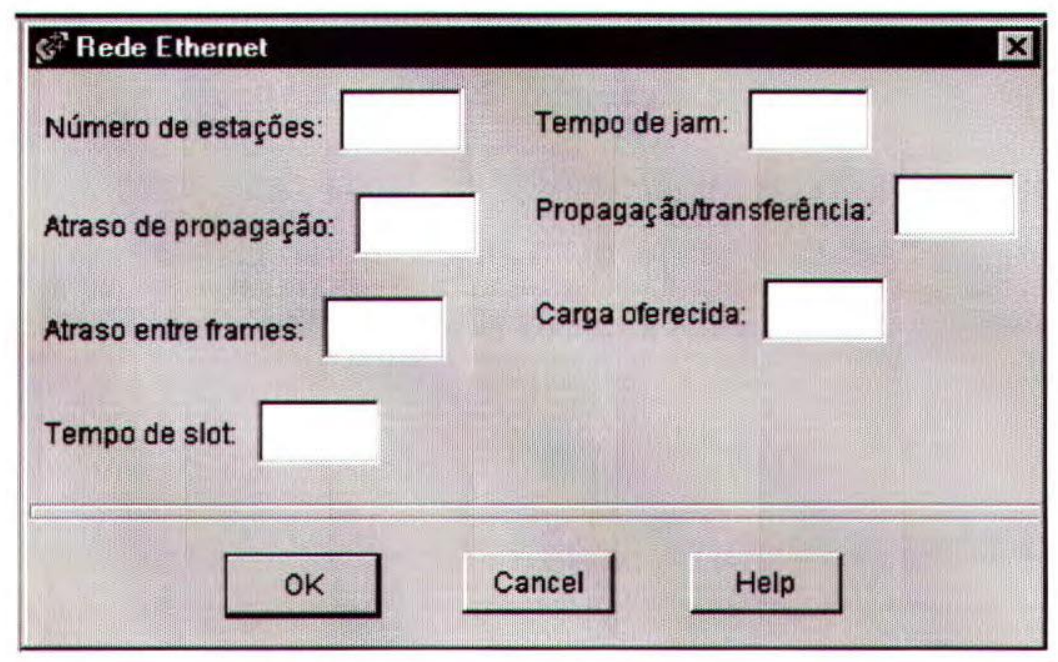

Figura 6.4: Caixa de diálogo de parametrização da rede Ethernet

Foram incluídas novas caixas de diálogo para a captação dos dados de entrada referente às redes de computadores, uma vez que variáveis como tipo de rede (Ethernet, Token Ring, etc...), número de estações, taxa de transmissão, tamanho do pacote, tamanho da rede física, devem ser fornecidas pelo usuário. A Figura 6.4 mostra a caixa de diálogo utilizada 
para parametrizar uma rede Ethernet e a Figura 6.5 mostra a caixa de diálogo da rede Token Ring.

Os botões e as caixa de diálogo foram implementados no Resource Workshop de modo similar ao descrito na seção 5.2.1. Todo o código referente ao tratamento dos botões e caixas de diálogo também foi implementado.

A parametrização das redes de computadores é diferente da parametrização padrão do ASiA (redes de fila). Para facilitar o uso do ASiA para usuários que não possuem muito conhecimento em redes de filas, a parametrização do módulo de redes é efetuada através de termos utilizados em redes de computadores e não através de termos utilizados em redes de filas. Por exemplo, número de estações no lugar de número de recursos, atraso de propagação ou tempo de jam no lugar de tempo de serviço, etc.

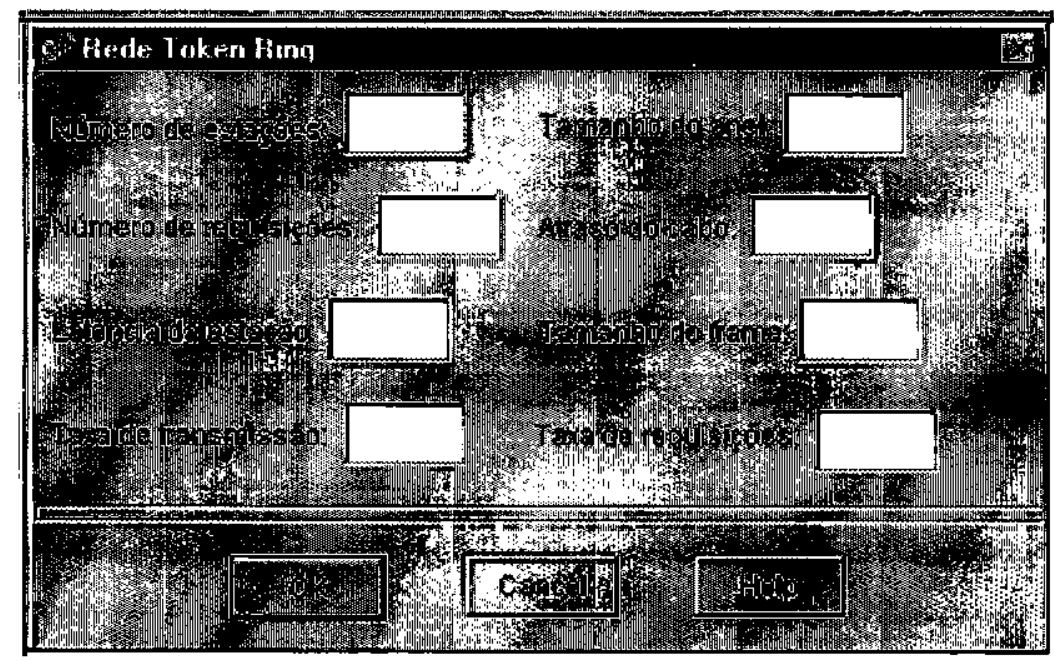

Figura 6.5: Caixa de diálogo de parametrização da rede Token Ring

\subsubsection{Verificação da consistência dos parâmetros}

O ASiA faz uma verificação de todo modelo definido através do seu editor gráfico. Nesta etapa são verificadas possíveis inconsistências no modelo, tais como: modelo sem entrada e com saída, modelo com entrada e sem saída, modelo faltando ligação (com um recurso sem ligação com nenhum outro recurso), etc. 
No Módulo Rede devem ser verificados os parâmetros definidos pelo usuário, para assegurar que não existem valores fora dos limites, valores não definidos e valores inconsistentes. Desta forma, alguns dos parâmetros verificados são: número de estações (deve ser um número inteiro entre 2 e 200 ), atraso de propagação (deve ser um número real), etc.

\subsubsection{Atualização das tabelas e gravação em arquivos}

A parametrização das redes modeladas pelo usuário segue o padrão do ASiA. Da mesma forma, a atualização das tabelas e a gravação em arquivos segue os passos definidos no ASiA.

Os parâmetros que são capturados pela caixa de diálogo de parametrização da rede Ethernet são: número de estações, atraso de propagação, atraso entre frames, tempo de slot, tempo de jam, razão propagação transferência e carga oferecida. Esses dados são capturados e organizados do seguinte modo (Tabela 6.1):

Tabela 6.1: Parâmetros da rede Ethernet

\begin{tabular}{|l|l|l|}
\hline Número de estações & $\begin{array}{l}\text { Número de servidores em inicia transmissão } \\
\text { (Figura 6.8) }\end{array}$ & char nestacao[3] \\
\hline Atraso de propagação & $\begin{array}{l}\text { Tempo de serviço em inicia transmissão (Figura } \\
6.8 \text { ) }\end{array}$ & char atrasoprop[7] \\
\hline Atraso entre frames & $\begin{array}{l}\text { Tempo de chegada em inicia transmissão (Figura } \\
6.8)\end{array}$ & char atrasoenfra[7] \\
\hline Tempo de slot & Tempo de serviço em tempo aleatório (Figura 6.8) & char temposlot[7] \\
\hline Tempo de jam & Tempo de serviço em backoff (Figura 6.8) & char tempojam[7] \\
\hline $\begin{array}{l}\text { Propagação } \\
\text { transferência }\end{array}$ & $\begin{array}{l}\text { Relacionado ao tempo de chegada no canal (Figura } \\
6.8)\end{array}$ & char proptransf[7] \\
\hline Carga oferecida & $\begin{array}{l}\text { Relacionado ao tempo de chegada no canal (Figura } \\
6.8)\end{array}$ & char cargaof[7] \\
\hline
\end{tabular}

Esses dados são do tipo caracter e o número entre [] indica o número de posições que essa variável irá ocupar, no caso 3 para número de estações e 7 para as demais variáveis. A captura dos dados é feita em caractere, mas para a verificação de consistência e para a 
gravação dos dados em arquivo é feita a transformação dos caracteres em números. $\mathrm{O}$ número de estações é um número inteiro e as demais variáveis são números reais.

Para a rede Token Ring os parâmetros que são capturados pela caixa de diálogo de parametrização da rede Token Ring são: número de estações, número de requisições, latência da estação, taxa de transmissão, tamanho do anel, atraso do cabo, tamanho do frame e taxa de requisições. Esses dados são capturados e organizados do seguinte modo (Tabela 6.2):

Tabela 6.2: Parâmetros da rede Token Ring

\begin{tabular}{|c|c|c|}
\hline Nome to modelo & 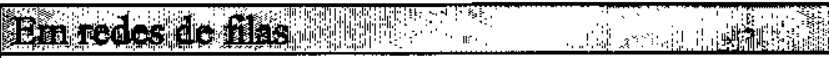 & 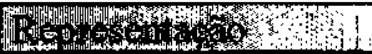 \\
\hline Número de estações & Número de servidores em token (Figura 6.13) & char nestacao[3] \\
\hline Latência da estação & $\begin{array}{l}\text { Relacionado ao tempo de serviço em inicia } \\
\text { transmissão (Figura 6.13) }\end{array}$ & char latencia[7] \\
\hline Taxa de transmissão & $\begin{array}{l}\text { Relacionado ao tempo de chegada em token } \\
\text { (Figura 6.13) }\end{array}$ & char taxatrans[7] \\
\hline Tamanho do anel & $\begin{array}{l}\text { Relacionado ao tempo de serviço em inicia } \\
\text { transmissão (Figura 6.13) }\end{array}$ & char tamanhoanel[7] \\
\hline Atraso do cabo & $\begin{array}{l}\text { Relacionado ao tempo de serviço em inicia } \\
\text { transmissão (Figura 6.13) }\end{array}$ & char atrasocabo[7] \\
\hline Taxa de requịsições & $\begin{array}{l}\text { Relacionado ao tempo de chegada no canal } \\
\text { (Figura 6.13) }\end{array}$ & char taxareq[7] \\
\hline $\begin{array}{l}\text { Número de } \\
\text { requisiçõos }\end{array}$ & $\begin{array}{l}\text { Relacionado ao tempo de chegada no canal } \\
\text { (Figura 6.13) }\end{array}$ & char nreq[7] \\
\hline Tamanho do frame & $\begin{array}{l}\text { Relacionado ao tempo de serviço em inicia } \\
\text { transmissão (Figura 6.13) }\end{array}$ & char tamanhoframe[7] \\
\hline
\end{tabular}

Esses dados são do tipo caracter e segue o que já foi descrito para a rede Ethernet. $O$ número de estações, o número de requisições e o tamanho do frame são números inteiros e as demais variáveis são números reais.

Os parâmetros capturados são organizados da forma apresentada na Tabela 6.3. Na primeira coluna tem-se os dados que serão gravados em arquivo: tipo de rede, número de estações, varl até var 6 que indicam as variáveis correspondentes a cada uma das redes (que podem ser vistas nas colunas 2 e 3). Na segunda coluna tem-se os dados capturados pela caixa de diálogo de parametrização da rede Ethernet. E na terceira coluna tem-se os dados capturados pela caixa de diálogo de parametrização da rede Token Ring. Para adaptar a tabela aos dados das duas redes, os valores de var7 e var8 da segunda cohuna são " 0 " para a rede Ethernet pois não são utilizados por essa rede. O mesmo acontece com o valor de var6 para a 
rede Token Ring. A variável tipo_rede (linha 1, coluna 1 da tabela) indica qual o tipo de rede que está gravado no arquivo. Se esse valor foi ' 1 ' indica que é a rede Ethernet e se for ' 2 ' indica a rede Token Ring.

Tabela 6.3: Tabela dos parâmetros das redes

\begin{tabular}{|l|l|l|}
\hline int nestacao & char auxnestacao[3] & char auxnestacao[3] \\
\hline float var1 & char auxatrasoprop[7] & char auxlatencia[7] \\
\hline float var2 & char auxatrasoenfra[7] & char auxtaxatrans[7] \\
\hline float var3 & char auxtemposlot[7] & char auxtamanhoanel[7] \\
\hline float var4 & char auxtempojam[7] & char auxatrasocabo[7] \\
\hline float var5 & char auxproptransf[7] & char auxtaxareq[7] \\
\hline float var6 & char auxcargaof[7] & "0" \\
\hline int var7 & "0" & char auxnreq[7] \\
\hline int var8 & “0" & char auxtamanhoframe[7] \\
\hline
\end{tabular}

Depois de capturados os valores através das caixas de diálogo de parametrização da rede, os dados são transferidos para as variáveis da coluna 1 (Tabela 6.3) e são gravados em arquivo. $\mathrm{O}$ arquivo gerado tem extensão ".red". O nome do arquivo é definido pelo usuário quando ele salva os arquivos que compõe o modelo.

\subsubsection{Geração do código fonte}

Outra modificação necessária foi quanto à geração do programa de simulação. A versão anterior do ASiA possuía um "gabarito" (Figura 6.6) que não permitia estruturas necessárias para redes de computadores. Desse modo foi criado um novo gabarito que se adequou melhor às simulações de redes de computadores. Esse novo gabarito pode ser visto na Figura 6.7 (GabaritoRede.dat). 


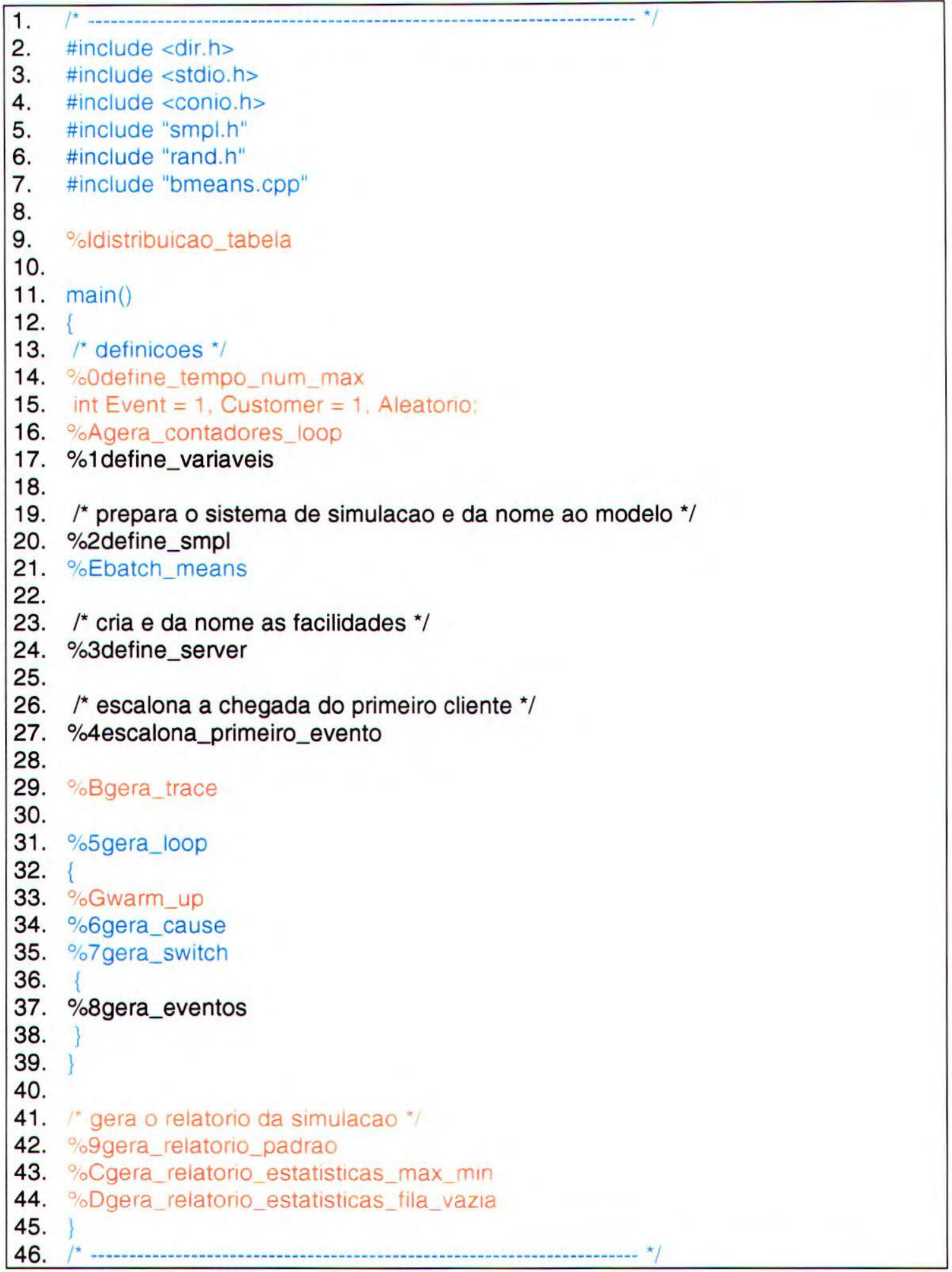

Figura 6.6: Gabarito padrão do ASiA 
O gabarito é um arquivo parecido com o produto final, onde trechos de código da linguagem alvo (SMPL) estão misturados com comandos que indicam ao gerador como buscar as informações necessárias nas várias tabelas que serão utilizadas. Os trechos de código são copiados para o produto final, enquanto os demais comandos (precedidos por um caracter especial - \%), determinam as primitivas do gerador a serem executadas. A estrutura do gabarito reflete exatamente o produto final a ser gerado, no caso, um programa de simulação em SMPL.

O gabarito padrão do $\mathrm{ASiA}$ possui algumas estruturas que não são necessárias para redes de computadores e não possui algumas outras que são necessárias. As linhas em azul nos gabaritos mostram as estruturas que não foram modificadas. As linhas 21, 23 e 24 da Figura 6.7 não são iguais às linhas 31, 34 e 35 da Figura 6.6 mas possuem a mesma idéia. Como para simulação de redes não é necessária a modificação destas linhas, não se justifica a colocação de procedimentos para o tratamento das mesmas.

No gabarito padrão do ASiA (Figura 6.6) as linhas 9, 14, 15, 16, 29, 33, 41, 42,43 e 44 (em vermelho) são as estruturas que não são necessárias para a simulação de redes. Por exemplo, a simulação de redes não utiliza distribuição tabelada, nem trace e nem warm up. Os relatórios gerados também são diferentes. $\mathrm{E}$ a definição de variáveis segue um outro tipo de padrão.

$\mathrm{Na}$ Figura 6.7 as linhas em verde são as estruturas que foram inclú́das no gabarito de redes e que não existiam no gabarito padrão. A linha 9 (gera_defines) faz a geração das constantes que serão utilizadas no programa de simulação. A linha 11 (gera_variáveis) cria as estruturas das variáveis necessárias ao programa gerado. A linha 13 (gera_funções) tem o objetivo de criar todas as funções que são utilizadas de modo organizar melhor a estrutura do programa. As linhas 30 e 31 geram as saídas do programa e a sua impressão.

As demais linhas em preto possuem similaridades entre os dois gabaritos, como por exemplo a linha 27 (Figura 6.7) em relação a linha 37 da Figura 6.6.

Além da inclusão de um novo gabarito, foi preciso modificar o Gerador de Aplicações para que este utilizasse o novo gabarito implementado. Novos procedimentos tiveram de ser incluídos, como leitura e execução dos passos descritos no gabarito. 


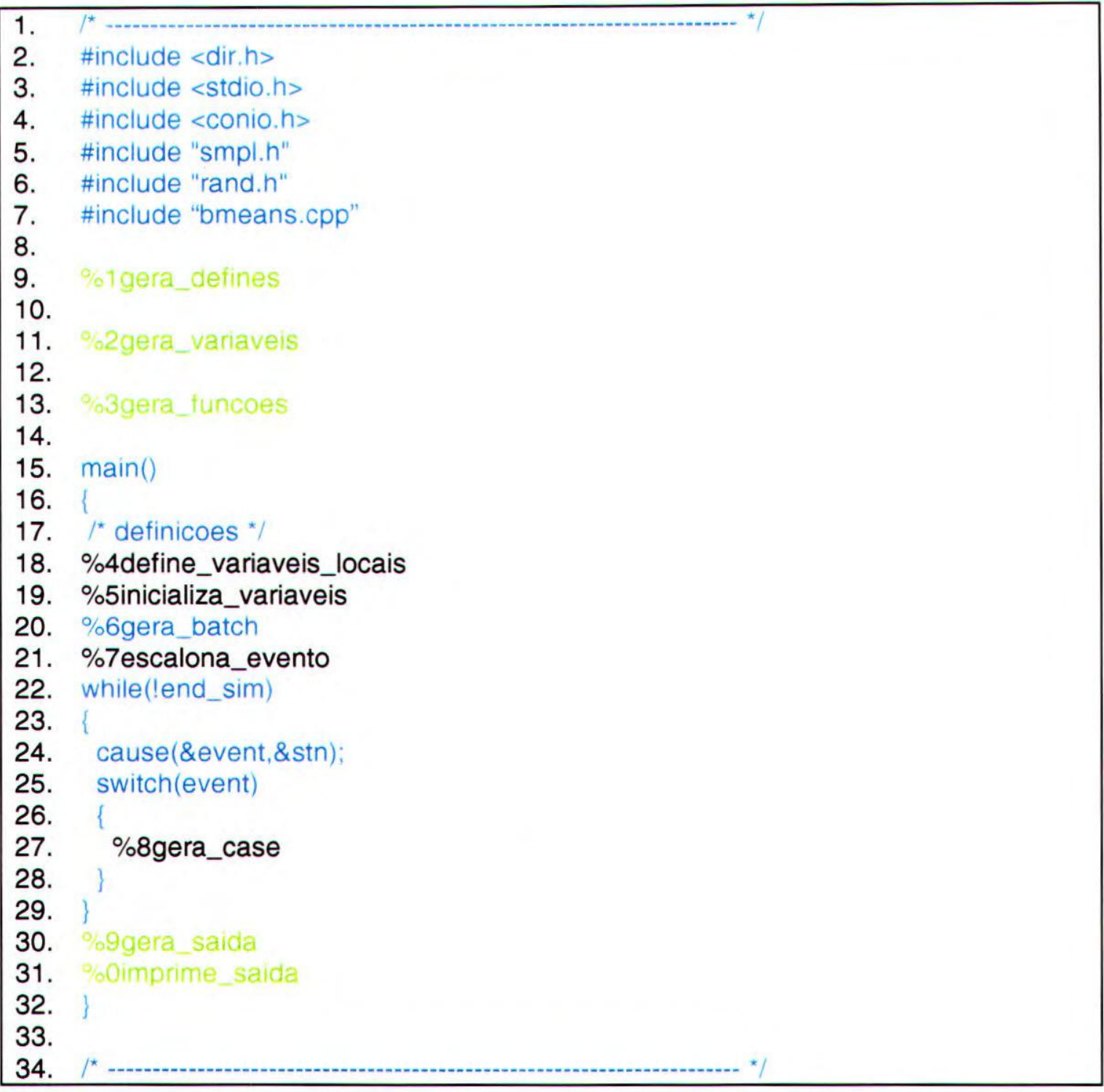

Figura 6.7: Gabarito para simulação de redes de computadores

Cada linha do gabarito precedido pelo caractere especial \% implica em execução de ações. E após cada \% existe um número que indica qual será o procedimento a ser executado. Apesar de existirem similaridades entre os dois gabaritos, decidiu-se a separação da geração do código para redes e para o $\mathrm{ASiA}$ padrão pois as tabelas utilizadas e as estruturas são diferentes para as duas abordagens.

Foram criados os procedimentos: Gera_defines, Gera_variaveis, Gera_funcoes, Define_variaveis_locais, Inicializa_variaveis, Gera_batch, Escalona_evento, Gera_case, Gera_saida e Imprime_saida. 
Nas próximas seções são apresentadas as redes Ethernet e Token Ring e as implementações dessas redes no ASiA. As redes Ethernet e Token Ring foram escolhidas por serem redes bastante difundidas. Essas redes possuem uma vasta literatura que permite maior facilidade na validação dos modelos e na validação da simulação.

\subsection{Redes Ethernet}

$\mathrm{O}$ modelo de rede Ethernet é composto por $\mathrm{N}$ estações conectadas por um cabo coaxial, que é o canal. A rede Ethernet suporta um máximo de 1024 estações com um tamanho total de cabo de $2,5 \mathrm{Km}$.

A rede Ethernet utiliza o protocolo CSMA/CD, ou seja, uma estação com mensagem para transmitir fica escutando o canal e, se o canal está livre, inicia a transmissão. Durante a transmissão, a estação contmua a escutar o canal e se outra estação inicia a transmissão antes da primeira terminar, ocorre colisão. Quando a estação detecta a colisão, ela aborta a transmissão, transmite uma mensagem nula que mostram às demais estações que ocorreu uma colisão, e agenda uma retransmissão depois de um tempo aleatório (backoff).

\subsubsection{Modelo para a rede Ethernet}

A rede Ethernet pode ser representada através do modelo da Figura 6.8. Neste modelo o canal de comunicação é representado por um servidor passivo, que fica alocado ao cliente até a finalização da transmissão ou até quando é detectada e tratada uma colisão. Uma vez de posse do canal de comunicação o cliente verifica se o canal está sendo utilizado por outra estação, se estiver o cliente libera o canal e espera um tempo aleatório até nova tentativa de transmissão. Se o canal não estiver sendo utilizado o cliente transmite a mensagem e verifica se ocorreu colisão, se ocorreu o cliente vai para o tratamento dả colisão (backoff). No recurso “backoff" considera-se a abortagem da transmissão e o envio de uma mensagem nula para sinalizar a colisão. $O$ canal é então liberado e espera-se um tempo aleatório para fazer nova 
tentativa de transmissão. Se o cliente conseguiu enviar a mensagem, a transmissão é finalizada e o canal é liberado. O modelo da Figura 6.8 é apresentado na tela do ASiA quando o usuário seleciona Rede Ethernet na caixa de diálogo Tipos de Rede da Figura 6.3.

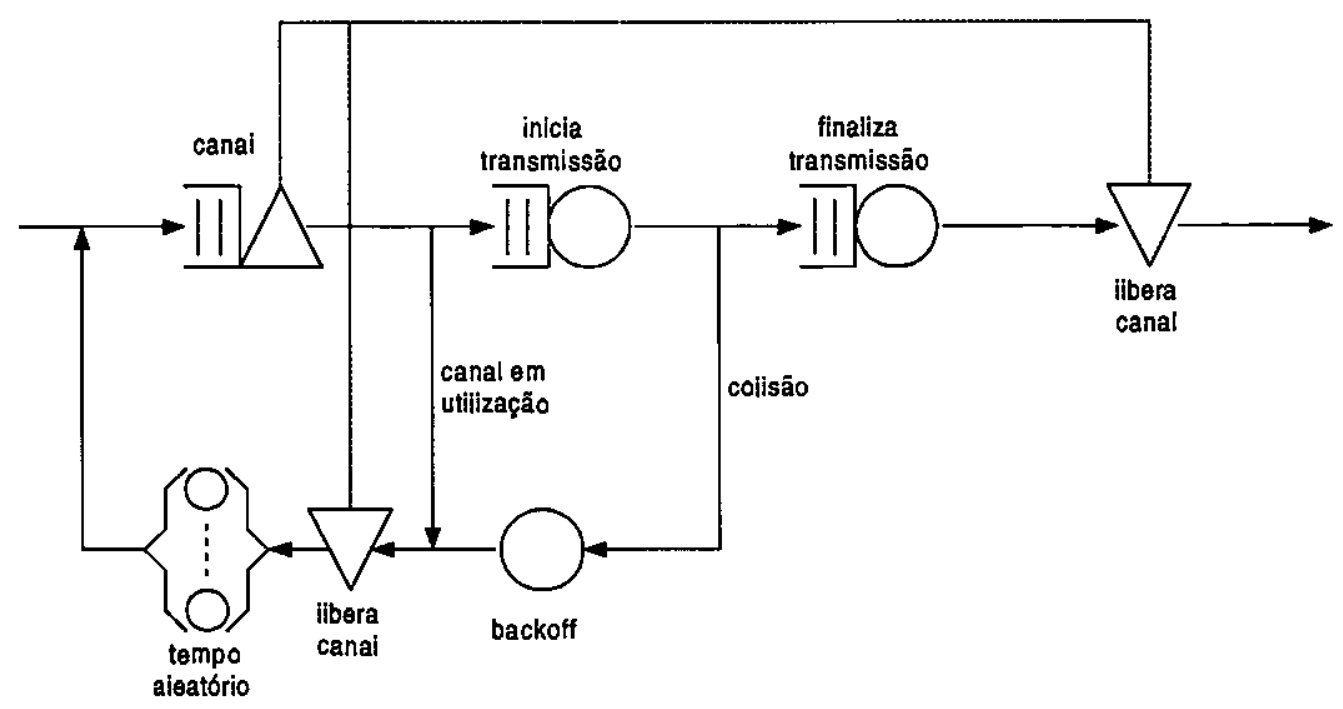

Figura 6.8: Modelo da rede Ethernet

$\mathrm{Na}$ implementação da rede Ethernet, uma variável simples é utilizada para representar o estado do canal (livre ou ocupado) e as estações são representadas por estruturas que ficam competindo pelo canal. As estações, em intervalos randômicos, geram requisições de transmissão, competem pelo canal de comunicação e, quando adquirem a posse do canal, transmitem seus pacotes. Quando uma transmissão termina, outra requisição é agendada. Os intervalos entre as requisições seguem uma distribuição exponencial com média definida.

\subsubsection{Programa de simulação para a rede Ethemet}

O diagrama do modelo de simulação da rede Ethernet utilizado é apresentado na Figura 6.9 [MAC87]. Neste modelo podem ser vistos os seis eventos que compõe o programa de simulação. 


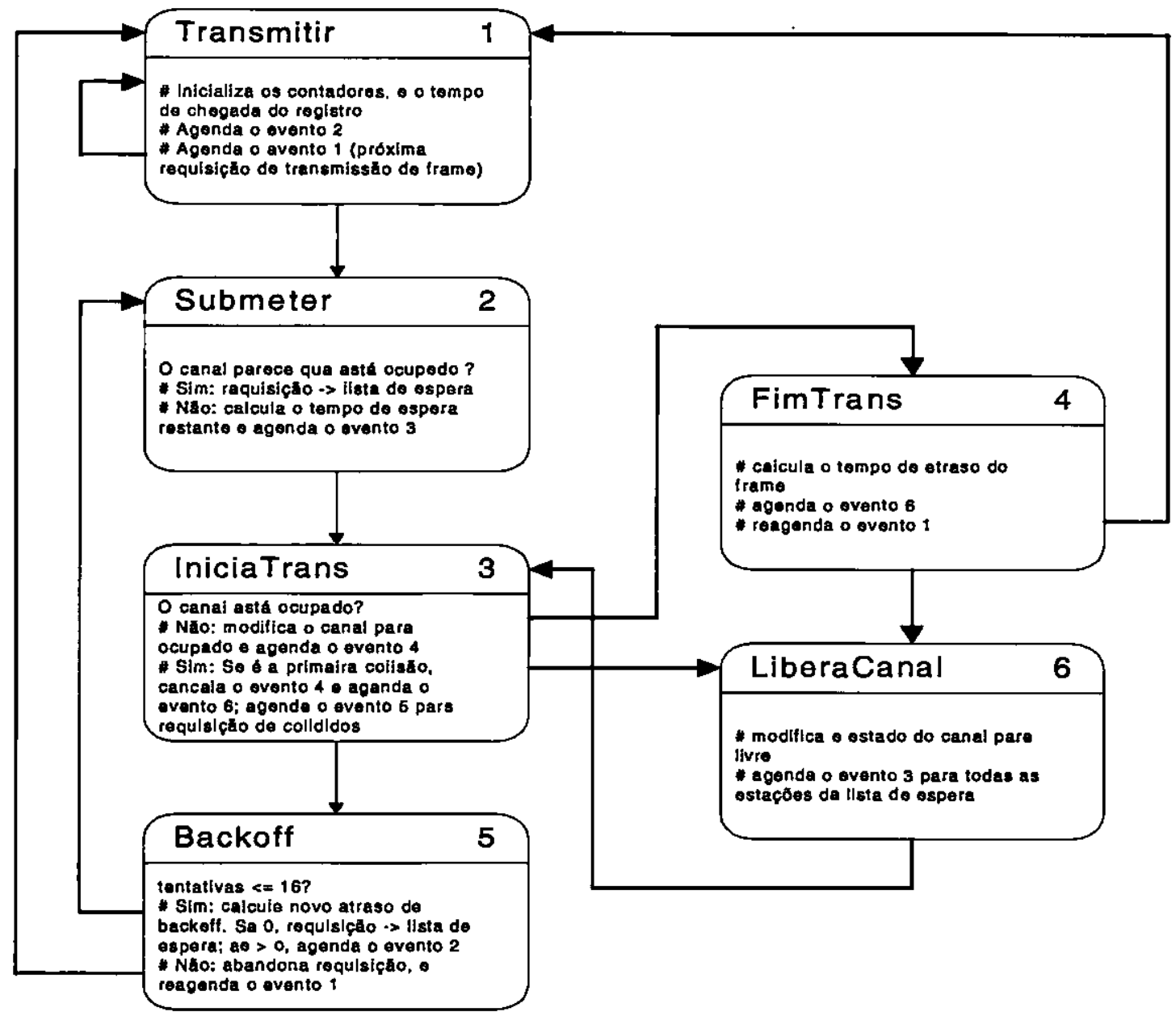

Figura 6.9: Modelo de simulação para rede Ethernet

O programa gerado pelo ASiA encontra-se na Figura 6.10, a seguir são analisados os eventos da simulação e são definidos em que linhas do programa gerado estes eventos estão representados.

$\mathrm{Na}$ inicialização do modelo, a primeira requisição de transmissão é agendada para o evento 1 , Transmitir.

$O$ evento Transmitir (Figura 6.10 - linha 35 a 52) representa a chegada de uma requisição de transmissão. Variáveis são zeradas, e o evento 2 , Submeter, é agendado.

O evento Submeter (Figura 6.10 - linha 54 a 65) determina um momento randômico para a requisição e corresponde ao processo de submeter do sistema Ethernet. $O$ canal de 
comunicação é representado por uma variável que pode assumir o valor ocupado ou livre, dependendo se uma operação de transmissão foi iniciada ou se completou uma transmissão.

No sistema Ethernet, para se evitar colisões, quando um canal passa de ocupado para livre um intervalo de espera é iniciado. A estação então espera até o fim desse intervalo para poder iniciar a sua transmissão. Esse tempo de espera é controlado pela função Submeter.

O evento IniciaTrans (Figura 6.10 - linha 67 a 90) representa o início de uma transmissão. Esta função primeiro verifica se o canal está liṿre, ou seja, se ninguém está transmitindo, porém, isso não garante que não irá ocorrer colisão. O IniciaTrans então modifica a variável do canal para ocupado e agenda o evento FimTrans para ocorrer no final do tempo de transmissão. Se, por outro lado, o canal está ocupado, então alguma outra estação está transmitindo e uma colisão irá ocorrer em algum momento no futuro.

No caso de ocorrência de colisão, o evento IniciaTrans cancela o evento FimTrans, e agenda o evento Backoff depois de um tempo que representa a mensagem nula que o Ethernet envia a todas as estações notificando a ocorrência de uma colisão.

O evento FimTrans (Figura 6.10 - linha 103 a 109) representa o fim de uma transmissão completada com sucesso. O evento LiberaCanal é então agendado para que o canal seja liberado para outras transmissões.

O evento Backoff (Figura 6.10 - linha 111 a 133) calcula um tempo de espera para nova tentativa de transmissão. Porém, o número de tentativas está limitado em 16, e se uma transmissão atinge 16 tentativas, esta requisição é abandonada.

O evento LiberaCanal (Figura 6.10 - linha 135 a 144) libera o canal depois de uma transmissão, tenha ela tido sucesso ou não. Todas as requisições que estavam na lista de espera são agendadas para o evento IniciaTrans depois de um certo intervalo de tempo.

Na Figura 6.10 tem-se a listagem completa do programa de simulação para rede Ethernet. Inicialmente, tem-se a declaração das variáveis, depois, todas as funções que compõe o programa e finalmente, o programa principal. 


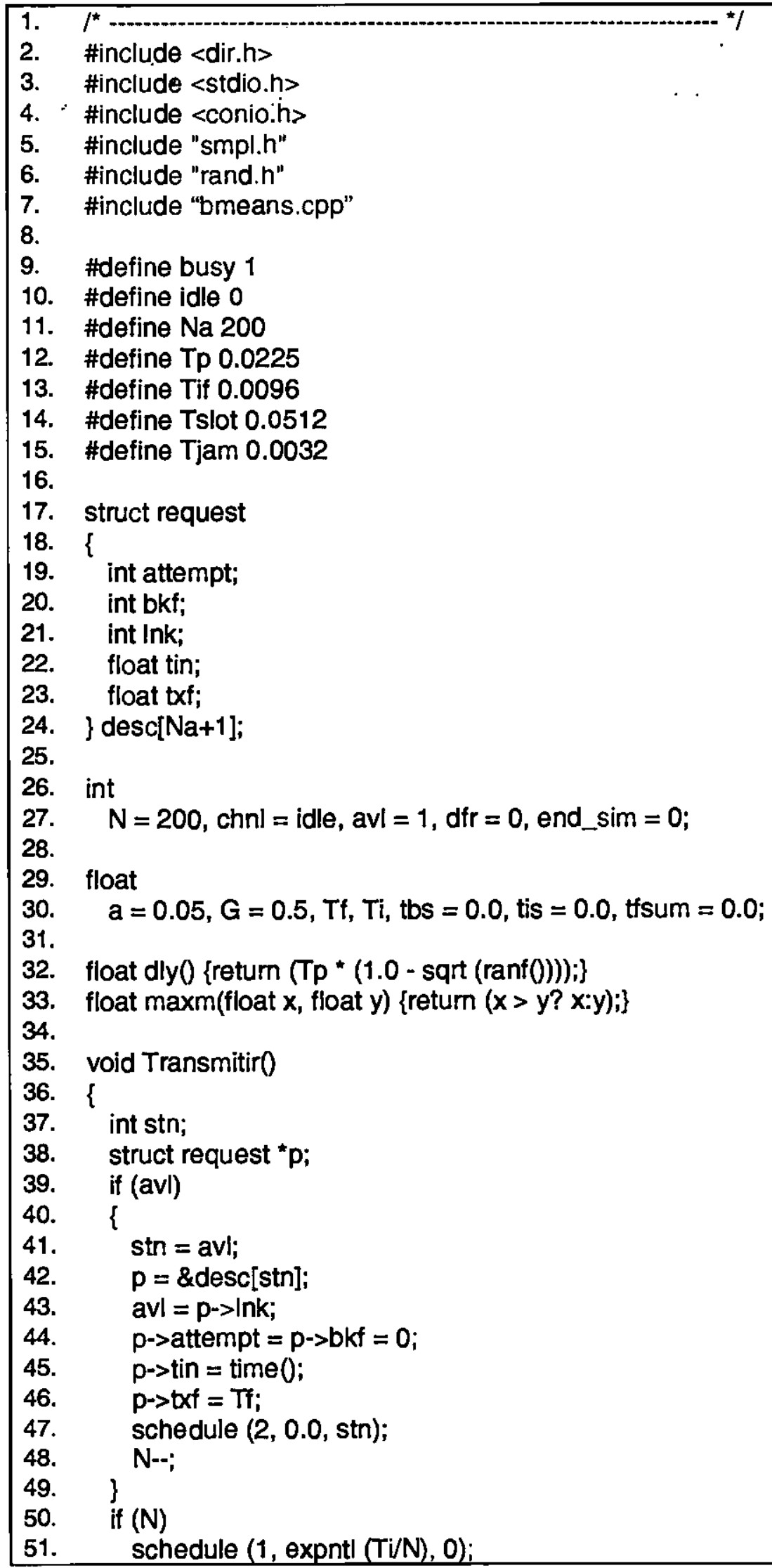




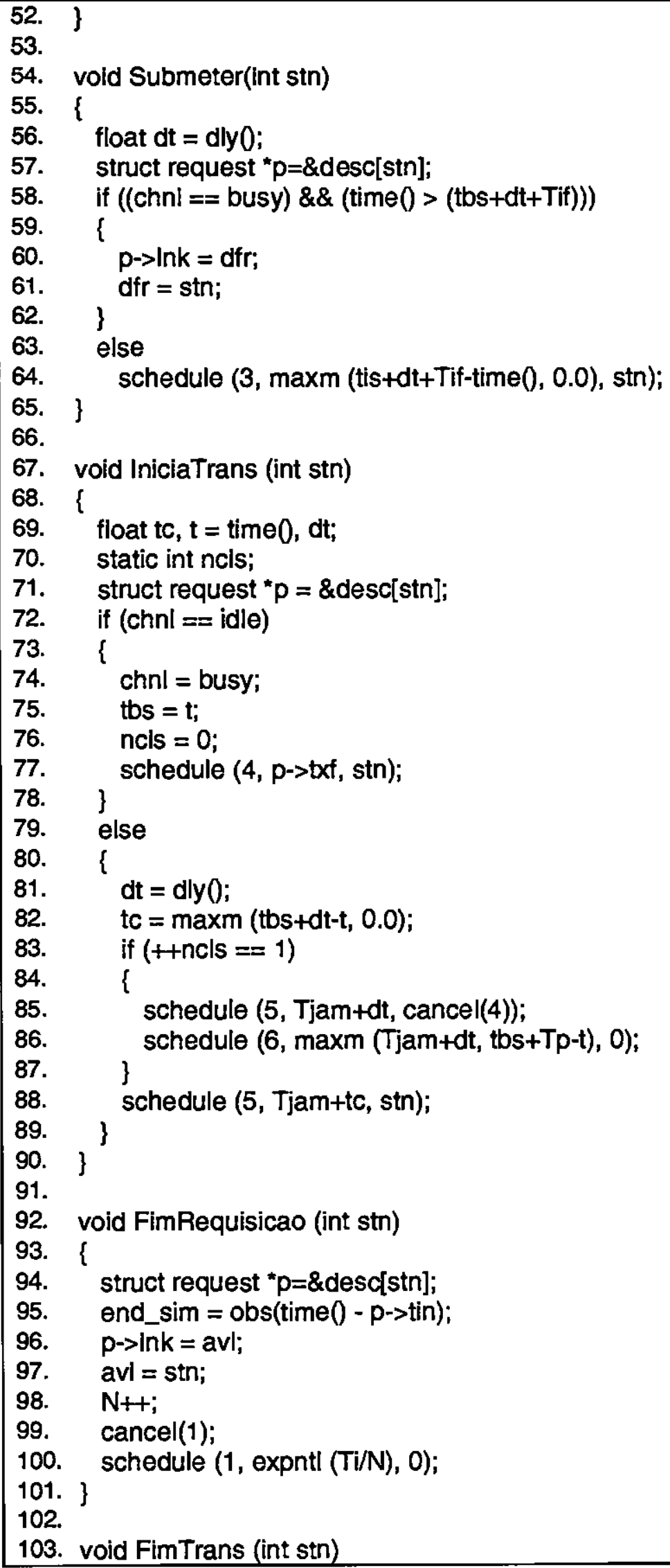




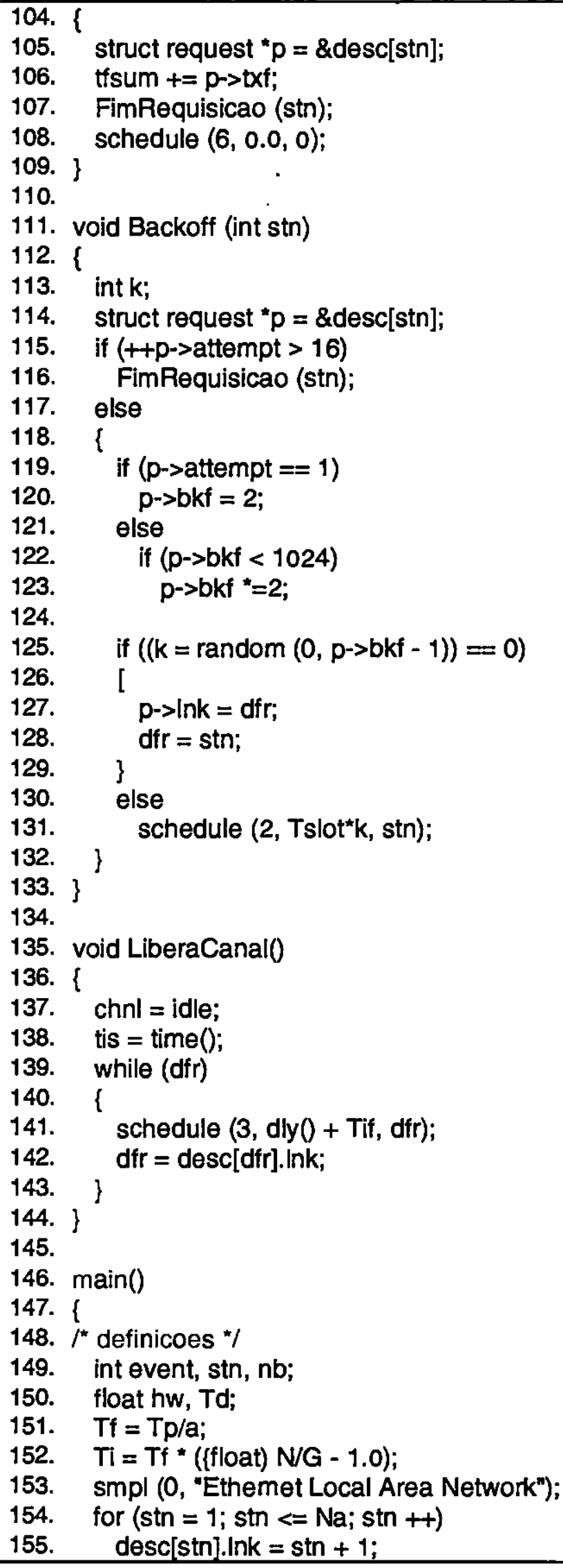


156. desc[Na].Ink $=0$;

157. init_bm $(2000,2000)$;

158. schedule $(1, T p, 0)$;

159. while (!end_sim)

160. \{

161. cause (\&event, \&stn);

162. switch (event)

163. \{

164. case 1: Transmitir(); break;

165. case 2: Submeter(stn); break;

166. case 3: IniciaTrans(stn); break;

167. case 4: FimTrans(stn); break;

168. case 5: Backoff(stn); break;

169. case 6: LiberaCanal(0; break;

170. \}

171. \}

172. civals (\&Td, \&hw, \&nb);

173. printf ("S $=\% .3 \mathrm{fnn}$ ", tfsum/time) );

174. printf ("D $=\% .3 f+/-\% .3 f n^{\prime \prime}, T d / T f$, hw/Tf);

175.

176.

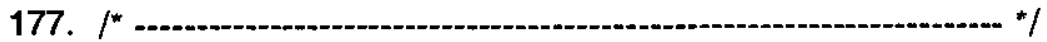

Figura 6.10: Programa de simulação para rede Ethernet

As linhas em azul da Figura 6.10 são as linhas do gabarito (Figura 6.7) que são copiadas na íntegra no produto final (programa de simulação gerado). Abaixo está especificado cada procedimento do Gerador de aplicações para o gabarito de rede e quais linhas são responsáveis por gerar:

Gera_defines: linha 9 a 15

Gera_variaveis: linha 17 a 30

Gera_funcoes: linha 32 a 144

Define_variaveis_locais: linha 149 e 150

Inicializa_variaveis: 151 a 156

Gera_batch: 157

Escalona_evento: 158

Gera_case: 164 a 169

Gera_saida: 172

Imprime_saida: 173 e 174 
Os resultados da simulação que são apresentados são o Throughput, representado pela letra $\mathrm{S}$ e o atraso médio normalizado representado pela letra $\mathrm{D}$. Para este programa, os valores encontrados foram:

- $S=0,501$

- $\mathrm{D}=2,14+/-0,118$

Os valores encontrados com esse programa correspondem aos resultados esperados de acordo com [MAC87].

\subsubsection{Utilização da simulação de uma Ethernet no ASiA}

Na parametrização (Figura 6.11) o usuário poderá definir diversas variáveis de modo a modificar a configuração da rede Ethernet. Estas variáveis são: $\boldsymbol{G}$ (carga oferecida), $\boldsymbol{a}$ (razão entre o tempo de propagação do canal pelo tempo de transmissão médio do frame), $N$ (número de estações na rede), $T p$ (atraso de propagação), Tif (tempo de atraso entre frames), Tslot (tempo de slot) e Tjam (tempo da mensagem de jam - mensagem nula que indica que ocorreu colisão).

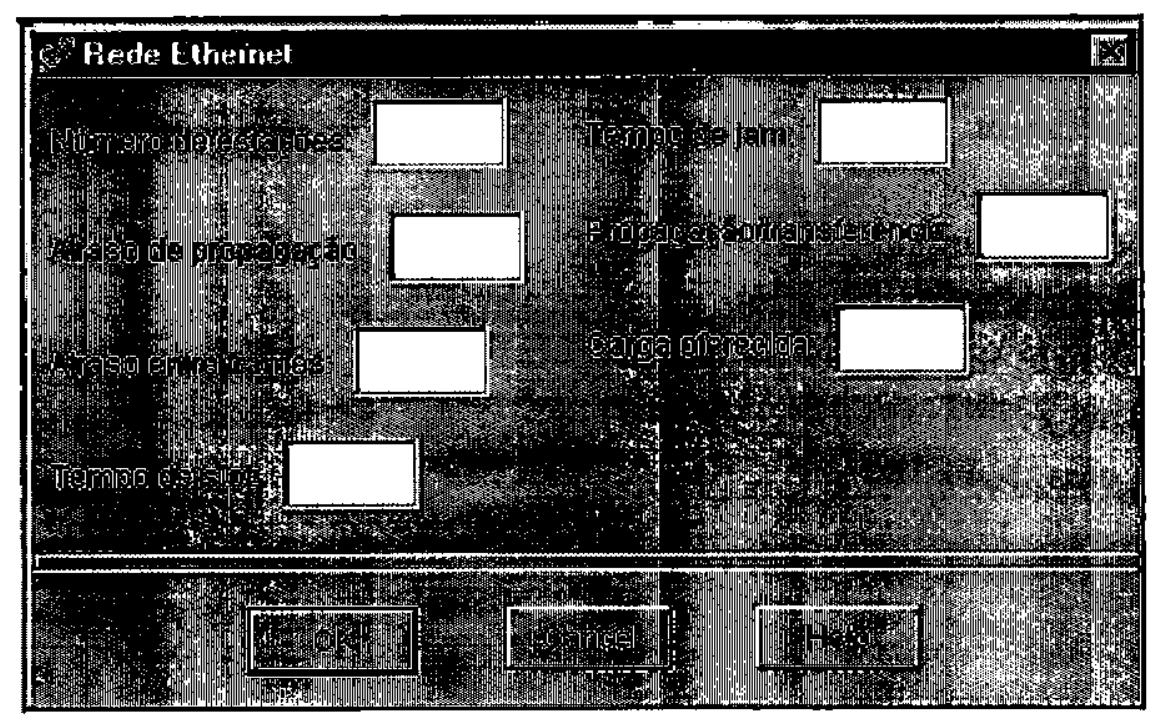

Figura 6.11: Caixa de diálogo de parametrização da rede Ethernet 
A Figura 6.12 mostra o modelo de simulação da rede Ethernet indicando os parâmetros (em vermelho) que podem ser modificados pelo usuário na caixa de diálogo de parametrização da rede Ethernet (Figura 6.11). O objetivo de cada parâmetro está descrito nos próximos parágrafos.

Disputando o canal (recurso passivo - Figura 6.12) tem-se $\mathrm{N}$ número de estações que ficam gerando requisições de transmissão de tempos em tempos. Esse tempo é definido pela carga oferecida (carga que a rede terá) e pela razão propagação/transferência, que indica o desempenho da rede. Um valor alto para essa razão indica que será gasto mais tempo em tratamento de colisão do que um valor baixo, uma vez que o tempo entre tentativas de transmissão de mensagens será maior.

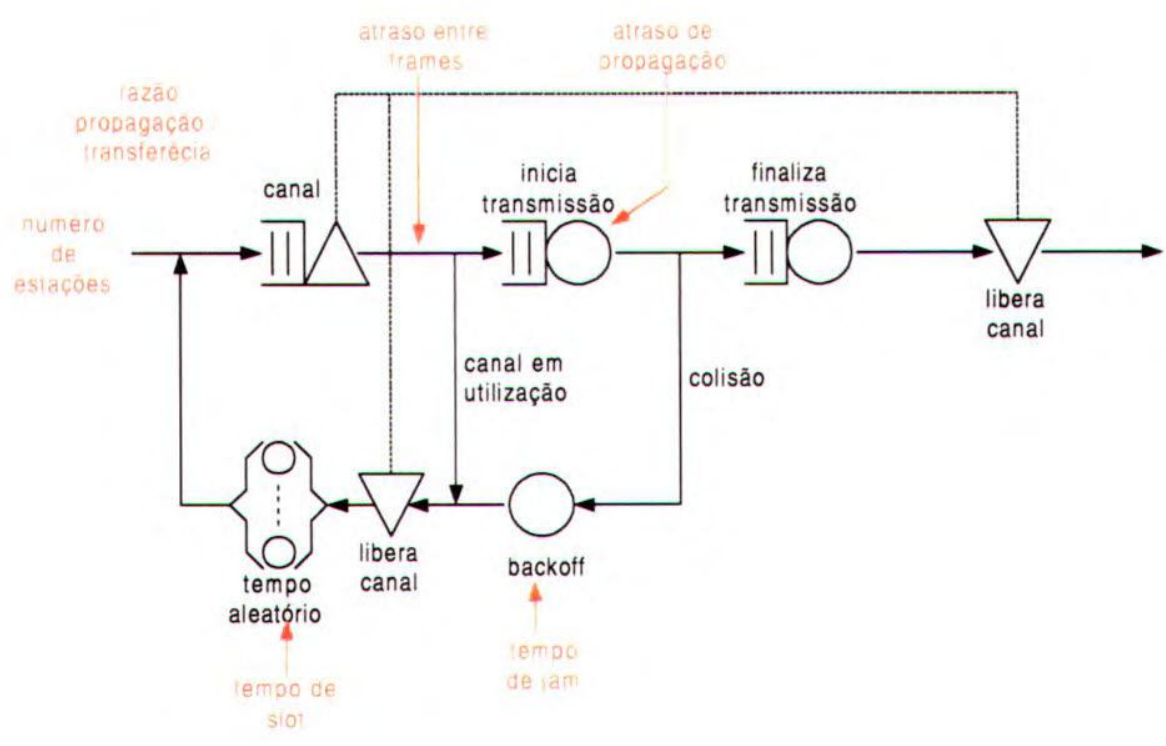

Figura 6.12: Modelo de simulação da rede Ethernet

Quando uma estação tem mensagem para transmitir, ela toma posse do canal e verifica se está sendo utilizado (através do tempo de atraso entre frames) Se o canal não está sendo utilizado, ele inicia a transmissão e continua escutando o canal um tempo (atraso de propagação - tempo de serviço do recurso inicia transmissão) verificando se ocorreu colisão. Se ocorrer colisão, a estação manda uma mensagem nula (tempo de jam - tempo de serviço 
do recurso backoff), libera o canal e fica em espera no recurso tempo aleatório (tempo de slot - tempo de serviço do recurso servidor infinito) até tentar nova transmissão. Se não ocorreu colisão, a estação finaliza a transmissão e libera o canal.

\subsection{Rede Token Ring}

Na rede Token Ring o meio de transmissão é fechado e forma um anel. A informação flui somente em uma direção e o acesso ao meio de transmissão é controlado através de um token. $\mathrm{O}$ token pode assumir um dos dois estados: ocupado ou livre. Um token livre indica que o meio de transmissão está disponível e o token ocupado indica que o meio de transmissão está sendo utilizado.

\subsubsection{Modelo para a rede Token Ring}

A rede Token Ring pode ser representada pelo modelo da Figura 6.13. Neste modelo uma facility é utilizada para representar o token. O estado da rede pode ser definido como o estado do token: livre quando o token está disponível e ocupado quando o token está sendo utilizado por outra estação.

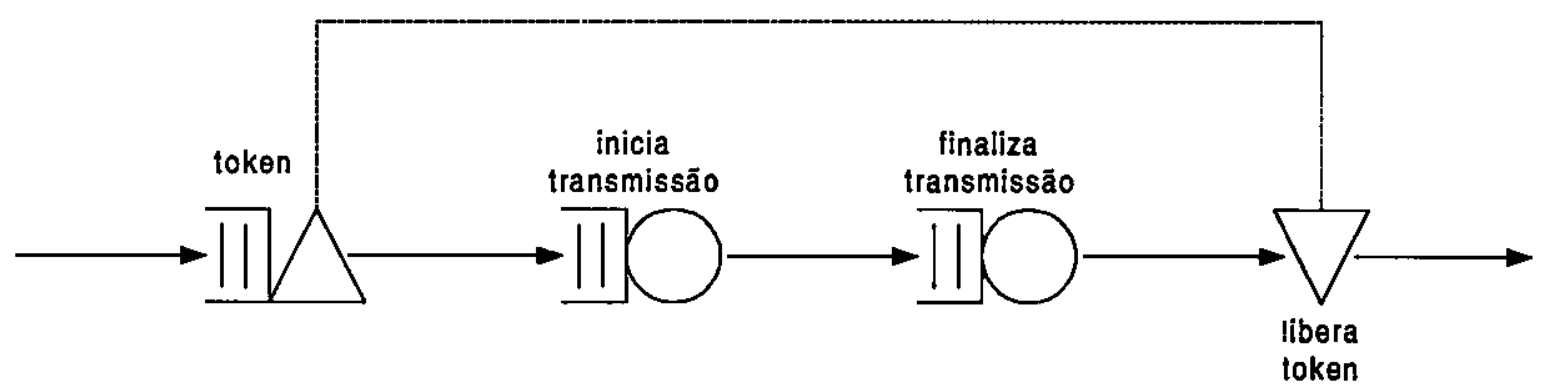

Figura 6.13: Modelo de rede Token Ring 
No modelo de rede Token Ring (Figura 6.13) o servidor passivo representa o token que é disputado pelas estações. Uma requisição ao token é gerada de tempos em tempos. Quando uma estação tem algo a transmitir, ela coloca sua requisição na fila de espera até o token ficar livre. Várias estações podem ter mensagem para transmitir e a próxima estação a transmitir será a estação que receber o token que circula de forma ordenada pela rede. Uma veż de posse do token a estação inicia a transmissão da mensagem, finaliza a transmissão e libera o token.

\subsubsection{Programa de simulação para a rede Token Ring}

O diagrama do modelo de simulação da rede Token Ring utilizado é apresentado na Figura 6.14 [MAC87].

O programa gerado pelo ASiA encontra-se na Figura 6.15. A seguir, são analisados os eventos da simulação e são definidos em que linhas do programa gerado, estes eventos estão representados.

A transmissão de um frame é representada por seis eventos: Chegada, RequisitaTrans, IniciaTrans, FimTrans, LiberaToken e FimTransEstacao. O evento Chegada (Figura 6.15 - linha 62 a 84) representa uma requisição de transmissão. $O$ tempo de chegada dessa requisição é guardado e o evento RequisitaTrans é agendado. O contador de requisições pendentes é incrementado e uma nova chegada de requisição é agendada.

O evento RequisitaTrans (Figura 6.15 - linha 86 a 111) verifica se a estação pode transmitir ou não, verificando se o token está livre. Se o token está livre é calculado o tempo até a chegada do token à estação e o evento IniciaTrans é agendado através da verificação da fila de requisições. Se alguma outra estação já havia agendado uma transmissão, a primeira estação verifica se o token irá passar primeiro por ela e se esse for o caso ela cancela a transmissão da outra estação e transmite primeiro.

A função tarrive (Figura 6.15 - linha 25 a 33) calcula o tempo no qual o token irá passar por cada estação. Nesta implementação, assumiu-se que o token permanece circulando constantemente pela rede, esteja ocupado ou livre. 


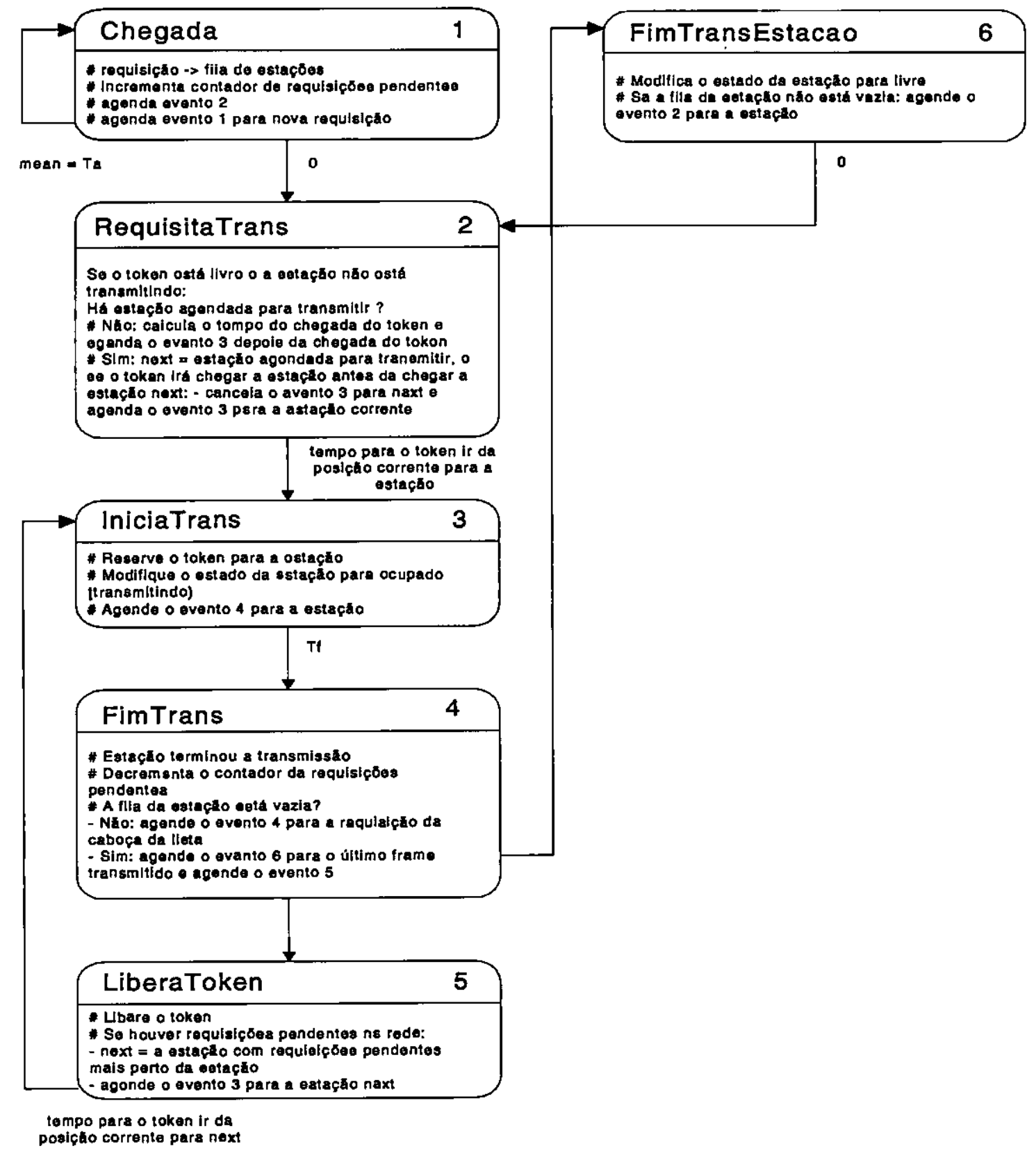

Figura 6.14: Modelo de simulação para rede Token Ring

O evento IniciaTrans (Figura 6.15 - linha 113 a 118) ocorre quando um token livre chega a uma estação com transmissões pendentes. O token é modificado para ocupado e o evento FimTrans é agendado. 
FimTrans (Figura 6.15 - linha 120 a 131) representa o fim da transmissão de um frame. A requisição de transmissão do frame é retirada da fila e o contador de requisições pendentes do anel é decrementado. Se a fila de transmissão da estação não está vazia, a estação mantém o token ocupado e inicia a transmissão de novo frame e agenda FimTrans.

Se a fila de transmissão da estação está vazia, os eventos LiberaToken e FimTransEstacao são agendados.

LiberaToken (Figura 6.15 - linha 133 a 144) representa a transmissão de um token livre. Depois de liberar o token, o contador de requisições pendentes é examinado. Se o contador não for zero, a estação com fila de transmissão não vazia mais próxima da estação que acabou de liberar o token é encontrada e o evento IniciaTrans é agendado para o tempo em que token irá chegar até a estação.

FimTransEstacao (Figura 6.15 - linha 146 a 151) marca o fim da transmissão de uma estação na rede. $O$ estado da estação é modificado para livre e se alguma requisição chegar a estação durante o evento de FimTransEstacao, o evento RequisitaTrans é agendado para novas transmissões de frames.

Na Figura 6.15 tem-se a listagem completa do programa de simulação para rede Token Ring.

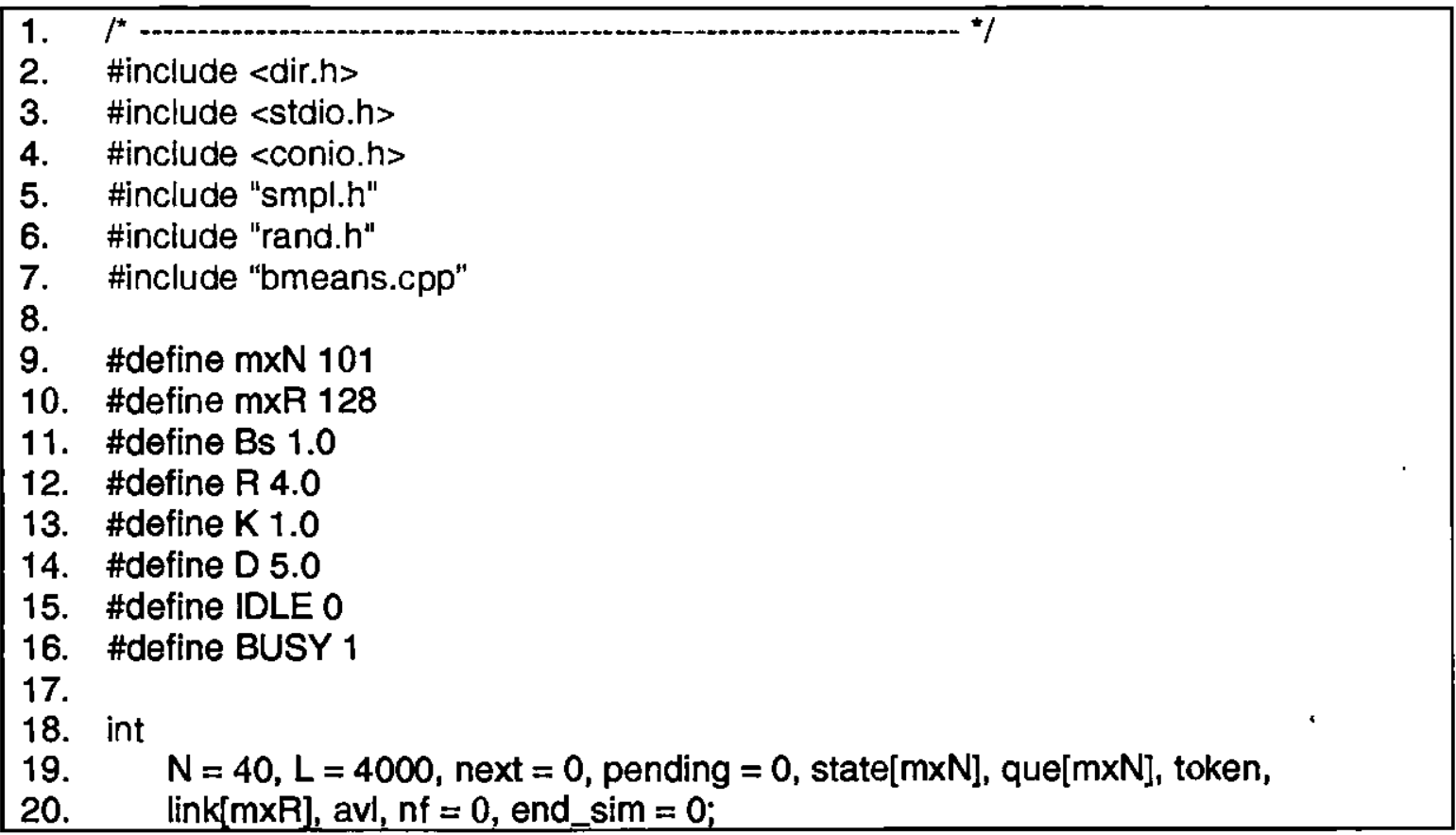


21.

22. float

23. lambda $=2.5, \mathrm{Ta}, \mathrm{Tf}$, tau, ts[mxR];

24.

25. float tarrive (int stn)

26. \{

27. float cycles, $f, f 1, f 2$;

28. cycles = time ()/tau;

29. $f 1=$ cycles - floor(cycles);

30. $t_{2}=$ (float) $\operatorname{stn} /($ float $) \mathrm{N}$;

31. $f=f 1<f 2$ ? $f 2-f 1: 1.0-(f 1-f 2)$;

32. retum (tau* (cycles $+f)$ );

33. \}

34.

35. void frame_complete (int stn)

36. \{

37. int req = que[stn];

38. $\mathrm{nft+}$;

39. end_sim $=$ obs $($ time ()$-$ ts $[$ req $]$ );

40. que[stn] = link[req];

41. link[req] $=\mathrm{avl}$;

42. $a v l=$ req;

43. \}

44.

45. int closest (int stn)

46. \{

47. int $\mathrm{i}=\operatorname{stn}+1, j=0$;

48. do

49. \{

50. if $(i>N) i=1$;

51. if (que[i])

52. \{

53. $\mathrm{j}=\mathrm{i}$;

54. break;

55. \}

56. else $\mathrm{i}++$;

57. \}

58. while $(\mathrm{i} l=(s t n+1))$;

59. retum (j);

60. \}

61.

62. void Chegada (int stn)

63. \{

64. int i, req;

65. if (avi)

66. \{

67. pending+t;

68. req $=\mathrm{avl}$;

69. avl = link[req];

70. $\quad$ link[req] $=0$;

71. ts[req] = time $($;

72. if (que[stn] $==0$ ) 


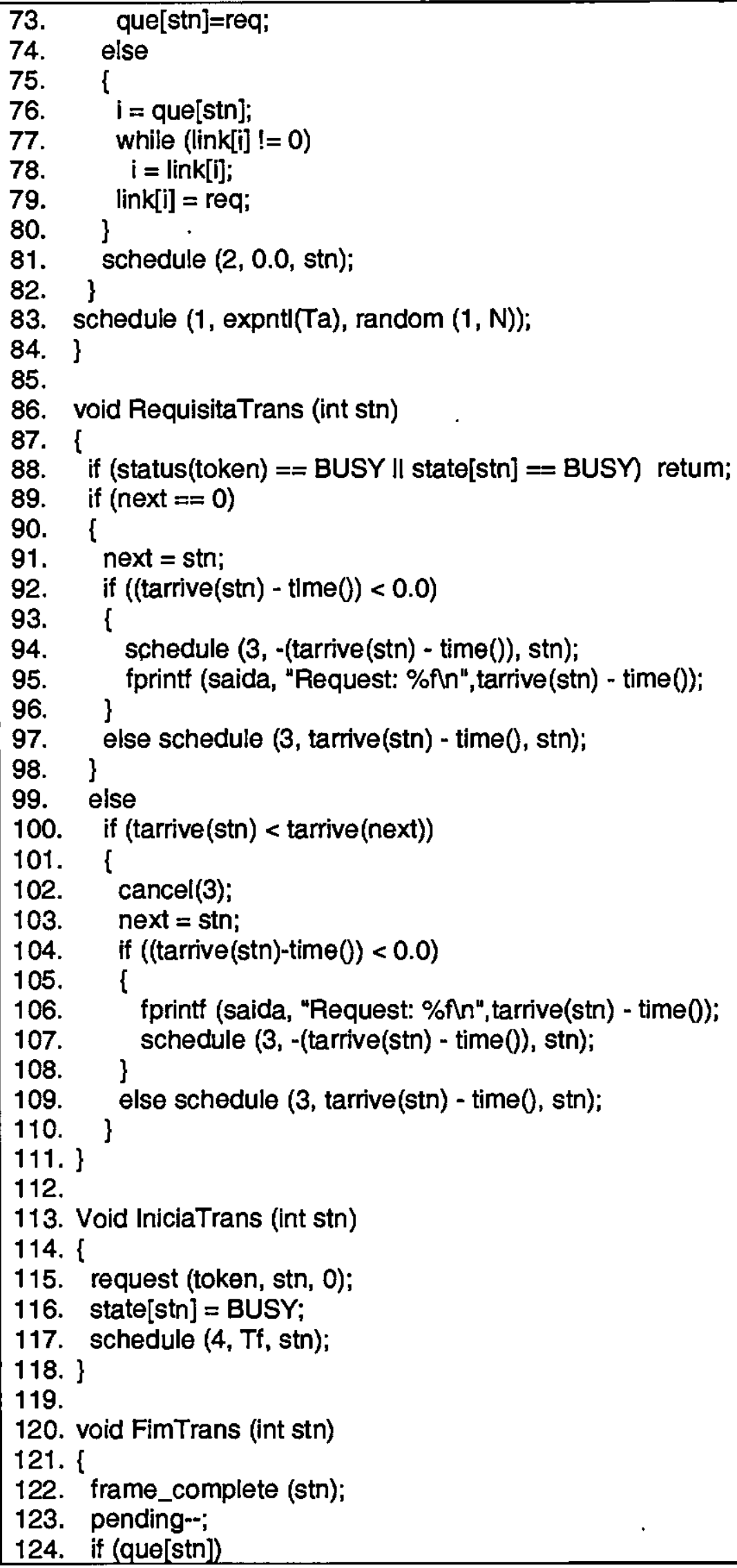


125. schedule $(4, \mathrm{Tf}, \mathrm{stn})$;

126. else

127. \&

128. schedule $(5$, Tf $>$ tau? 0:tau-Tf, stn);

129. schedule (6, tau, stn);

130. \}

131. $\}$

132.

133. void LiberaToken (int stn)

134. \{

135. release (token, stn);

136. if (pending)

137. \&

138. next $=$ closest $(\operatorname{stn})$;

139. if ((tamive(next)-time 0$)<0.0$ )

140. schedule(3, -(tamive(next)-time()), next);

141. else schedule( 3 , tamive(next)-time 0 , next);

142. \}

143. else next $=0$;

144. \}

145.

146. void FimTransEstacao (int stn)

147. ?

148. state[stn] = IDLE;

149. if (que[stn])

150. schedule $(2,0.0, s t n)$;

151. $\}$

152.

153. main()

154. \{

155. $/ *$ definicoes */

156. int event, stn, i, nb;

157. float $H, T d, X, S$;

158.

159. for $(s \operatorname{tn}=1 ; \operatorname{stn}<=N ; \operatorname{stn}++)$

160. \&

161. state[stn]=IDLE;

162. que[stn] $=0$;

163. \}

164. for $(i=1 ; i<m x R ; i++)$

165. $\operatorname{link}[i]=i+1$;

166. link $[m x R-1]=0$;

167. $a v l=1$;

168. $\mathrm{Tf}=$ (float) $L / R$;

169. $\mathrm{Ta}=1.0 \mathrm{E} 6 /\left(\mathrm{N}^{*} \mathrm{lambda}\right)$;

170. tau $=D^{*} K+($ float $)\left(B^{*} N\right) / R$;

171. smpl (0, "token ring LAN model");

172. token = facility ("token", 1);

173. init_bm $(100,1000)$;

174. schedule $(1,0.0$, random $(1, N))$;

175.

176. while (!end_sim) 
177. \{

178. cause (\&event, \&stn);

179. switch (event)

180. \{

181. case 1: Chegada (stn); break;

182. case 2: RequisitaTrans (stn); break;

183. case 3: IniciaTrans (stn); break;

184. case 4: FimTrans (stn); break;

185. case 5: LiberaToken (stn); break;

186. case 6: FimTransEstacao (stn); break;

187. )

188. )

189. civals(\&Td, \&H, \&nb);

190. $X=1.0 \mathrm{E} 6^{*}$ (float)nf/time0;

191. $S=U($ token);

192. printf ("Inıntempo de atraso médio(Td") $=\% .4 \mathrm{f} \mathrm{ms.} \ln ^{\prime \prime}, 0.001^{\star} \mathrm{Td}$ );

193. printf ("intervalo de confiança para $\mathrm{Td}^{\prime}=\% .4 \mathrm{f} \mathrm{ms.} \rightarrow \% .4 \mathrm{f} \mathrm{ms.} \ln ^{\mu}, 0.001^{\star}(\mathrm{Td}-\mathrm{H})$, $\left.0.001^{*}(T d+H)\right)$

194. printf ("throughput $=\% .3 f$ frames/seg. $(S=\% .4 f) \backslash n^{\prime \prime}, X, S$ );

195. printf ("atraso médio normalizado $=\% .3 \mathrm{fn} ", \mathrm{Td} / \mathrm{Tf}$ );

196. $\}$

197.

198. $I^{\star}$ -

Figura 6.15: Programa de simulação para rede Token Ring

As linhas em azul da Figura 6.15 são as linhas do gabarito (Figura 6.7) que são copiadas na íntegra no produto final (programa de simulação gerado). Abaixo está especificado cada procedimento do Gerador de aplicações para o gabarito de rede e quais linhas são responsáveis por gerar:

Gera_defines: linha 9 a 16

Gera_variaveis: linha 18 a 23

Gera_funcoes: linha 25 a 151

Define_variaveis_locais: linha 156 e 157

Inicializa_variaveis: 159 a 172

Gera_batch: 173

Escalona_evento: 174

Gera_case: 181 a 186

Gera_saida: 189 a 191

Imprime_saida: 192 e 195 
Os resultados da simulação que são apresentados são: o tempo de atraso médio, o intervalo de confiança, o Throughput, e o atraso médio normalizado. Para este programa, os valores encontrados são:

- tempo de atraso médio (Td') $=1,0688 \mathrm{~ms}$.

- intervalo de confiança para Td' $=1,0635 \mathrm{~ms} . \rightarrow 1,0742 \mathrm{~ms}$.

- throughput $=101,131$ frames/seg. $(\mathrm{S}=0,1011)$

- atraso médio normalizado $=1,069$

Os valores encontrados com esse programa correspondem aos resultados esperados de acordo com [MAC87].

\subsubsection{Utilização da simulação de uma Token Ring no ASiA}

Na parametrização de rede (Figura 6.16) o usuário poderá definir diversas variáveis de modo a modificar a configuração da rede Token Ring. Estas variáveis são (de acordo com o programa da Figura 6.15): $N$ (número de estações na rede), $L$ (tamanho do frame em bits), lambda (taxa de requisições em frames/segundo/estação), Bs (latência da estação em bits), $\boldsymbol{R}$ (taxa de transmissão em bits/ $\mu \mathrm{s}$ ), $\boldsymbol{K}$ (tamanho do anel em $\mathrm{Km}$ ) e $\boldsymbol{D}$ (atraso do cabo em $\mu \mathrm{s} / \mathrm{Km})$.

As variáveis utilizadas para a parametrização da rede Token Ring estão relacionadạ ao modelo na Figura 6.17. Neste modelo, $\mathrm{N}$ estaçóes disputam pelo token de acordo com a taxa de transmissão, com a taxa de requisição e com o número de requisiçöes. Uma vez de posse do token, a estação inicia a transmissão da mensagem. $O$ tempo que a mensagem irá demorar para ser enviada depende da latência da estaçāo, do tamanho do anel, do atraso do cabo e do tamanho do frame. Quando a transmissão é finalizada, a estação libera o token. 


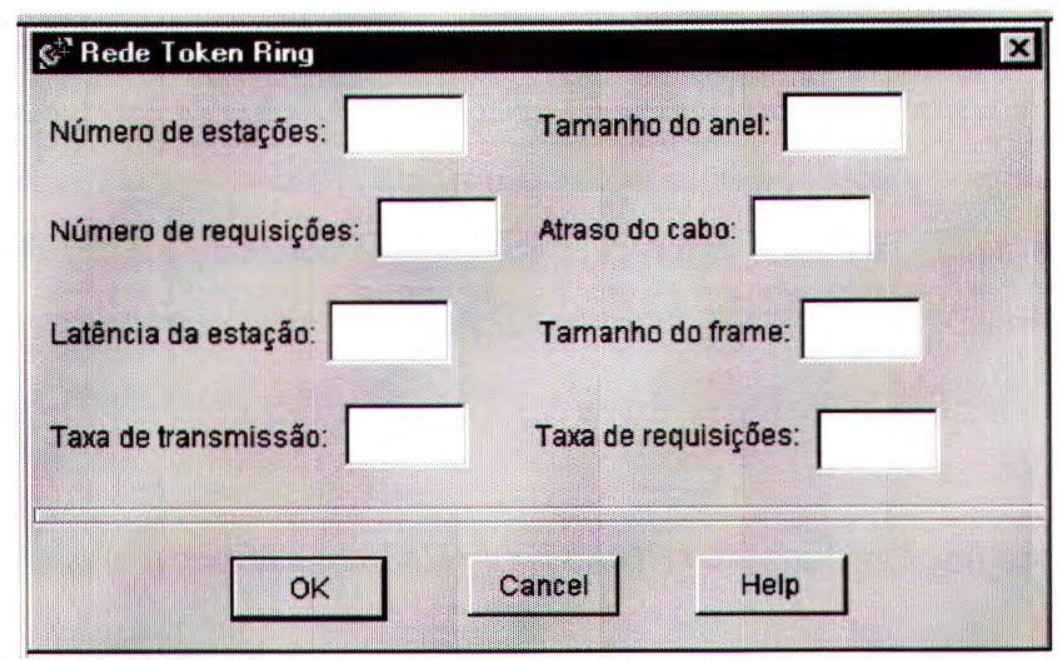

Figura 6.16: Caixa de diálogo de parametrização da rede Token Ring

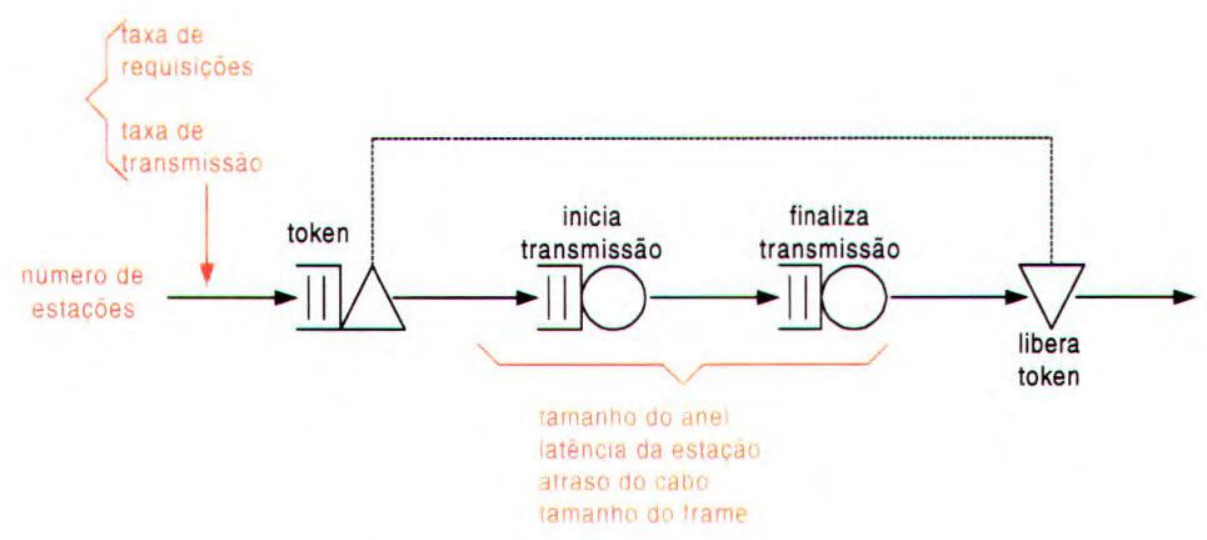

Figura 6.17: Modelo para a rede Token Ring

\subsection{Outros recursos a serem incluídos no módulo de redes}

\subsubsection{Pontes}

Ponte é um equipamento ativo que atua na camada de enlace de dados do modelo ISO/OSI, que têm como finalidade interligar redes de diferentes padrões (ethernet, fast 
ethernet, token ring, token bus, etc.) e isolar o tráfego entre suas portas. Como elemento de interligação de redes, a ponte faz conversão entre os protocolos dessas redes adequando os cabeçalhos, as temporizações, o tamanho dos dados, etc. Como elemento isolador de tráfego, faz com que os dados alcancem somente a porta correspondente ao seu destino e não as outras. Dessa forma, dados não ficam circulando por segmentos de rede desnecessariamente. Colisões detectadas em cada porta de uma ponte não são propagadas às outras portas [TAN97] [SOA95].

Dotado de um algoritmo de self-learning (auto-aprendizado), a ponte constrói duas tabelas internas com os endereços das estações conectadas a cada lado dele, aprendendo de modo dinâmico e automático o endereço das mesmas e fazendo atualizações constantes para checar se estações foram adicionadas e/ou retiradas da rede.

Não enviar pacotes desnecessários de um lado a outro, dá à ponte a característica de filtro de tráfego, podendo ser então utilizada para isolar ilhas de tráfego numa rede com o objetivo de aumentar a performance dessa. Assim, por exemplo, uma ponte pode ser colocada na "saída" de um laboratório que contenha vários servidores, para que o tráfego entre servidores não se propague para o resto da rede, aumentando assim a performance da mesma. Este tipo de característica é útil tanto em redes 802.3 como 802.5 .

Recentemente, aproveitando a inteligência das pontes, foram definidos algoritmos padrões para possibilitar criar caminhos alternativos (ou redundantes) numa rede de comunicação para aumentar a confiabilidade da mesma. Estes algoritmos ligam ou desligam as portas das pontes em função de eventuais falhas em segmentos da rede. Para o 802.3, o nome desse algoritmo é Spanning Tree; para o 802.5 é Source Routing.

Assim, além dos indispensáveis leds de monitoração, em função do tipo de rede, é interessante que a ponte possua algoritmos para caminhos alternativos.

A performance de uma ponte é medida pelo número de pacotes analisados por segundo (filtering rate) e pelo número de pacotes que ela consegue transmitir de um segmento ao outro por segundo (forwarding rate).

A importância do estudo de pontes está no fato de que qualquer organização possui muitas LANs separadas que devem interagir entre si. Essa necessidade torna 0 uso de ponte extremamente comum e por isso, um estudo do seu desempenho se torna essencial. 


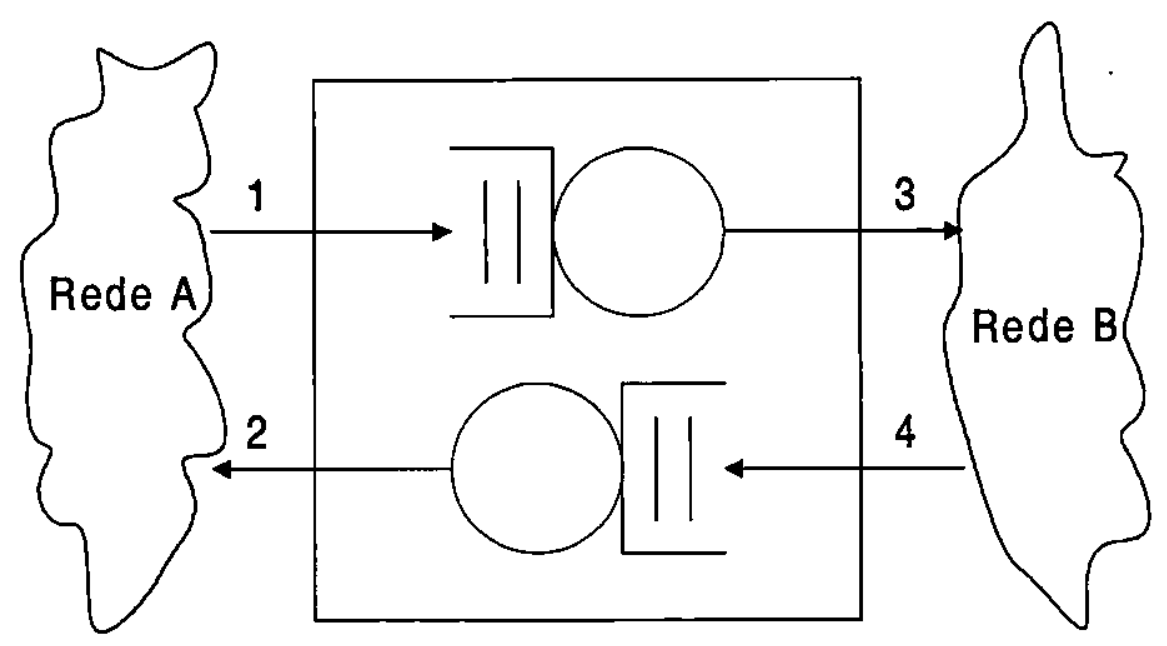

Figura 6.18: Modelo em redes de fila de uma ponte

Um possível modelo para uma ponte bidirecional é apresentado na Figura 6.18. A ponte tem por função unir duas redes do tipo Ethernet ou Token Ring, desse modo de cada lado da figura acima se tem uma rede. Por exemplo, uma rede ethernet do lado esquerdo e uma rede token ring do lado direito. As setas indicam entrada e saída dos dados. A seta 1 indica que a rede $\mathrm{A}$ está enviando dados para a rede $\mathrm{B}$, que recebe os dados pela seta 3 . $\mathrm{E}$ a seta 4 indica que a rede $B$ está enviando dados para a rede $A$, que por sua vez, recebe os dados pela seta 2. Nessa representação a fila que se forma nos recursos representa o buffer e o serviço oferecido é o envio dos dados.

Para o modelo proposto na Figura 6.18 o tempo de serviço de cada um dos servidores deverá representar o tempo necessário para fazer a transferência, considerando:

- Tempo de transferência dos dados - esse tempo depende forma em que a ponte realiza a transferência.

- Conversão de protocolos - se as redes A e B forem diferentes será necessário realizar a conversão de protocolos. 


\subsubsection{Rede ATM}

A rede ATM ("Assynchronous Transfer Mode") é um complemento da rede STM ("Synchronous Transfer Mode") que é utilizado como espinha dorsal das redes de telecomunicações para transferência de voz e dados em pacotes para longas distâncias. É um mecanismo de comutação de circuitos na rede, onde a conexão é estabelecida entre dois pontos finais antes de se iniciar a comunicação, e é desligada após a comunicação. Deste modo os pontos finais alocam e reservam a largura de banda necessária à conexão, que permanece reservada mesmo quando não há transmissão. No STM existe perda de largura de banda quando é reservada uma conexão com uma largura de banda correspondente ao pico, ou seja, quando há a "rajada", mas seria bom que a largura de banda consumida pelos períodos de silêncio pudesse ser usada para qualquer outra conexão, ou seja, que os slots de tempo durante os periodos de silêncio pudessem transportar dados de outras conexões. Ou quando apenas parte da largura de banda é utilizada. Por estes motivos, o modo de transferência STM torna-se ineficiente na gestão da largura de banda. O ATM surgiu, desse modo, para resolver esses problemas.

A evolução das redes de longa distância (WANs, "Wide Area Networks") começa com a comutação de pacotes, passa pelo chaveamento de quadros ("Frame Relay") e chega à comutação de células. Tanto a comutação de pacotes quanto o chaveamento de quadros transmitem os dados em quadros de tamanho variável, tipicamente contendo centenas ou milhares de bytes de informação. A tecnologia de comutação de células emprega pacotes (denominados agora de células) de tamanho fixo igual a 53 bytes: cinco de cabeçalho e quarenta e oito de dados. A idéia é comutar velozmente essas células durante seu trajeto e carregar, em cada célula, apenas o identificador de conexão e os dados, sendo o tamanho da célula pequeno e fixo, o que facilita a recuperação dos dados no caso de perda de células por congestionamento ou qualquer outra razão, pois a quantidade de dados em cada célula é pequena. Essa filosofia é denominada "banda sob demanda" pelo fato da rede prover exatamente a banda efetivamente necessária às aplicações. ATM comuta as células na velocidade em que são submetidas para transmissão (toda a comutação é feita por um hardware dedicado a esse fim). Em sua essência, este mecanismo é muito parecido com a 
comutação de pacotes e por isso foi denominado "comutação rápida de pacotes de tamanho pequeno e fixo".

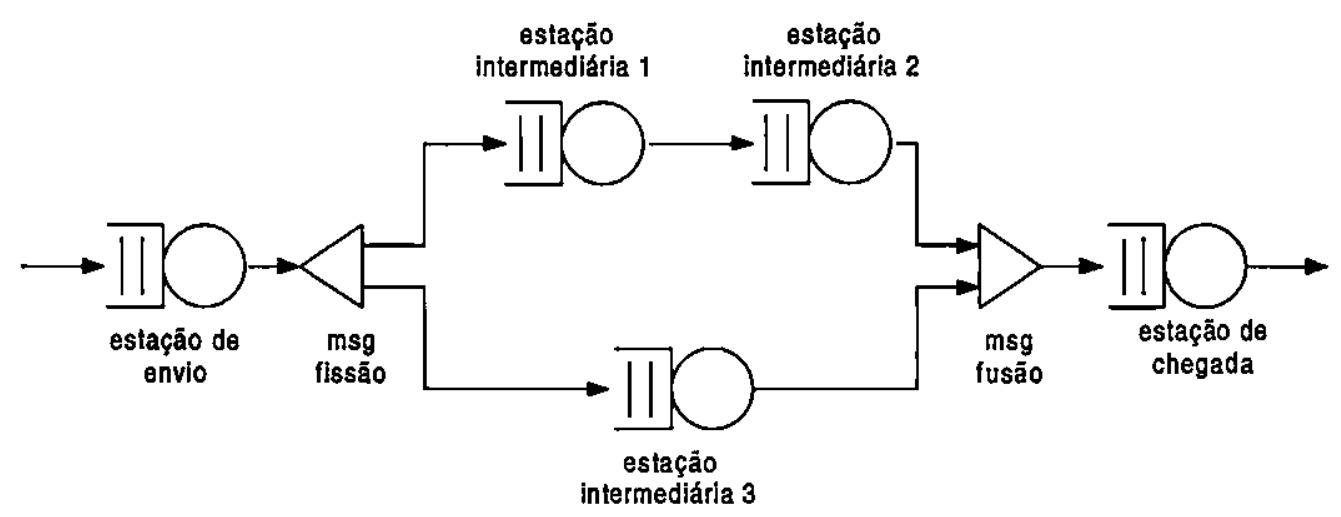

Figura 6.19: Modelo de simulação para a rede ATM

Um possível modelo para a rede ATM é apresentado na Figura 6.19. Neste modelo as mensagens chegam a estação de envio e esperam na fila até serem enviadas. Da estação de envio a mensagem segue para msg fissão onde sofre uma quebra na qual parte da mensagem vai para a estação intermediária 1 e a outra parte para a estação intermediária 3. Da estação intermediária 1 o pedaço de mensagem segue para a estação intermediária 2 e deste ponto então segue para msg fusão. $O$ pedaço de mensagem que seguiu para a estação intermediária 3 também vai para msg fusão onde a mensagem é remontada. Depois de refeita a mensagem, essa vai para a estação de chegada.

Este modelo representa uma das características de rede ATM que é a divisão da mensagem em pedaços menores que podem seguir por caminhos distintos até um ponto em que a mensagem deve ser remontada para o término da transmissão. 


\subsection{Considerações finais}

Neste capitulo foram apresentadas considerações sobre a implementação do módulo de simulação de redes de computadores. Um usuário inexperiente em simulação de sistemas tem em mãos uma ferramenta que auxilia o uso de simulação sem conhecimento de redes de fila. Por outro lado, um usuário mais experiente pode, através das funcionalidades implementadas, criar modelos mais complexos, seja de rede de computador ou outro sistema, obtendo assim um uso eficiente da simulação.

No próximo capítulo serão apresentadas as conclusões $e$ as contribuições obtidas com o desenvolvimento deste trabalho, além de propostas para expansões no ASiA e pesquisas futuras. 


\section{Conclusões}

Este capitulo encerra a dissertação revisando os tópicos fundamentais abordados, destacando as conclusões e contribuições obtidas após a implementação do módulo de simulação de redes de computadores além de propostas para trabalhos futuros.

\subsection{Introdução}

A simulação tem sido utilizada nas mais diversas áreas do conhecimento humano devido à flexibilidade e baixo custo apresentados. É uma ferramenta bastante poderosa, pois permite a análise de sistemas em fase de projeto (sem a necessidade de sua implementação) e de sistemas já existentes (sem interferências no seu funcionamento). Essas características são bastante atraentes, uma vez que testes podem ser feitos exaustivamente antes da tomada de qualquer decisão sobre um determinado problema a se resolver.

O grande avanço da microeletrônica tem provocado uma evolução e proliferação de sistemas computacionais de forma muito rápida. Os antigos sistemas centralizados foram substituídos por um grande número de sistemas, na maioria dos casos monousuários. A disseminação desses sistemas gerou, nas últimas décadas, a necessidade de interligação entre os sistemas, na maioria dos casos através de redes locais.

Devido à grande importância das redes de interconexão nos sistemas atuais, torna-se essencial a utilização de ferramentas que possibilitem a avaliação de seu desempenho. Essas ferramentas são úteis, pois permitem a detecção de possíveis gargalos ou problemas, além de auxiliar no entendimento das diferentes modalidades de interconexão.

Devido a característica flexível da simulação e a existência de uma variedade de simuladores de redes, é visível a importância da ferramenta de simulação de redes do ASiA. 
Essa ferramenta possibilita ao usuário a representação de sistemas em rede de forma a facilitar a modelagem e simulação do sistema.

\subsection{Conclusões}

A utilização de redes de filas básicas para a modelagem de redes de computadores, visando a simulação destes sistemas, não conduz a modelos que possibilitem a obtenção de resultados confiáveis. Através do desenvolvimento de modelos para alguns tipos de redes (Ethernet e Token Ring) pôde-se observar que a utilização apenas dos recursos básicos de redes de filas levou a modelos muito simplificados, que não representam características importantes das redes de computadores.

A versão anterior do ASiA oferecia ao usuário os recursos básicos de redes de fila (um servidor com uma fila, vários servidores com uma fila, um servidor com várias filas e vários servidores com várias filas). Assim uma primeira etapa na realização deste trabalho foi a determinação dos recursos a serem adicionados ao ASiA para a simulação de redes de computadores.

Baseando-se no estudo desenvolvido, três novos recursos foram adicionados ao ASiA: servidor sem fila, posse múltipla de recursos e servidor infinito. Desse modo expandiu-se as funcionalidades do ASiA. Esses novos recursos foram implementados de modo que possam ser utilizados tanto na modelagem de redes de computadores como na modelagem de sistemas mais complexos, estendendo as possibilidades do ASiA como um todo e não apenas para simulação de redes de computadores.

Implementadas as novas funcionalidades foi possível o desenvolvimento do módulo de simulação de redes. Esse módulo facilita o uso da simulação para os usuários que não estão familiarizados com a teoria de redes de fila e de simulação, pois possui modelos de rede prontos que o usuário pode utilizar para avaliar o desempenho de uma rede específica. Os modelos do módulo de redes são apresentados ao usuário através de símbolos e nomenclatura da área de redes de computadores, facilitando seu entendimento e se for o caso, a sua 
modificação. Os parâmetros dos modelos prontos podem ser modificados de modo a possibilitar a avaliação do impacto de diferentes valores nesses parâmetros.

O usuário também tem a possibilidade de modelar uma rede que ainda não está implementada no Módulo Rede utilizando os recursos disponíveis na barra de ferramentas que está incrementada com as novas funcionalidades desenvolvidas.

O Módulo Rede desenvolvido modificou a estrutura da versão original do ASiA pois novos ícones e novas caixas de diálogo foram acrescentadas. O Gerador de Aplicações foi modificado para a simulação de redes, pois um novo gabarito foi desenvolvido e desse modo, foi acrescentado o código necessário para o tratamento das ações descritas no novo gabarito. Um novo arquivo é gerado pelo ASiA (extensão “.RED”) que contém os parâmetros de modelagem da rede.

\subsection{Contribuições deste trabalho}

As principais contribuições deste trabalho são:

- Inclusão de um módulo de simulação de redes de computadores que permite a um usuário menos experiente o uso da simulação de redes de computadores, uma vez que a parametrização do modelo de redes de computadores é específica e o usuário não precisa parametrizar dados como tempo de chegada, tempo de serviço, e outros parâmetros que são específicos para redes de filas.

- Inclusão de novas funcionalidades como servidor sem fila, posse múltipla de recursos e servidor infinito que aumentam a gama de sistemas que podem ser simulados. Ou seja, sistemas mais complexos podem ser modelados no ASiA, uma vez que essa modificação foi introduzida no ASiA e não somente no módulo de simulação de redes de computadores.

- Utilização do ASiA para avaliação de desempenho de redes locais de computadores, que permite que sistemas que já estejam em uso ou não sejam avaliados de modo a observar a existência de gargalos.

- Definição das características necessárias para implementação de pontes no ambiente ASiA. 


\subsection{Trabalhos futuros}

Como sugestões para trabalhos futuros, os seguintes pontos podem ser abordados:

- Inclusão da simulação de pontes especificada na seção 6.5.1 deste trabalho.

- Inchusão de simulação de redes ATM e outras redes mais atuais no módulo de simulação de redes. Uma descrição da rede ATM está na seção 6.5.2.

- Implementação de mais funcionalidades no ASiA, através da utilização das idéias contidas na estrutura de redes de fila estendida do pacote de simulação RESQ [SOA92]. Um exemplo seria a implementação de usuários (customers) que geralmente não são desenhados explicitamente nos diagramas, mas existem certas circunstâncias em que se quer permitir ao usuário criar cópias de si mesmo, e permitir que o usuário e suas cópias sigam diferentes caminhos. As cópias produzidas podem ser novos usuários independentes ou então podem estar relacionadas entre si e se juntarem futuramente em algum lugar apropriado do modelo. Um uso deste fato pode ser encontrado na modelagem da quebra de mensagens em pacotes para transmissão em um sistema de comunicação e seu futuro reagrupamento no destino. Este sistema é utilizado na rede ATM, o que permitiria a representação da rede ATM no ambiente ASiA. Uma outra funcionalidade que poderia ser implementada é a utilização de submodelos. Um submodelo é um subconjunto dos recursos de um modelo que são separados dos recursos restantes, ou para uma melhor estruturação e clareza, ou para a resolução (análise do submodelo) em separado.

\subsection{Considerações finais}

Analisando-se os objetivos e a motivação inicialmente propostos para este trabalho, conclui-se que a extensão do ambiente de simulação ASiA atingiu seus objetivos, pois: 
- Criou-se um módulo de simulação que torna o uso da simulação de redes de computadores mais simples para usuários inexperientes visto que a geração do modelo e parametrização são específicos e não necessita do conhecimento de redes de fila por parte do usuário.

- Usuários mais avançados tem a possibilidade de usar as novas funcionalidades permitindo a criação de modelos mais complexos, permitindo a descrição mais detalhada dos sistemas em geral e não apenas de redes de computadores. 

[AGH88] Aghazarm, B., Miranda Jr., J.A., Transmissão de Dados em Sistemas de Computação, Editora Érica, 1988

[ALT96] Alta Group of Cadence Design Systems, Bones Networking Modules, Network Modeling and Simulation building blocks for Bones Designer, www.cadence.com/alta/products/hhtml/bones/main.html, 1996

[BAN96] Banks, J., Norman, V., Second Look at Simulation Software, Non-tradicional uses can yield unexpected benefits, ORMS Online Edition, August 1996, Volume 23, Number 4, http://lionhrpub.com/orms/orms-8-96/simsoft.html, 1996

[BOR96] Borland International, Inc., Borland C++ Version 5.01, Copyright 1991, 1996

[BRU97] Bruschi, S.M., Extensão do ASiA para Simulação de Arquiteturas de Computadores, Dissertação de Mestrado apresentada ao ICMC - USP, 1997

[CAC97] CACI Products Company, Comnet III High-Fidelity Network Simulation Tool, http://www.caciasl.com:80/comnetthree.html, 1997

[CAD98] Cadence Design Systems, BONeS Designer, www.cadence.com/alta/ products/newdatasheets/designer.html, 1998

[CAD98a] Cadence Design Systems, BONeS Interactive Simulation Manager, www.cadence.com/alta/ products/newdatasheets/isim.html, 1998

[CUB95] Cubert, R., Fiswick, P., SIM++ Version 1.0, Department of Computer and Information Science and Engineering, University os Florida, USA, July 1995

[EDW92] Edwards, G., Sankar, R., Modeling and Simulation of Networks using CSIM, Simulation, v.58, n.2, pp.131-136, fevereiro de 1992

[HOO90] Hoover, S.V., Perry, R.F., Simulation, A Problem - Solving Approach, AddisonWesley Publishing Company, 1990

[IMA97] ImageNet Computer Aided Network Engineering, ImageNet Ships CANE Release 2.0, http://www.imagenet-cane.com, May 1997

[ISR97] ISR Software Library, Design \& Analysis Tools, www.isr.umd.edu /ISR /resources/software/design.html, 1997

[JUM93] Jump, R J, NetSim Reference Manual Version 1.0, Rice University, Electrical \& Computer Engineering Department, May 1993

[KIA95] Kian, L., MODSIM, An Evaluation Report, , www-gscit.fcit.monash.edu.au / kian/modsim html, 1995 
[KIA96] Kian, L., COMNET3, An Object Oriented Approach to Network Simulation, www-gscit.fcit.monash.edu.au/ - kian/comnet.html, 1996

[MAC87] MacDougall, M.H., Simulating Computer Systems Techniques and Tools, The MIT Press, 1987

[MIT92] Mitrani, I., Simulation Techniques for Discrete Event Systems, Cambridge University Press, 1992

[NAU94] Naugle, M.G., The Ilustrated Network Book, VNR Communications Library, 1994

[NON97] Nonato, S.A., Utilização de Redes de Petri em Sistemas Computacionais, Minidissertação de Mestrado apresentada ao ICMC - USP, 1997

[NON99] Nonato, S.A., Utilização de Redes de Petri em Sistemas Computacionais, Dissertação de Mestrado apresentada ao ICMC - USP, 1999

[OBA97] Obaidat, M.S., Modeling and Simulation of Computer Systems and Networks: Part I: Networks, Simulation, Vol. 68, no. 1, January 1997, pag 6-7

[OGA95] Ogawa, C.L., Criação de um Sistema de Ajuda para um Editor Gráfico em Ambiente Windows, Relatório de Bolsa de Iniciação Científica CNPq, processo no. 800596/90-0, ICMC - USP, fevereiro/1995

[OGA96] Ogawa, C.L., Aprimoramento e Expansão do Editor Gráfico para o Ambiente de Simulação Automático ASiA, Relatório de Bolsa de Iniciação Científica FAPESP processo no. 95/0385-0, ICMC - USP, março/1996

[OGA97a] Ogawa, C.L., Aprimoramento e Expansão Ambiente de Simulação Automático ASiA, Relatório de Bolsa de Iniciação Científica FAPESP processo no. 95/0385-0, ICMC - USP, março/1997

[OGA97b] Ogawa, C.L., Aprimoramento e Expansão do Ambiente de Simulação Automático $A S i A$, Relatório do Projeto de Graduação para obtenção do diploma em Ciências da Computação do ICMC - USP, 1997

[OLI98] Oliveira, L.L., Um Módulo de Análise de Resultados para o ASiA, Tese de Mestrado apresentada ao ICMC - USP, 1998

[PED95] Pedroso, Jr.W.G., Santana, M J, Calonego,Jr. N, Santana, R H C, ASiA ModV Módulo Visual para o ASiA, Descrição da Implementação ICMC - USP, 1995

[PED96] Pedroso, Jr.W.G., Módulo Visual: Uma Interface Gráfica para o Ambiente de Simulação Automático, Tese de mestrado ICMC - USP, 1996

[PEG91] Pegden, C.D., Shannon, R.E., Sadowski, R.P., Introduction to Simulation Using SIMAN, McGraw-Hill International Editions, 1991 
[PIE97] Piekarski, A.E.T., Redefinição do Processos do Ambiente de Simulação Automático (ASiA), Minidissertação de Mestrado apreșentada ao ICMC - USP, 1997

[PIE98] Piekarski, A.E.T., Uma Proposta de Reengenharia para o Ambiente de Simulação Automático (ASiA), Dissertação de Mestrado apresentada ao ICMC USP, 1998

[ROB83] Roberts, N, Andersen, D., Deal, R., Garet, M., Shaffer, W., Introduction to Computer Simulation, A System Dynamics Modeling Approach, Addison-Wesley Publishing Company, 1983

[SAN94] Santana, R.H.C., Ambiente de Simulação Automático para Modelamento $e$ Análise de Sistemas Distribuidos, Projeto apresentado ao ICMC - USP como parte dos requisitos para o concurso para provimento de um cargo de professor assistente junto ao Departamento de Ciências de Computação e Estatística, 1994

[SCH87] Schriber, T.J., The Nature and Role of Simulation in the Design of Manufacturing Systems, Simulation in CIM and Artificial Intelligence Techniques, Society for Computer Simulation, pp:5-18

[SCH95] Schiriber, T.J., Brunner, D.T., Inside Simulation Software: how it works and why it matters, Proceedings of the 1995 Winter Simulation Conference, pp. 110-117, 1995

[SHA88] Sharma, s., Lauwrence, L. R., Modular Design for Simulation, Software Pratice and Experience, v.18, n.10, 945-966, 1988

[SHA92] Shannon, R.E., Introduction to Simulation, Proceedings of the 1992 Winter Simulation Conference, 1992

[SHI75] Shimizu, T., Simulação em Computador Digital, Editora Edgard Blucher Ltda, 1975

[SAN90] Santana, M.J., An Advanced Filestore Architecture for a Multiple-LAN Distributed Computing System, Tese (Doutorado), University of Southampton, England, 1990

[SOA90] Soares, L.F.G., Modelagem e Simulação Discreta de Sistemas, VII Escola de Computação, IME-USP, São Paulo, 1990

[SOA90a] Soares, L.F.G., Redes Locais, Editora Campus, 1990

[SPO94a] Spolon, Renata, Um Editor Gráfico para um Ambiente de Simulação Automático, Tese de Mestrado apresentada ao ICMC - USP, agosto/1994

[SPO94b] Spolon, Renata, Um Editor Gráfico para o ASiA, Manual do Usuário, Notas Didáticas do ICMC - USP, 1994 
[SP094c] Spolon, Rẹnata, EdGraf - Editor Gráfico para o ASiA, Descrição da Implementação, Relatórios Técnicos ICMC - USP, 1994

[SP094d] Spolon, Roḅerta Spolon, Renata, Santana, M J; Santana, R H C, Gerador de aplicação para o ASiA - Descrição de Implementação, Relatórios Técnicos ICMC - USP, 1994

[SP094e] Spolon, Roberta, Um Gerador de Aplicação para um Ambiente de Simulação Automático, Tese de Mestrado apresentado ao ICMC - USP, 1994

[SPO95] Spolon, Renata; Spolon, Roberta, Santana, M J; Santana, R H C, Editor Gráfico para modelos de rede de fila em um ambiente de simulação automático, XXVII SBPO, Vitória, 6 - 8 nov, 95

[SPO95a] Spolon, Roberta, Spolon, Renata, Santana, M J; Santana, R H C, Um gerador de aplicação para simulação de sistemas discretos, XXVII SBPO, Vitória, 6 - 8 nov, 95

[STA94] Stamper, D.A., Local Area Networks, The Benjamin/Cummings Publishing Company Inc., 1994

[STA97] Starling, S.L, Introduction to Simulation, California State University, Hayard, http://barney.sbe.csuhayward.edu/ starling/Starling/simchap.htm, notas de aula, 1997

[SYS93] Sysnet Telemática, Siștemas Abertos para Redes de Comunicação, Guia de Aplicação para Sistema Abertos de Comunicação, Sysnet Telemática e Engecon, 1993

[SYS94] Systems Modeling Corporation, ARENA Getting Started Guide, 1994

[SYS95] Systems Modeling Corporation, ARENA Help on line, 1995

[SYS95a] Systems Modeling Corporation, ARENA 2.0 Release Notes, 1995

[SYS98] System Modeling Corporation, Arena version 3.0, www.sm.com/ arena/ arena.htm, 1998

[TAN89] Tanenbaum, A.S., Computer Network, Second Edition, Prentice Hall International Editions, 1989

[TAR86] Tarouco, L.M.R., Redes de Computadores Locais e de Longa Distância, McGrall-Hill, 1986

[ULS99] Ulson, R.S., Simulação Distribuída em Plataformas de Portabilidade: Viabilidade de Uso e comportamento do Protocolo CMB, Tese (Doutorado) apresentada ao Instituto de Física de São Carlos, Universidade de São Paulo, 1999 